\title{
DYNAMIC PRICING FOR MANAGED LANES: SYNTHESIS OF CURRENT BEST PRACTICES AND FRAMEWORK FOR INTEGRATION WITH CONNECTED AND AUTOMATED VEHICLES
}

\author{
A Thesis \\ Submitted to \\ School of Engineering and Applied Science of \\ University of Virginia
}

In partial fulfillment of

the requirements of the degree of

MASTER OF SCIENCE

by

Mengmeng Ye

December 2017 


\section{APPROVAL SHEET}

The thesis

is submitted in partial fulfillment of the requirements

for the degree of

MASTER OF SCIENCE

Mengmeng Ye, AUTHOR

The thesis has been read and approved by the examining committee:

Dr. T. Donna Chen, Advisor

Dr. Brian Smith

Dr. Michael D. Fontaine

Accepted for the School of Engineering and Applied Science:

Craig H. Benson, Dean, School of Engineering and Applied Science

December 2017 


\section{ACKNOWLEDGEMENTS}

I would like to express the deepest appreciation to my advisor Dr. T. Donna Chen for her continuous support of my research and personal choice. Her immense knowledge always enlightens me and guides me solve research problems step by step. Her endless patience helped me grow from a newbie to a skilled researcher. I learned a lot from her not only about all the professional knowledge but also about her attitude towards career and life. I feel very lucky and grateful to have Dr. Chen as my advisor!

I am also very grateful to Dr. Michael Fontaine, who is always very helpful to my research and coursework. His broad knowledge and insightful comments always inspire me a lot. His passion for work and commitment to research always motivate me a lot. His classes are always interesting, useful and easy to understand. I really enjoyed his class!

I would also like to thank Dr. Brian Smith and Dr. John Miller, for their broad knowledge and unlimited help!

At last, I would like to express my thanks to my parents and my little brother, for their endless love and support! 


\begin{abstract}
Congestion pricing is an effective way to manage travel demand on transportation facilities. The most common (and fastest-growing) form of congestion pricing in the US are variably priced high occupancy/toll (HOT) facilities which run parallel to non-priced general purpose (GP) lanes. The parallel general purpose (GP) lane density or volume can serve as a predictive tolling component for HOT lane demand in subsequent time periods. This thesis explores the future of dynamic pricing for managed lanes in two parts. First, motivated by the opening of the I-66 Inside the Beltway managed lanes in northern Virginia, this research proposes a combination tolling framework (utilizing both historic and real-time traffic data) for pricing of managed lanes that do not have parallel GP lanes. Second, motivated by connected and automated vehicle (CAV) technology, this research explores a reservation-based tolling system for managed lanes.
\end{abstract}

This thesis first reviews best practices among existing HOT lane facility operations in the US, synthesizing a series of academic and agency expert interviews which address topics including tolling basis, toll update frequency, toll elasticity of demand, maximum and minimum pricing caps, occupancy restrictions, toll signage, facility access, and incident management on managed lanes which have parallel GP lanes. However, on facilities without parallel GP lanes, existing dynamic algorithms (which rely partly on GP lane metrics) fall short in providing sufficient predictive power. In this thesis, we propose a tolling framework (based on expert insights discussed in best practices) for HOT facilities which do not have parallel GP lanes. This framework considers both user preference for the price-certainty of a time-of-day pricing scheme as well as the flexibility of a dynamic pricing scheme to accommodate realtime fluctuations in traffic demand. Without GP lane metrics, the framework utilizes historical traffic on the managed lanes as a predictive tolling component.

Currently, dynamic tolling schemes are largely reactive to the real-time traffic flow. With the introduction of CAV technology, it is possible to enhance these existing mechanisms of tolling. The second part of this thesis explores a reservation-based dynamic pricing scheme, which allows connected vehicles to reserve the managed lane in advance (at a discount). The pricing scheme is designed to be operational with mixed (connected and non-connected) fleets, as the dynamic toll updates in discrete intervals (much like in current practice). A hypothetic two-lane (one HOT lane and one GP lane) highway system is assumed to demonstrate the conceptual tolling framework. 
Simulation results suggest that, compared with traditional dynamic pricing algorithms, the proposed reservation tolling system increases the predictability of the upstream traffic's demand for the downstream HOT facility, and the tolling scheme is able to handle saturated traffic conditions (by ensuring a reasonable level of service in the managed lane) and keep HOT lane density at a desired density. The system is also demonstrated to be functional with a mixed fleet with a two-tiered second-best pricing scheme. Under most traffic conditions, the proposed tolling scheme is effective in keeping traffic demand (both CAVs and non-CAVs) on the HOT lane near goal density. Likewise, under most traffic conditions, the proposed tolling scheme ensures reservation equity for non-CAV users (non-CAVs choose the HOT lane at nearly the same rate as CAVs, despite CAVs' ability to reserve in advance). 


\section{TABLE OF CONTENTS}

\section{Contents}

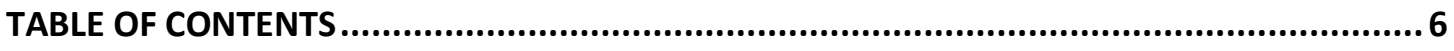

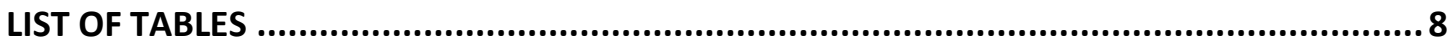

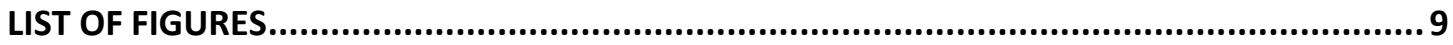

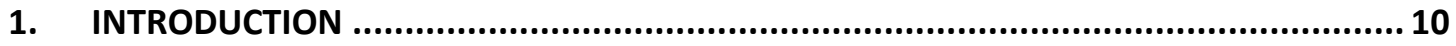

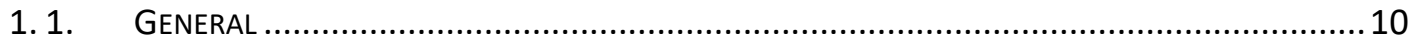

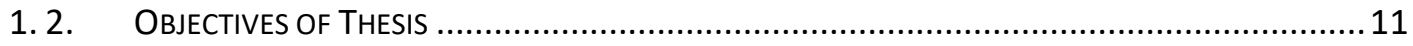

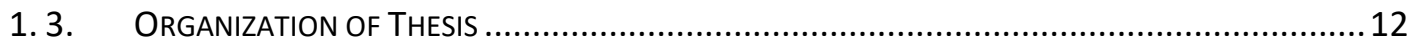

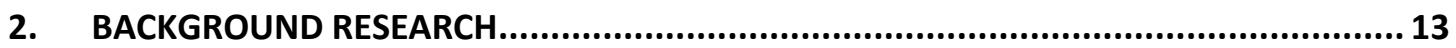

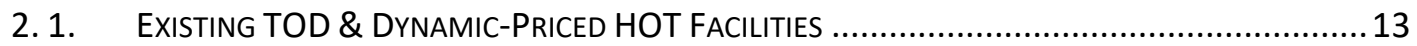

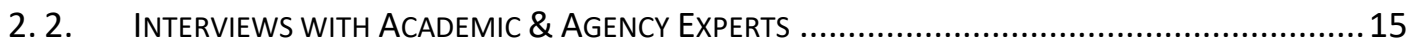

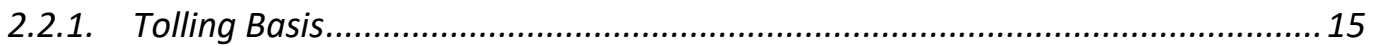

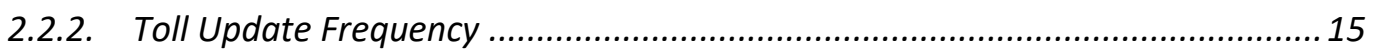

2.2.3. Toll Elasticity of Demand and Pricing Caps .................................................... 16

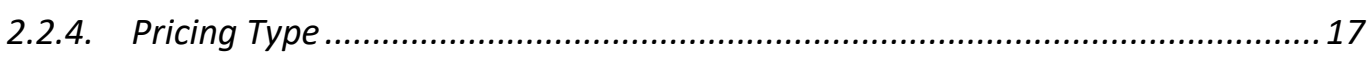

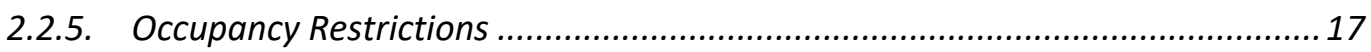

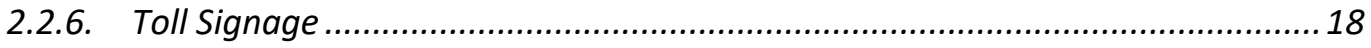

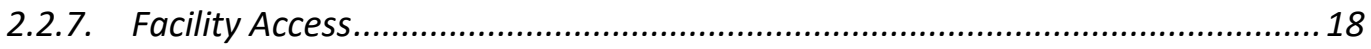

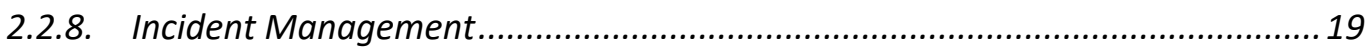

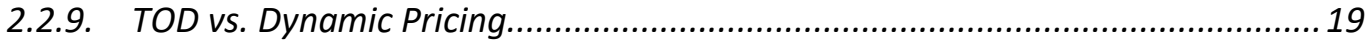

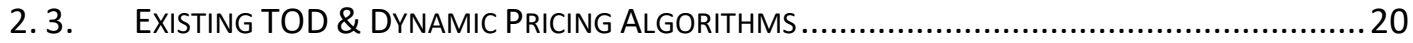

2.3.1. Existing TOD Pricing Algorithms in Practice ..................................................... 20

2.3.2. Existing Dynamic Pricing Algorithms in Practice ........................................... 21

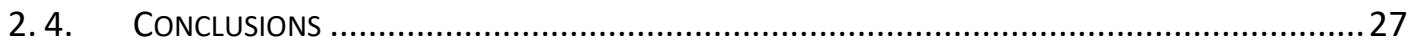

3. TOLLING FRAMEWORK ON NON-CAV ENVIRONMENT ….......................................... 28

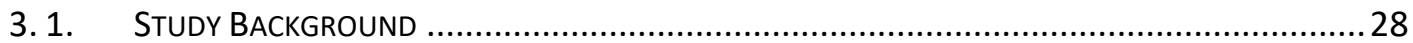

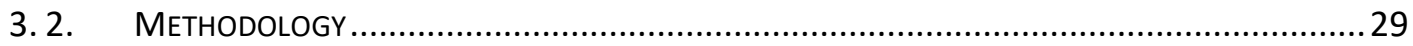

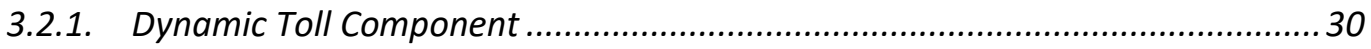

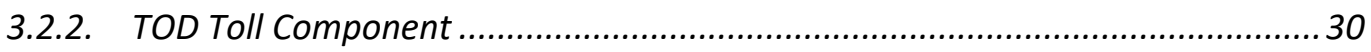

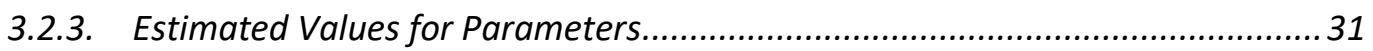




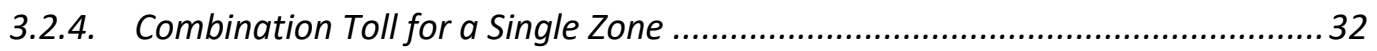

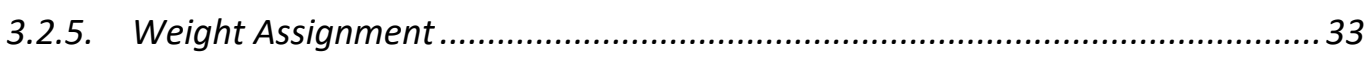

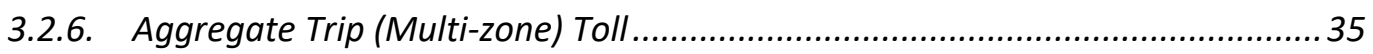

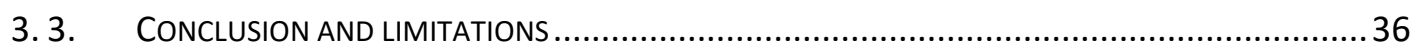

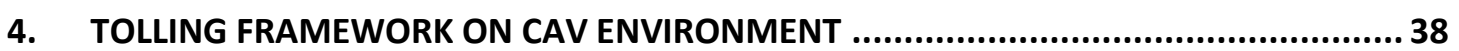

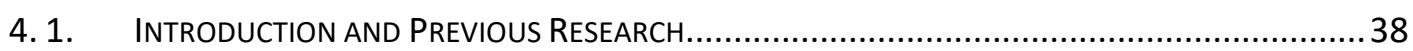

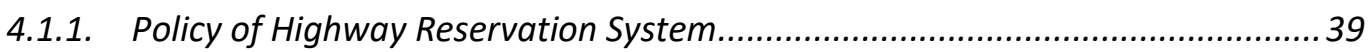

4.1.2. Token- and Auction-based Reservation Systems............................................. 40

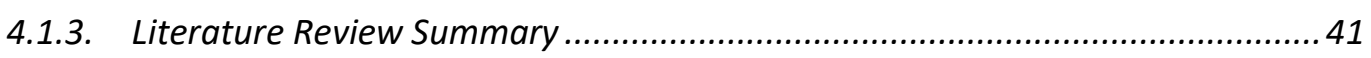

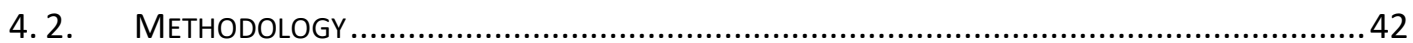

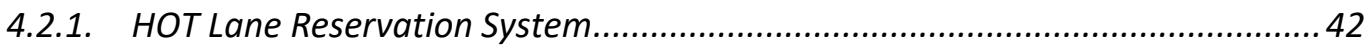

4.2.2. Framework of Highway Reservation System .................................................. 43

4.2.3. Goal of the Reservation System ..................................................................... 47

4.2.1. Second-Best Pricing-Based Dynamic Pricing Policy .......................................... 48

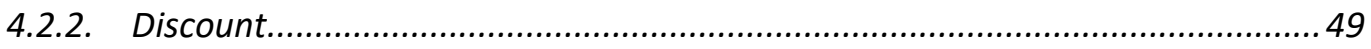

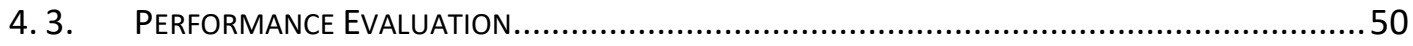

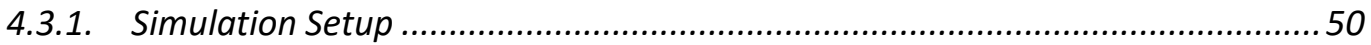

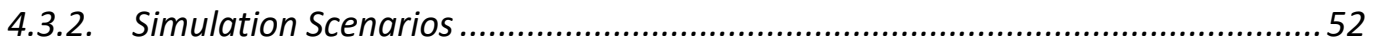

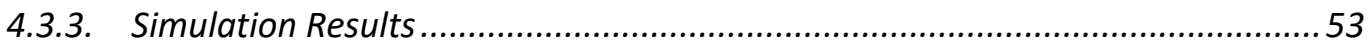

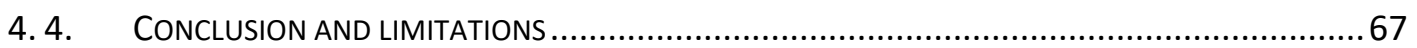

5. CONCLUSIONS, LIMITATIONS AND FUTURE WORK ...............................................69

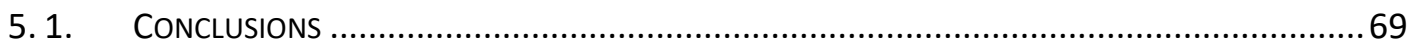

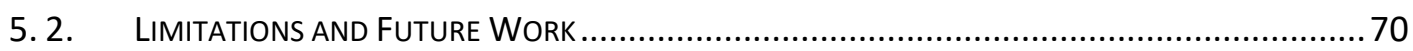

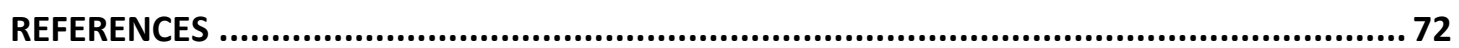

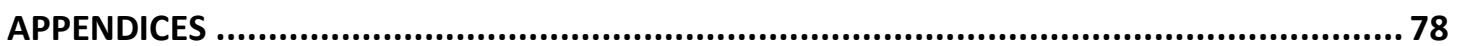

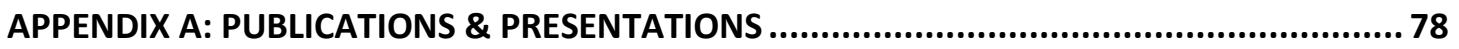

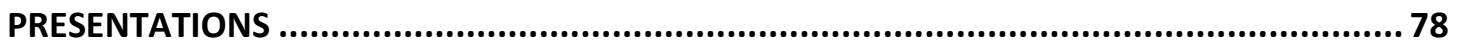

APPENDIX B: SIMULATION RESULTS FOR MIXED FLEET .................................................. 79 


\section{LIST OF TABLES}

Table 1 Existing TOD and Dynamic-Priced HOT Facilities ................................................ 14

Table 2 Relationship between LOS and Traffic Density (Hourdos et al., 2015)....................22

Table 3 Toll Increments on I-394 (Hourdos et al., 2015) ...................................................22

Table 4 Toll Boundaries and Default Rates on I-394 (Hourdos et al., 2015) ..........................22

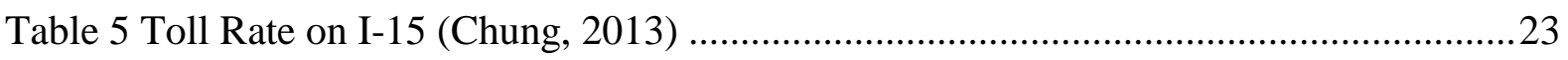

Table 6 Willingness to pay for different HOT facilities in the US ..................................... 32

Table 7 Income and VOT on Northern Virginia Area ..................................................... 45

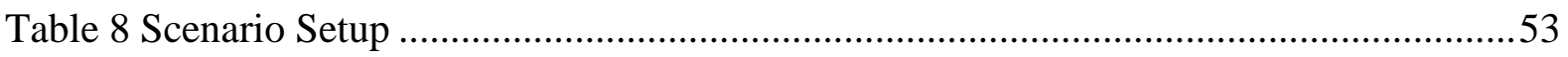

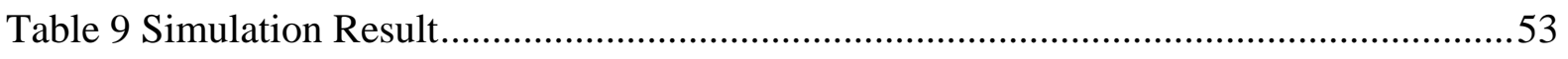

Table 10 Comparison of Final No. of Vehicles Choose HOT lane of Discount and No Discount .56

Table 11 Comparison of Revenue W/ Discount and W/O Discount .56 


\section{LIST OF FIGURES}

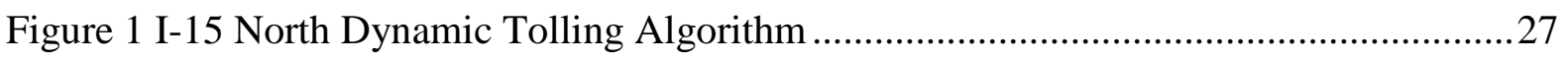

Figure 2 I-66 Inside the Beltway Corridor Map (VDOT, 2015) ........................................28

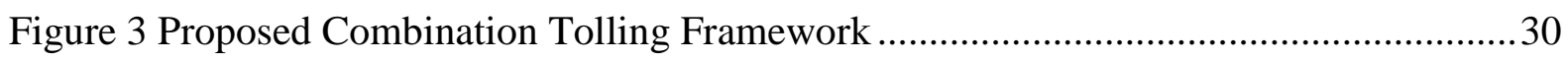

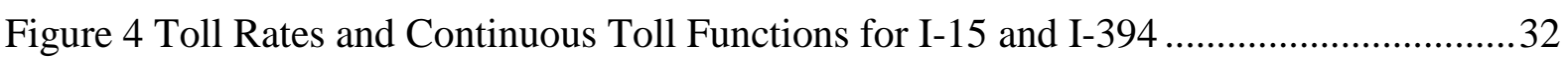

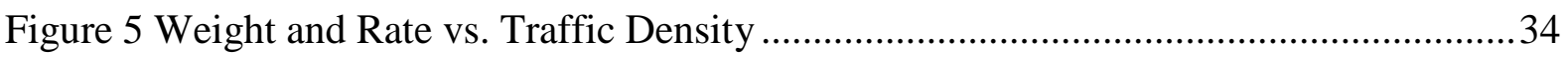

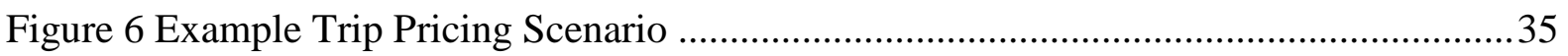

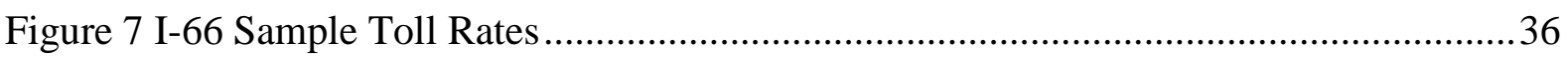

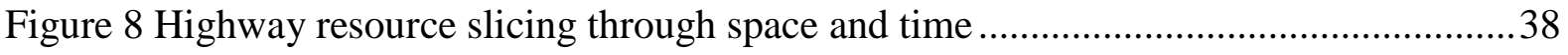

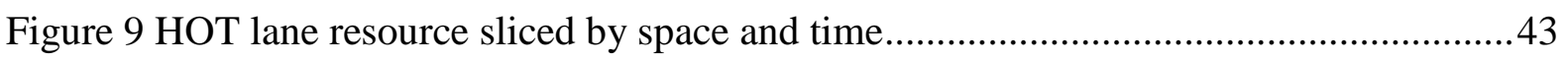

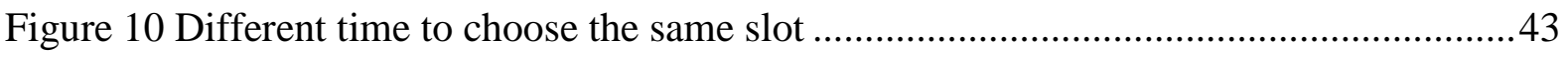

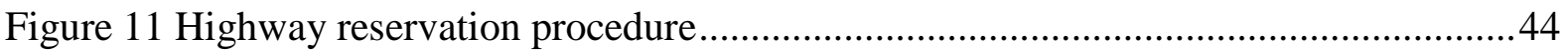

Figure 11 Value of Travel Time Distribution ................................................................ 46

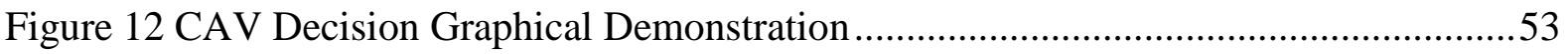

Figure 13 No. of Vehicles Choose HOT Lane after Each Decision Time...............................54

Figure 13 Percentage of Vehicles Choose HOT Lane after Each Decision Time ...................55

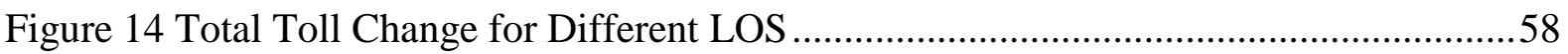

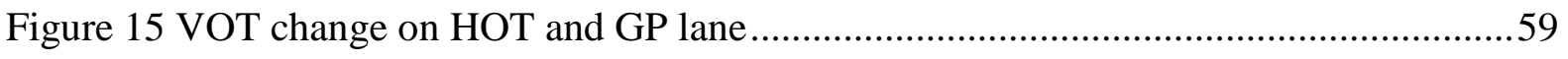

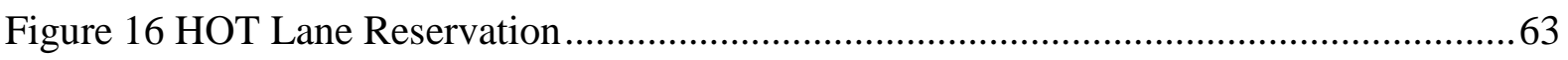

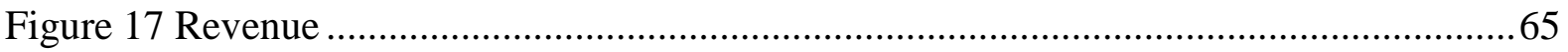

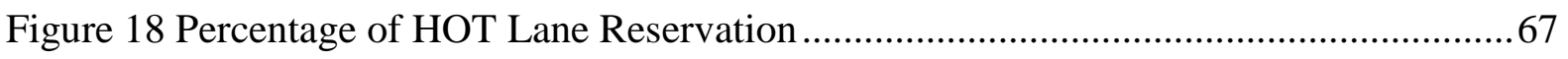




\section{INTRODUCTION}

\section{1. General}

Congestion pricing has been used as an efficient method for dealing with traffic congestion (de Palma et al., 2011), and currently priced facilities generally fall under one of three categories: static, time-of-day (TOD), and dynamic pricing. Static pricing is typically used with the goal of raising revenue while TOD pricing and dynamic pricing are used to actively manage traffic demand (FHWA, 2014). TOD pricing establishes a toll schedule based on historical traffic volume variations across different time periods of the day. TOD tolls are published in advance, and the price for a trip is predictable for the users (Chung, 2013). In contrast, dynamic pricing, which varies pricing in near real-time based on actual corridor conditions, can account for traffic conditions which vary from historical norms but offers less certainty for the user (Chung, 2013). The most common type of variably priced facility in the US is the High Occupancy/Toll (HOT) lane. These facilities are (barrier- or stripe-) separated lanes within a freeway, offering a direct tolled substitute route to the non-tolled general purpose (GP) lanes. On HOT lanes, low occupancy vehicles are charged a toll, while High Occupancy Vehicles (HOVs) are allowed to use the lanes free of charge or at reduced rates (FHWA, 2014).

Dynamic pricing schemes are growing in popularity on many HOT facilities in the US, such as I-394 in Minnesota and I-15 in San Diego (I-15 Express Lanes, I-394 Express Lanes). However, the reactive nature of dynamic pricing works best when the traffic condition of the upcoming pricing interval matches the increasing or decreasing trend of the previous interval. In other words, current dynamic pricing schemes toll incoming managed lane traffic at the congestion level of the current traffic (or the increase or decrease in current traffic compared to the previous interval). To be more predictive, some dynamic tolling algorithms have added an element to capture traffic volume or speed in the GP lanes. This method provides a way to anticipate the change of traffic on both HOT and GP lanes so that dynamic pricing can be more robust with a pseudo-predictive element. However, all HOT lane facilities currently in the US have both priced HOT lanes and non-priced general purpose lanes (GP lanes). Existing dynamic pricing algorithm on HOT lanes do not consider situations where there are no GP lanes, which lack the predictive element of GP lanes. To generate a more robust algorithm for predicting an effective toll on HOT lane, the first part of this thesis proposes a combination pricing framework to implement variable pricing for a tolled facility which does not have a direct substitute route, motivated by the proposed conversion of HOV lanes to HOT lanes on 
I-66 Inside the Beltway in Northern Virginia. First, this study reviews existing TOD and dynamic priced facility practices in the US, offering insight into best practices on currently operated HOT lanes via extensive expert interviews. Based on expert insights, this study proposes a new pricing framework which combines TOD and dynamic pricing elements. This framework considers both the user preference for the predictability of a time-of-day pricing scheme as well as the flexibility of a dynamic pricing scheme to accommodate real-time fluctuations in traffic demand.

Although adding a predictive component to existing dynamic tolling schemes can increase the predictability, existing dynamic tolling schemes (with or without GP lanes) are still largely reactive to the real-time traffic flow. With the introduction of CAV technology, it is possible to gather traffic flow information ahead of time by incorporating the route choice of upstream traffic. The second part of this thesis explores a reservation-based dynamic pricing scheme. This algorithm allows CAVs to reserve the HOT lane in advance (at a discount). The basic tolling algorithm was generated from the theory of second-best pricing, in an imperfect economic market where not all routes are tolled (Verhoef, 2000). The addition of the price discount for advanced reservations is similar to airline pricing and hotel booking. The earlier the vehicle reserves the HOT lane, the better discount they will get. This mechanism encourages users to book the HOT lane as early as possible. In this case, the operator can collect the reservation information and, in turn, increase certainty and predictability of the approaching demand for the HOT lane. The pricing scheme is also designed to be operational with mixed (connected and non-connected) fleets, as the dynamic toll updates in discrete intervals (much like in current practice). A hypothetic two-lane (one HOT lane and one GP lane) highway system is simulted here to demonstrate the conceptual tolling framework.

\section{2. Objectives of Thesis}

The objective of this study is to develop a pricing scheme for dynamically priced facility both on the non-CAV environment and CAV environment. The proposed tolling scheme can increase the predictability of traffic demand on HOT lane and dynamically adjusting toll to manage traffic demand on HOT lane. Specific objectives include:

- To explore existing dynamic priced facilities in the United States and best practices for their pricing schemes. 
- Propose a combination dynamic and time-of-day pricing algorithm in the non-CAV environment for HOT facilities (especially for facilities which do not have parallel GP lanes).

- Propose a new reservation-based dynamic pricing algorithm in the CAV environment using the advanced vehicle-to-infrastructure technology.

\section{3. Organization of Thesis}

This thesis is organized into the following sections:

Chapter 1 presented the introduction of the study in a combination of objectives and organization of the thesis.

Chapter 2 includes a background research that covers existing dynamic priced facilities in the US and experts' insights on current tolling schemes.

Chapter 3 proposes a flexible, combination tolling algorithm in the non-CAV environment for HOT facilities which do not have parallel GP lane.

Chapter 4 proposes a reservation-based tolling algorithm in the CAV environment (with mixed non-CAV and CAVs and all CAVs) via a simulation of a hypothetical single-lane managed lane running parallel to a single-lane untolled GP lane.

Chapter 5 presents the conclusions of the study, limitations and future work. 


\section{BACKGROUND RESEARCH}

\section{1. Existing TOD \& Dynamic-Priced HOT Facilities}

The majority of HOT facilities in the US utilize dynamic pricing algorithms while some use pre-established toll schedules in a TOD scheme. TOD HOT facilities can be categorized either as single zone HOT facilities (such as SR-91 Express Lanes in Orange County, CA) or multizone HOT facilities (such as Katy Managed Lanes in Houston, TX). Table 1 below displays basic information about eleven existing TOD and dynamic priced HOT facilities in the US. As seen in Table 1, some existing HOT facilities allow HOV2+ vehicles to travel toll-free. However, some are only free for HOV3+ vehicles. The dynamic toll rate update frequency ranges from every 3 to 15 minutes. Most facilities toll 24/7, with select facilities only tolling during morning and afternoon peak hours.

To enhance the understanding of existing HOT tolling practices, 11 expert interviews were carried out with academic and agency experts who lent insight into both the wider behavioral research and day-to-day operations of managed lane operations. The interviews included faculty from three universities and representatives from Washington Department of Transportation, Santa Clara Valley Transportation Authority, Orange County Transportation Authority, San Diego Association of Governments, Texas Department of Transportation, North Central Texas Council of Governments, and Georgia State Road and Tollway Authority. From expert interviews, nine main topics emerged as primary points of discussion, as summarized below. 
Table 1 Existing TOD and Dynamic-Priced HOT Facilities

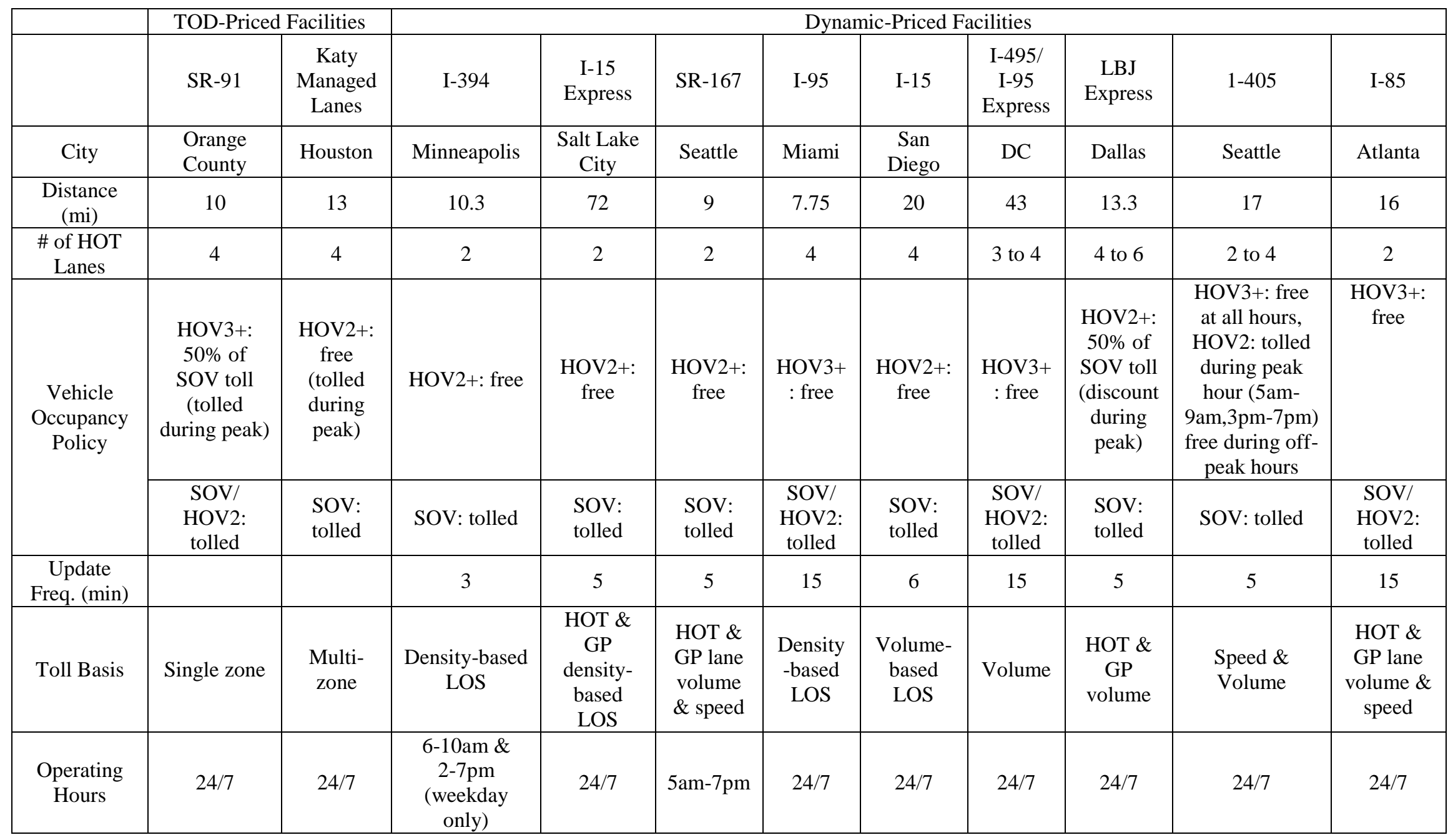




\section{2. Interviews with Academic \& Agency Experts}

\subsubsection{Tolling Basis}

Currently, all dynamically priced freeway facilities in the US have both HOT lanes and general purpose (GP) lanes. Some facilities, such as MN I-394, use algorithms that only account for HOT lane metrics, which leads to more stability in the tolling algorithm outputs (Hourdos et al., 2015). However, facilities whose pricing algorithms account for both HOT and GP lane performance have flexibility in the algorithm to weigh those inputs based on relative performance of both sets of lanes, which can provide predictive power in the pricing model (T. Patterson, 2016). For example: On GA I-85, while the toll algorithm is weighed heavily towards HOT lane metrics, GP lane volumes remain in the algorithm to serve as a predictive indicator of HOT lane performance in subsequent time intervals (C. Tomlinson, 2016) On WA I-405, not accounting for GP lane metrics at the beginning of operations meant HOT lanes were underpriced, which resulted in the capacity selling off too quickly. On the other hand, during the opening days of WA SR-167, accounting for GP lane metrics made the algorithm too sensitive and led to unnecessary toll fluctuations (T. Patterson, 2016). It is important to note that GA I-85 and the northern portion of WA I-405 are single lane HOT facilities, where GP lane metrics are more useful as a leading predictor of subsequent demand (and performance) of HOT lanes.

\subsection{2. $\quad$ Toll Update Frequency}

Experts generally agree that toll update frequency is set based on limits of technology and algorithm feedback speed. A 5-minute toll update frequency is the most common on existing facilities (including CA SR-237, GA I-85, WA SR-167 and I-405). MN I-394 utilizes the shortest toll update frequency at every 3 minutes. Users may not be sensitive to the toll update frequency, as they see the instantaneous rate at a specific time, no matter how frequently it is updated (D. Levinson, 2016). Additionally, the public generally knows the toll rates to anticipate during typical traffic conditions, thus update frequency is not important to them $(\mathrm{C}$. Tomlinson, 2016). Gocman et al. (2015) simulated methods to estimate toll revenue using data from SR-91. In this study, the toll update frequency varied from 1 minute to 1 hour, and the total simulated revenue was about the same no matter the update frequency. 


\subsubsection{Toll Elasticity of Demand and Pricing Caps}

Experts agree that stated preference survey findings of willingness-to-pay (WTP) for tolls is much lower than what people actually are willing to pay when examining empirical HOT lane data. Experience from Katy Freeway Managed Lanes reveals that while the stated preference survey results show users' WTP for travel time savings at \$22 per hour, analysis of empirical HOT lane usage data found an average WTP of \$51 per hour of travel time savings on the managed lanes (Devarasetty et al. 2012). In fact, on MN I-394, WA SR-167, and I-405, facilities experience increased demand in HOT lanes when tolls are high since users perceive a higher utility of HOT lanes when toll rates increase (Janson and Levinson, 2014). On I-10 Katy Freeway, approximately $10 \%$ of users consistently use HOT lanes even when speeds are slower than GP lanes (M. Burris, 2016). Additionally, there is a small portion of people who choose to use HOT lanes almost every day no matter the operating conditions. For Houston managed lanes, only $15 \%$ of travelers are truly deciding between GP and HOT lanes (about 5\% always use HOT lanes, about 80\% always use GP lanes) (M. Burris, 2016). SANDAG invested in a 7-month study to examine toll elasticity of demand and found it varies with toll price point, the day of the week, and direction of travel (S. Koblentz, 2016). Experts agree that the best way to calibrate facility-specific pricing parameters is to begin operations then collect back data, with Texas Department of Transportation implementing a policy which requires all new dynamically priced facilities to implement TOD tolling for 6 months to generate data for dynamic tolling parameters (S. Koblentz, 2016; L. Sexton \& M. Saenz, 2016).

Experts are generally against pricing caps for full algorithm flexibility. Pricing caps are implemented when legislation or contracts require them. GA I-85 has a maximum price cap of $\$ 0.90$ per mile, however, a $\$ 13.95$ per trip max toll rate (regardless of trip distance) is currently being used to allow more flexibility in managing HOT lane demand (C. Tomlinson, 2016). WA SR-167 has a \$9 per trip price cap, and I-405 has a \$10 per trip price cap. Even at these maximum rates, there is still excessive demand for the express lanes (T. Patterson, 2016). CA SR-237 has no published maximum toll but there is an internal soft cap (flexible price cap which is set by operators but not advertised to public) that started at $\$ 5.00$ per trip and has now increased to $\$ 7.00$ per trip, with the additional option of going to HOV-only mode if maximum toll is not effective in controlling demand (C. Emoto, 2016).

In terms of minimum toll rates, GA I-85 began operations with a $\$ 0.10$ per mile minimum toll, but has since dropped to $\$ 0.01$ per mile to encourage HOV2s to use the facility 
during off-peak hours (M. Wilkins \& A. Gillespie, 2016). WA SR-167 and I-405 have minimum toll rates of $\$ 0.50$ and $\$ 0.75$ per trip. CA SR-237 has a $\$ 0.30$ per trip minimum toll. Experts generally agree that if a minimum toll rate is set, the goal is to cover maintenance and administrative costs.

\subsubsection{Pricing Type}

Dynamic HOT facilities generally fall under one of three categories: distance-based, trip-based, and zone-based. Distance-based dynamic HOT facilities calculate the price based on a real-time rate and the distance each user travels. Trip-based dynamic HOT facilities calculate the price based on specific origin and destination (entry-exit) pairs. Zone-based (also known as segment-based) dynamic HOT facilities calculate the price based on each zone (within which price can be calculated based on distance or trips).

Pricing based on the most congested zone of a trip is a popular approach in existing dynamic pricing algorithms, and such is the approach on GA I-85, WA SR-167, and I-405. On GA I-85, all trips upstream of the most congested zone are tolled at the rate of the most congested zone, to "reserve" capacity (C. Tomlinson, 2016). On WA I-405, total trip pricing is the sum of prices in each zone (independent of upstream and downstream zones) ( $\mathrm{T}$. Patterson, 2016). User feedback has indicated some discomfort with the uncertainty of zonebased pricing since advertised toll rates on signs do not cover every possible trip (A. Gillespie, 2016).

\subsubsection{Occupancy Restrictions}

Experts agree that occupancy restrictions on HOT facilities lead to high violation rate, as they are difficult to enforce. CA SR-237 has HOV-only restriction when speeds fall below a threshold for several consecutive time periods (C. Emoto, 2016). On WA SR-167, when SOV restriction is introduced (to maintain $45 \mathrm{mph}$ for $\mathrm{HOV} 2+$ and transit), violation rates increase dramatically (T. Patterson, 2016). GA I-85 allows the flexibility to go into HOV3-only mode if congestion is extreme. However, current experience suggests the public is not informed enough to know what to do if such a sign is displayed (e.g., if a SOV is already in the facility, do they need to exit?) (C. Tomlinson, 2016). Experts agree that it is preferable to have a high (or no) pricing cap so that occupancy restrictions are not necessary. 


\subsubsection{Toll Signage}

Expert opinions vary on whether travel time savings should be displayed on HOT lane signage. Few facility currently displays travel time estimates in HOT lanes while most display travel time estimates in the GP lanes (I-405 in WA display travel times for both GP and HOT lanes). Agencies expressed concern that if estimated travel times do not match actual travel times, HOT lane users will demand toll refund (C. Tomlinson, 2016; T. Patterson, 2016). However, the non-transparency of travel time savings can create a situation where users perceive a higher utility of the tolled lane when toll rates are high (D. Levinson, 2016). Directly posting estimated travel time savings can mitigate the situation where higher toll rates create higher demand in HOT lanes (D. Levinson, 2016).

However, research has also shown that drivers generally overestimate their travel time savings on the order of 2 to 3 times in magnitude, so displaying estimated travel time savings may not reflect the actual utility of the tolled facility as perceived by users. On Katy Freeway, frequent QuickRide users in the morning peak estimated travel time savings are averaging 34.7 minutes whereas operational data shows average savings (for the entire year of 2002) at 17.3 minutes (Burris et al., 2004). A potential alternative to displaying travel time savings is to display speed differential between HOT and GP lanes (C. Tomlinson, 2016). It is possible that the "feel" of driving faster than the adjacent lane is more important than absolute travel time savings (C. Tomlinson, 2016). In addition, drivers value more than just travel time in their choice to use express lanes. Survey of users on Minnesota I-394 HOT lanes reveal that travelers also value the travel time reliability, perceived sense of safety, better emergency response, and better enforcement that come with express lanes (Cho et al., 2011)

\subsubsection{Facility Access}

Experts agree ease of access to priced facilities has tradeoffs: Barrier separation allows for less "friction" between HOT and GP traffic. However, users complain about limited access to HOT lanes compared to striping separation. Upon initial opening of WA SR-167, HOT lanes were separated by striping only, allowing users to "buy-in" to the facility more dynamically On WA I-405, where HOT lanes are barrier-separated, users rely more on historical knowledge (T. Patterson, 2016). 


\subsubsection{Incident Management}

Experts agree that dynamic tolling algorithms generally cannot account for extreme incidents or capacity reductions (e.g., when a crash is blocking all or most of lanes on HOT or GP facility). Manual monitoring and override are necessary for such situations. The strategy for incident management varies by where the incident occurs. In the case of incidents blocking HOT lanes, tolling is generally turned off upstream of the incident, but turn continues downstream (C. Tomlinson, 2016; T. Patterson, 2016). When an incident blocks most of GP lanes, tolling is turned off, and HOT lanes upstream of the incident is typically used as relief route (C. Tomlinson, 2016; T. Patterson, 2016). When the incident is more minor (e.g., GP lanes slowing down but still flowing), the weighting of GP metrics in the algorithm is increased to allow tolling in HOT lane to anticipate demand from GP lanes (C. Tomlinson, 2016; T. Patterson, 2016). On SR-91, customers can call in to request toll rebates during minor incident events (S. Koblentz, 2016).

\subsubsection{TOD vs. Dynamic Pricing}

Studies have demonstrated TOD pricing (based on periodically updated historical data) as an effective way to mitigate congestion (Carey and Srinivasan, 1993; Joksimovic et al., 2005). Similarly, dynamic congestion pricing is also effectively at reducing congestion, but can also demonstrate undesired side-effects, such as substantial re-routing to minor roads and only small reductions in travel distance (May and Milne, 2000). Considering the ability to account for real-time traffic conditions, does dynamic pricing necessarily outperform TOD pricing? A previous study shows that when travel demand is predictable, TOD tolling can perform as well as dynamic tolling, provided that the toll profiles are optimized against the demand level (Wu et al., 2010). But under severe congestion, dynamic tolling is adaptive to demand fluctuations; its performance is more robust and stable (Yin and Lou, 2009).

For fully dynamic priced facilities with no GP lanes (and therefore do not have true substitute routes), users will have to make the decision to choose the facility further upstream than a facility with both HOT and GP lanes (R. Lindsey, 2016; C. Tomlinson, 2016). Furthermore, these users do not have an easy way to "buy in" and "buy out" of the facility as users on facilities with both GP and HOT lanes (T. Patterson, 2016). More sophisticated dynamic tolling algorithms (such as facility I-15 North of SR-56 in San Diego, CA and SR167 in Seattle, WA) take into account both HOT lane and GP lane metrics, with GP lane 
metrics providing a predictive component in the tolling algorithm (T. Patterson, 2016). With no GP lane metrics, the dynamic HOT tolling algorithm lacks a predictive component and is purely reactive, and can lead to over-adjustment of toll rates (T. Patterson, 2016). When facilities are fully priced, experts recommend considering TOD tolling in place of true dynamic pricing, to reflect the price certainty users prefer when the decision to use the facility requires pre-planning (T. Patterson, 2016; D. Levinson, 2016).

\section{3. Existing TOD \& Dynamic Pricing Algorithms}

\subsection{1. $\quad$ Existing TOD Pricing Algorithms in Practice}

\section{Express Lanes, Orange County, CA}

The toll schedule on SR-91 is seasonally renewed on the first day of January, April, June, and October (OCTA, 2016). The average volume (veh/h/ln) at hour k on the day of the week is the average directional volume over the past 12 consecutive weeks, excluding days/hours with holidays and major incidents (OCTA, 2003). The toll rate is then determined through the following process.

Assume that average volume for season period $t$ is already known, toll rate for next season period $t+1$ is

$$
\begin{cases}Q_{k, t}>1650, & \text { Toll }_{k, t+1}=\text { Toll }_{k, t}+\$ 1.00 ; \text { Toll }_{k, t+2}=\text { Toll }_{k, t+1} \\ 1650>Q_{k, t}>1600, & \text { Toll }_{k, t+1}=\text { Toll }_{k, t}+\$ 0.75 ; \text { Toll }_{k, t+2}=\text { Toll }_{k, t+1} \\ 1600>Q_{k, t}>1360, & \text { Toll }_{k, t+1}=\text { Toll }_{k, t} \\ 1360>Q_{k, t}, & \text { Toll }_{k, t+1}=\text { Toll }_{k, t}-\$ 0.50\end{cases}
$$

Where,

- $Q_{k, t}$ : the directional average volume $(\mathrm{veh} / \mathrm{h} / \mathrm{ln})$ at hour $\mathrm{k}$ on the day of week in period $\mathrm{t}$

- Toll $_{k, t}$ : TOD toll rate at hour $\mathrm{k}$ in season period $\mathrm{t}$

If the directional average volume exceeds $1600 \mathrm{veh} / \mathrm{h} / \mathrm{ln}$ in the current period and the toll has just increased in the previous period, then the toll for next period will remain the same. This design helps keep the toll rates stable and prevents the toll rate from unnecessarily frequent increases. The toll rate tables are posted on the 91 Express Lanes website, and there are several different toll rate tables for each direction of flow, holidays, etc. 


\subsection{2. $\quad$ Existing Dynamic Pricing Algorithms in Practice}

Existing dynamic toll algorithms can be classified broadly as either discrete or continuous. Discrete toll algorithms involve a step-based toll rate table, with toll rates changing based on pre-set incremental values. Continuous toll algorithms base toll rates directly on (near) real-time traffic count data. I-394 MnPass Express Lanes are using discrete toll algorithms. However, the proposed continuous algorithms for I-394 in MN include several continuous alternatives to the current discrete toll scheme.

Existing dynamic toll algorithms can also be classified by different lane metrics as HOT lane metrics only or both HOT \& GP lane metrics. Most of the HOT lane dynamic pricing algorithms (I-394 MN, I-15 South CA) only consider HOT metrics, such as HOT volume or HOT density. Some algorithms (SR-167 WA, I-15 North CA) consider both HOT and GP metrics, which add more predictability to the toll.

\subsubsection{Dynamic Pricing Algorithms only consider HOT lane metrics}

\section{I-394 MnPass Express Lanes, Minneapolis, MN (Discrete)}

I-394 MnPass Express Lanes is the first dynamic priced HOT lane facility in the US with multiple ingress/egress points. I-394 Express Lanes has five toll zones and two toll sections. Each section has its own price and travelers who traverse both are charged the sum of the two tolls up to a maximum of $\$ 8.00$ per trip. The toll zones are defined as the sections between successive toll tag plazas. Each trip is defined as the distance from the plaza at which the vehicle's toll tag is first detected to the plaza that it is detected last. The driver locks in on a toll price at the time it is first detected but is actually charged upon exiting the toll section (Hourdos et al., 2015). The objective of I-394 Express Lanes is to maintain a level of service (LOS) C or better performance in HOT Lanes (Hourdos et al., 2015). Traffic count and speed data are collected in every 30 seconds, and the toll rate increments are determined by the corresponding traffic density (Hourdos et al., 2015).

The tolls are derived from the following steps:

A. Convert traffic volume and speed readings to density, reported every 30 seconds. The traffic density calculations are then averaged over a 6-minute time period. The relationship between traffic density D and LOS are shown in Table 2 below. 
Table 2 Relationship between LOS and Traffic Density (Hourdos et al., 2015)

\begin{tabular}{|c|c|}
\hline LOS & Traffic Density (D) (Vehicles/Lane/Mile) \\
\hline A & $0-11$ \\
\hline B & $>11-18$ \\
\hline C & $>18-29$ \\
\hline D & $>29-35$ \\
\hline F & $>35-45$ \\
\hline
\end{tabular}

B. Calculate the change of density $(\Delta \mathrm{D})$ between consecutive tolling periods. For each zone, density at period $t, D_{t}$, is the maximal 6-minute density downstream. Change density at $\mathrm{t}$ is $\Delta \mathrm{D}=\mathrm{D}_{\mathrm{t}}-\mathrm{D}_{\mathrm{t}-1}$. A sample toll increment lookup table is shown in Table 3.

Table 3 Toll Increments on I-394 (Hourdos et al., 2015)

\begin{tabular}{|c|c|c|c|c|c|c|}
\hline$\Delta D$ & $\mathbf{1}$ & $\mathbf{2}$ & $\mathbf{3}$ & $\mathbf{4}$ & $\mathbf{5}$ & $\mathbf{6}$ \\
\hline $\mathbf{2 0}$ & $\$ 0.00$ & $\$ 0.25$ & $\$ 0.50$ & $\$ 0.75$ & $\$ 1.00$ & $\$ 1.25$ \\
\hline $\mathbf{2 1}$ & $\$ 0.00$ & $\$ 0.25$ & $\$ 0.50$ & $\$ 0.75$ & $\$ 1.00$ & $\$ 1.25$ \\
\hline $\mathbf{2 2}$ & $\$ 0.00$ & $\$ 0.25$ & $\$ 0.50$ & $\$ 0.75$ & $\$ 1.00$ & $\$ 1.25$ \\
\hline $\mathbf{2 3}$ & $\$ 0.00$ & $\$ 0.25$ & $\$ 0.50$ & $\$ 0.75$ & $\$ 1.00$ & $\$ 1.25$ \\
\hline $\mathbf{2 4}$ & $\$ 0.00$ & $\$ 0.25$ & $\$ 0.50$ & $\$ 0.75$ & $\$ 1.00$ & $\$ 1.25$ \\
\hline $\mathbf{2 5}$ & $\$ 0.00$ & $\$ 0.25$ & $\$ 0.50$ & $\$ 0.75$ & $\$ 1.00$ & $\$ 1.25$ \\
\hline $\mathbf{2 6}$ & $\$ 0.00$ & $\$ 0.25$ & $\$ 0.50$ & $\$ 0.75$ & $\$ 1.00$ & $\$ 1.25$ \\
\hline $\mathbf{2 7}$ & $\$ 0.00$ & $\$ 0.25$ & $\$ 0.50$ & $\$ 0.75$ & $\$ 1.00$ & $\$ 1.25$ \\
\hline $\mathbf{2 8}$ & $\$ 0.00$ & $\$ 0.25$ & $\$ 0.50$ & $\$ 0.75$ & $\$ 1.00$ & $\$ 1.25$ \\
\hline $\mathbf{2 9}$ & $\$ 0.00$ & $\$ 0.25$ & $\$ 0.50$ & $\$ 0.75$ & $\$ 1.00$ & $\$ 1.25$ \\
\hline
\end{tabular}

C. Use the toll increment lookup table to find the change in toll. The toll at period $t$ is the previous toll at $\mathrm{t}-1$ plus the change from the lookup table.

$$
\operatorname{Toll}_{t}=\text { Toll }_{t-1}+\Delta \text { Toll }
$$

For each LOS, there is a minimum, maximum, and default toll rate. The default rate is only used at system start-up when there is no previous data to create an initial $\Delta \mathrm{D}$. The boundaries and default rates are showing in Table 4.

Table 4 Toll Boundaries and Default Rates on I-394 (Hourdos et al., 2015)

\begin{tabular}{|c|c|c|c|c|c|}
\hline LOS & Min K & Max K & Minimum Rate & Maximum Rate & Default Rate \\
\hline A & 0 & 11 & $\$ 0.25$ & $\$ 0.50$ & $\$ 0.25$ \\
\hline B & 12 & 18 & $\$ 0.50$ & $\$ 1.50$ & $\$ 0.25$ \\
\hline C & 19 & 29 & $\$ 1.50$ & $\$ 2.50$ & $\$ 1.50$ \\
\hline D & 30 & 35 & $\$ 2.50$ & $\$ 3.50$ & $\$ 3.00$ \\
\hline E & 36 & 45 & $\$ 3.50$ & $\$ 6.00$ & $\$ 5.00$ \\
\hline F & 46 & 50 & $\$ 6.00$ & $\$ 8.00$ & $\$ 8.00$ \\
\hline
\end{tabular}




\section{I-15 Express Lanes, San Diego, CA (Discrete)}

At the beginning of I-15 Express Lanes operations in 1998, the facility was 8-miles long and terminated south of SR-56 (Supernak et al., 2001). The original tolling algorithm is based on a volume-based LOS lookup table. The goal of the originally implemented discrete toll algorithm is to keep the HOT lanes at a minimum LOS of $\mathrm{C}$. The toll rates were renewed every 6 minutes and were determined by the latest 12-minute volume of the two HOT lanes based on the volume-toll lookup table. The goal travel speed in the HOT lane was set at 65 mph. Sample toll rates are shown in Table 5.

Table 5 Toll Rate on I-15 (Chung, 2013)

\begin{tabular}{|c|c|c|c|c|c|}
\hline & $\begin{array}{c}\text { 12-min Volume } \\
\text { Lower Thresholds }\end{array}$ & $\begin{array}{c}\text { Equivalent Hourly } \\
\text { Volume }\end{array}$ & Density & \multirow[t]{2}{*}{ LOS } & \multirow[t]{2}{*}{ Price $(\$)$} \\
\hline & (vehs) & (vehs) & (vehs/ln/mile) & & \\
\hline 1 & 240 & 1200 & 18 & $\mathrm{~A}$ & $\$ 0.50$ \\
\hline 2 & 240 & 1200 & 18 & A & $\$ 0.75$ \\
\hline 3 & 290 & 1450 & 22 & B & $\$ 1.00$ \\
\hline 4 & 320 & 1600 & 25 & $\mathrm{~B}$ & $\$ 1.25$ \\
\hline 5 & 350 & 1750 & 27 & $\mathrm{~B}$ & $\$ 1.50$ \\
\hline 6 & 380 & 1900 & 29 & $\mathrm{~B}$ & $\$ 1.75$ \\
\hline 7 & 410 & 2050 & 32 & $\mathrm{~B}$ & $\$ 2.00$ \\
\hline 8 & 424 & 2120 & 33 & $\mathrm{C}$ & $\$ 2.25$ \\
\hline 9 & 440 & 2200 & 34 & $\mathrm{C}$ & $\$ 2.50$ \\
\hline 10 & 450 & 2250 & 35 & $\mathrm{C}$ & $\$ 2.75$ \\
\hline 11 & 460 & 2300 & 35 & $\mathrm{C}$ & $\$ 3.00$ \\
\hline 12 & 470 & 2350 & 36 & $\mathrm{C}$ & $\$ 3.25$ \\
\hline 13 & 480 & 2400 & 37 & $\mathrm{C}$ & $\$ 3.50$ \\
\hline 14 & 490 & 2450 & 38 & $\mathrm{C}$ & $\$ 3.75$ \\
\hline 15 & 500 & 2500 & 38 & $\mathrm{C}$ & $\$ 4.00$ \\
\hline 16 & 610 & 3050 & 47 & $\mathrm{D}$ & $\$ 4.50$ \\
\hline 17 & 620 & 3100 & 48 & $\mathrm{D}$ & $\$ 5.00$ \\
\hline 18 & 630 & 3150 & 48 & $\mathrm{D}$ & $\$ 5.50$ \\
\hline 19 & 640 & 3200 & 49 & $\mathrm{D}$ & $\$ 6.00$ \\
\hline 20 & 650 & 3250 & 50 & D & $\$ 6.50$ \\
\hline 21 & 660 & 3300 & 51 & $\mathrm{D}$ & $\$ 7.00$ \\
\hline 22 & 670 & 3350 & 52 & $\mathrm{D}$ & $\$ 7.50$ \\
\hline 23 & 680 & 3400 & 52 & D & $\$ 8.00$ \\
\hline
\end{tabular}

\section{I-394 MnPass Express Lanes, Minneapolis, MN (Continous)}

The proposed continuous algorithms for I-394 in MN include several continuous alternatives to the current discrete toll scheme.

\section{A. Base Continuous Toll Function}

The base continuous toll algorithm is based solely on HOT lane density, as shown below: 


$$
\text { Toll }_{\text {continuous }}=\alpha * D_{\text {HOT }}^{\beta}
$$

Where,

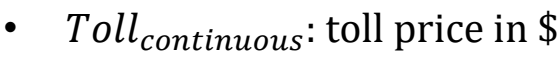

- $D_{\text {нот }}$ : density in vehicles/mile/lane

- $\quad \alpha \& \beta$ : parameters which can be adjusted to achieve the desired curve (rate of toll change), $\alpha$ can be measured by value of travel time (VOTT) or WTP (Janson and Levinson, 2014).

B. Unweighted Value Pricing

The unweighted value pricing approach is based on the relative utility of HOT lanes compared to GP lanes. Here the toll is based on differences in lane densities measured along parallel detectors in the HOT and GP lanes. Maximum downstream densities are used in calculations.

$$
\text { Toll }_{\text {Value }_{\text {unweighted }}}=\gamma *\left(D_{G P}-D_{H O T}\right)
$$

Where,

- Toll $_{\text {Value }_{\text {unweighted }}}$ : toll price in \$

- $D_{G P}$ and $D_{H O T}$ : density in vehicles/mile/lane for GP and HOT lanes, respectively

- $\gamma$ : scaling parameter to convert difference in HOT lane and GP lanes densities to \$ (Janson and Levinson, 2014)

C. HOT $_{\text {weighted }}$ Value Pricing

The $\mathrm{HOT}_{\text {weighted }}$ Value Pricing continuous tolling framework for I-394 highlights the fact that density differences between GP and HOT lanes do not correlate to travel speed differences. As density increases, travel speed differences are greater. HOT $_{\text {weighted }}$ Value Pricing places increasing weight on HOT lane density as the density difference between HOT and GP lanes grows. Higher HOT densities result in greater fluctuations in tolls.

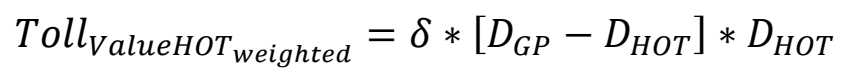

Where, 
- Toll ValueHoT $_{\text {weighted }}$ : toll price in \$

- $D_{G P}$ and $D_{H O T}$ : density in vehicles/mile/lane for GP and HOT lanes, respectively

- $\delta$ : scaling parameter to convert $\mathrm{HOT}_{\text {weighted }}$ density difference between HOT and GP lanes to \$ (Janson and Levinson, 2014)

D. GP weighted Value Pricing

$\mathrm{GP}_{\text {weighted }}$ Value Pricing is preferred when HOT lane density is very low and GP lane density is much higher. In this situation, toll price is tied more to GP congestion and less to travel time savings (relative utility) associated with HOT lane.

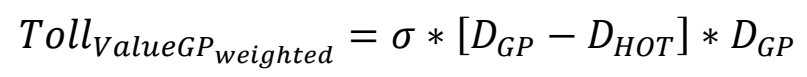

Where,

- Toll ValueGP $_{\text {weighted }}$ : toll price in $\$$

- $\mathrm{D}_{\mathrm{GP}}$ and $\mathrm{D}_{\mathrm{HOT}}$ : density in vehicles/mile/lane for GP and HOT lanes, respectively.

- $\sigma$ : scaling parameter to convert $\mathrm{GP}_{\text {weighted }}$ density difference between HOT and GP lanes to \$ (Janson and Levinson, 2014)

\subsubsection{Dynamic Pricing Algorithms consider both HOT and GP lane metrics}

\section{SR-167, Seattle, WA}

The SR-167 HOT lanes opened in 2008. Tolling algorithm for SR-167 considers both the volume and speed on both HOT and GP lane. The toll renews every 5 min based on the equation below.

$$
\operatorname{Toll}_{t}=\operatorname{Toll}_{t-1}+\text { Toll }_{\text {increment }} *(\text { Increment Level })
$$

Where,

- Toll $_{t}$ : the toll at period $\mathrm{t}$

- Increment level: account for both HOT and GP lane speed and volume, detailed equation shows as below

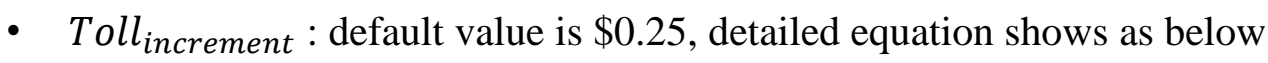




$$
\text { Increment Level }=\operatorname{Round}\left(W_{H O T} * T I M_{H O T}+W_{G P} * T I M_{G P}\right)
$$

Where,

- $\quad$ TIM $_{\text {HOT }} \&$ TIM $_{G P}$ : toll increment measure, detailed equation shows as below

- $W_{\text {HOT }} \& W_{G P}$ : weight for HOT \& GP lanes $(0.9 \& 0.1$ by default $)$

$$
T I M_{\text {HOT }}=W_{\text {volume change }} * \frac{V^{\prime}}{v_{\text {scale }_{\text {HOT }}}}+W_{\text {speed change }} *\left(-S^{\prime}\right)
$$

Where,

- $V^{\prime}$ : volume change

- $S^{\prime}$ : speed change

- $W_{\text {volume change }} \& W_{\text {speed change }}$ : the weight of volume/speed change (equal values by default)

- $v_{\text {scale_Hот }}$ : conversion factor converting volume to speed

\section{I-15 North, San Diego, California}

I-15 North of SR-56 is a zone-based dynamic pricing algorithm, which has entries and exits along the HOT corridor. The algorithm takes inputs of travel time savings on HOT lane and value of travel time (VOT) and calculate toll rate (min $\$ 0.05 /$ mile, max $\$ 1 / \mathrm{mile}$ ). The pricing algorithm takes both time and space into account.

Toll rate at period $\mathrm{t}$ is decided by the time savings at the period ( $\mathrm{t}-1)$ and VOT at time period $t$.

$$
P_{t}=\frac{C T S_{t-1} * V O T_{t}}{L}
$$

Where,

- $\quad P_{t}$ : toll rate at period $\mathrm{t}$

- $C T S_{t-1}$ : cumulative time savings

- L: downstream length 
The cumulative time savings $C T S_{t-1}$ takes into account all the downstream zones (which are the zones have potential time savings). Take zone 2 for example.

Zone 1 to $\mathrm{n}$

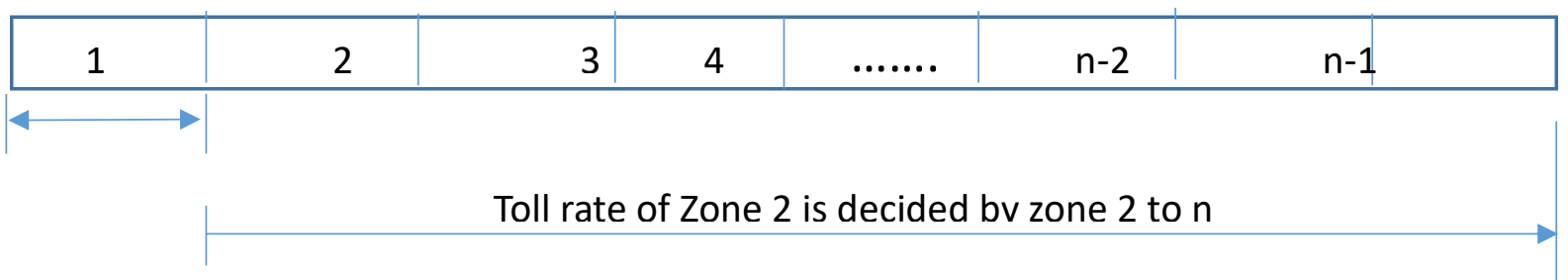

Figure 1 I-15 North Dynamic Tolling Algorithm

The time saving on zone 2 is

$$
C T S_{2}=\left(\frac{L_{2}}{V_{2 G P}}-\frac{L_{2}}{V_{2 H O T}}\right)
$$

Where,

- $C T S_{2}$ : travel time difference between HOT and GP on zone 2

- $L_{2}$ : the length of zone 2

- $V_{2 H O T} \& V_{2 G P}$ : the travel speed of HOT lane \& GP lane on zone 2

The cumulative time savings $C T S_{t-1}$ for zone 2 consider all time savings on zone 2 to zone n. The toll rate for zone 2 is

$$
\text { Toll Rate } \text { at time } t \text { for zone } 2=\frac{\sum_{i=2}^{n} C T S_{i, t-1} * V O T_{t}}{\sum_{i=2}^{n} L_{i}} \quad(\$ / \mathrm{mile})
$$

\section{4. Conclusions}

As more transportation agencies consider variably priced toll facilities to manage congestion and provide alternative sources of transportation funding, there is a need to synthesize best practices on existing priced facilities. This chapter includes a summary of operations on existing variable priced facilities in the US, aggregated through literature review and interviews with academic and agency experts. 


\section{Tolling Framework on Non-CAV environment}

This chapter proposed a tolling algorithm on the non-CAV environment for HOT facilities which do not have parallel GP lane using I-66 Inside the Beltway as a case study.

\section{1. Study Background}

I-66 Inside the Beltway is a part of a multimodal corridor in Northern Virginia connecting suburban Virginia communities with downtown Washington, DC. The corridor offers commuters several travel choices for their trip, but continues to face congestion challenges with growing demand. Currently, only vehicles with two or more occupants, vehicles with Clean Special Fuel license plates issued before July 1, 2011, motorcycles, and Dulles Airport users are permitted to travel I-66 Inside the Beltway during morning and evening peak hours (from 6:30 to 9:00am in the eastbound direction and from 4:00 to 6:30pm in the westbound direction) on weekdays. The transformation of I-66 Inside the Beltway will convert all lanes to variable-priced toll lanes during weekday peak hours (eastbound from 5:30 to 9:30 am and westbound from 3:00 to 7:00 pm). Carpools and Vanpools (with two or more people, increasing to high occupancy vehicles with three or more travelers [HOV3+] in 2020), transit, on-duty law enforcement and first responders will travel the corridor for free. The toll revenue will be used to improve transit and other modes along the I-66 corridor which will contribute to better quality and more frequent transit services for those commuters who choose not to drive (VDOT, 2016).

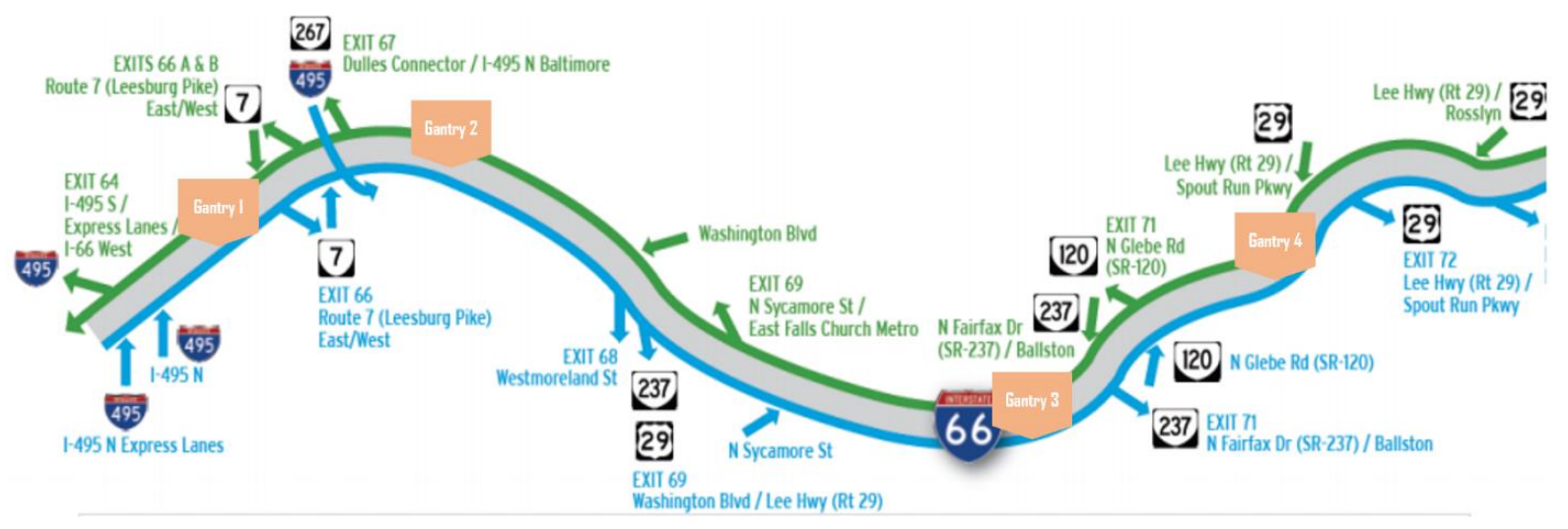

Figure 2 I-66 Inside the Beltway Corridor Map (VDOT, 2015) 
There are four toll gantries along I-66 Inside the Beltway, which separates the corridor into four toll zones (Soroush, 2015). Toll prices within each zone will change dynamically based on real-time traffic volumes to manage demand to ensure a more reliable trip.

\section{2. Methodology}

Considering I-66 Inside the Beltway's unique situation of having no true parallel substitute routes, a combination framework incorporating both TOD and dynamic tolling components is proposed here. For HOT lanes with parallel GP lanes, GP lane density or volume can serve as a predictive tolling component for HOT lane demand in subsequent time periods, in addition to the reactive tolling component of current period HOT lane volume or density. Without GP lanes, a facility like I-66 can utilize historical traffic patterns on the tolled lanes as a predictive tolling component, adding robustness to an otherwise purely reactive tolling algorithm. While TOD tolling is more predictable based on historical data, dynamic tolling is more flexible in handling unexpected fluctuations in traffic volume. While this combination framework can work for any facility, its application is arguably more needed when GP lane metrics are not present.

Additionally, at a priced facility's initial implementation, traffic volumes/demand is uncertain and will fluctuate during the ramp-up period (Lemp and Kockelman, 2009). Drivers' uncertainty about the choice to use the facility is higher. Setting a TOD component as part of the pricing algorithm allows drivers to have some certainty to lead to a more informed decision about whether to use the priced facility. At the same time, having an algorithm that also incorporates a dynamic tolling component can account for unexpected demand fluctuations.

Figure 3 below shows the proposed combination tolling framework. For each of the four toll zones on I-66 Inside the Beltway, the toll is the combination of dynamic and TOD pricing components, which are weighed by the relative difference between near real-time dynamic volumes and historical volumes. The total toll a traveler pays is then the aggregate of the zone pricing across multiple zones traversed. Two forms of multi-zone pricing schemes are proposed in this framework.

Each component of the Combination Tolling Framework is discussed in detail in the subsection below, starting from the dynamic and TOD components, to the weighting of both components with dynamic and TOD weights, to aggregating the toll across multiple zones. 


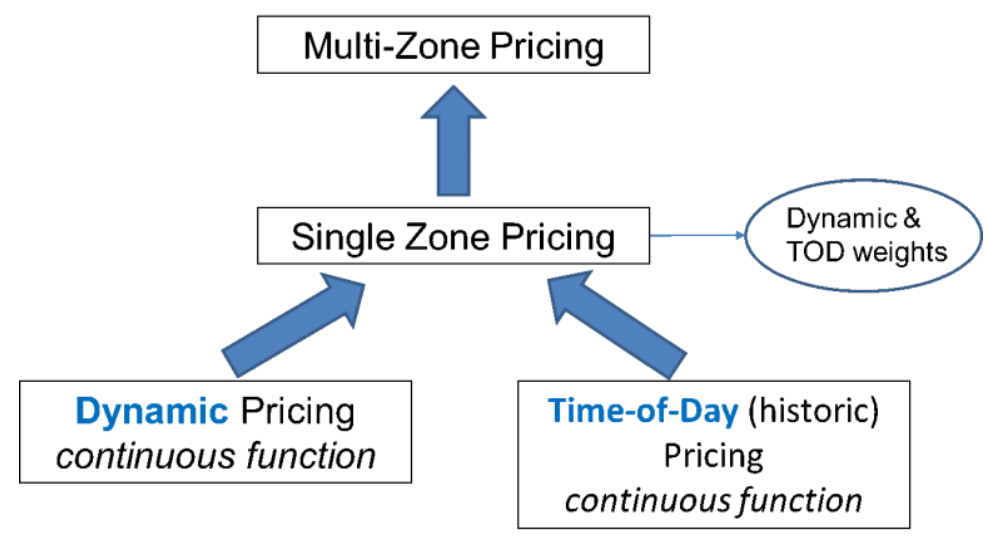

Figure 3 Proposed Combination Tolling Framework

\subsubsection{Dynamic Toll Component}

The proposed dynamic tolling algorithm continuous tolling function, as shown in Equation 1. Since I-66 Inside the Beltway has no adjacent free lanes during the priced hours, the lane performance metric of the function only considers the density of the priced lanes.

$$
\text { Toll }_{t, \text { dynamic }}=\left(\theta * D_{t, \text { dynamic }}\right)^{\beta}
$$

Where,

- Toll $_{t, \text { dynamic }}$ : dynamic toll rate at time $t$, measured in $\$ /$ mile

- $\mathrm{D}_{\mathrm{t}, \mathrm{dynamic}}$ : lane performance metric, dynamic density reading at time $\mathrm{t}$, measured in veh/ln/mile in this framework

- $\theta$ : scaling parameter to convert lane performance to $\$$, determined by the value of travel time (VOTT)

- $\quad \beta$ : describes the non-linear relationship between the increase in density and decrease in travel speed

\subsubsection{TOD Toll Component}

This price component will take on the same form as the dynamic toll component, it's based on historical density, not actually toll, as shown in Equation 14.

$$
\text { Toll }_{t, \text { historic }}=\left(\theta * D_{t, \text { historic }}\right)^{\beta}
$$

It is advisable to calibrate parameters for $\beta$ and $\theta$ based on back data collection. TOD toll rates for specific time increments (e.g., every hour) can then be set by looking at data from a specified previous period (e.g., previous 12 weeks). 


\subsection{3. $\quad$ Estimated Values for Parameters}

To estimate potential values for parameters $\theta$ and $\beta$, current toll rates on I-394 in Minneapolis and I-15 in San Diego (Figure 4(a)) were investigated as a starting point. As most existing HOT facilities are operated by private organizations with proprietary algorithms, there is limited open information on actual toll rates concerning lane performance measures. Such information is publicly available for I-394 and I-15. Hence these two facilities provide the basis for base parameter estimation in this study.

Given pricing plan for normal operation of MnPASS Lanes, each level of service has minimum and maximum density boundaries which correspond to minimum and maximum toll rates. Thus, the toll rate (\$/mile) shown in Figure 4(a) is the rates within each density boundary divided by the distance of I-394. I-15 Express Lanes has a volume-toll lookup table which includes a maximum toll rate per volume threshold. In Figure 4(a), those volumes were converted to equivalent density values.

As shown in Figure 4(b), power regression was utilized to estimate the parameters for $\theta$ and $\beta$ based on current toll tables (Figure 4(a)).

The results from the power regression shows the value of $\theta, \beta$ and $\mathrm{R}^{2}$ in $\mathrm{I}-15$ are $0.01817,2.311504,0.979007$ respectively. The value of $\theta, \beta$ and $\mathrm{R}^{2}$ in $\mathrm{I}-394$ are 0.01599 , $1.740526,0.981059$ respectively.

The parameter $\beta$ describes the rate of deterioration of lane performance as volumes (or density) increase on the priced facility. This parameter is facility-specific due to unique facility physical traits (such as geometry, lane width, frequency of ingress/egress points, etc) and local driving culture (a corridor full of commuters will tend to have a more disciplined style of driving than a corridor with high volumes of visitors [unfamiliar drivers]). Based on $\beta$ values from I-15 and I-394, a reasonable range of $\beta$ values may lie between 1.5 and 2.5.

The values for $\theta$ in these toll tables should, in theory, be proportional to average VOTT on these facilities. However, empirical studies of willingness-to-pay on priced facilities (as listed in Table 6) show that such figures vary widely across facilities, the direction of flow, and time of day. Based on the power regressions from I-15 and I-394, reasonable values of $\theta$ may lie between 0.015 to 0.020 . 


\begin{tabular}{|l|l|l|l|}
\hline \multicolumn{2}{|l}{ I-15 } & \multicolumn{2}{l|}{ I-394 } \\
\hline $\begin{array}{l}\text { Density } \\
\text { (vehs/ln/mile) }\end{array}$ & $\begin{array}{l}\text { Toll } \\
\text { rate } \\
\text { (\$/mile) }\end{array}$ & $\begin{array}{l}\text { Density } \\
\text { (vehs/ln/mile) }\end{array}$ & $\begin{array}{l}\text { Toll } \\
\text { rate } \\
\text { (\$/mile) }\end{array}$ \\
\hline $\mathbf{1 8}$ & 0.063 & $\mathbf{0}$ & 0.024 \\
\hline $\mathbf{1 8}$ & 0.094 & $\mathbf{1 1}$ & 0.049 \\
\hline $\mathbf{2 2}$ & 0.125 & $\mathbf{1 2}$ & 0.049 \\
\hline $\mathbf{2 5}$ & 0.156 & $\mathbf{1 8}$ & 0.146 \\
\hline $\mathbf{2 7}$ & 0.188 & $\mathbf{1 9}$ & 0.146 \\
\hline $\mathbf{2 9}$ & 0.219 & $\mathbf{2 9}$ & 0.243 \\
\hline $\mathbf{3 2}$ & 0.250 & $\mathbf{3 0}$ & 0.243 \\
\hline $\mathbf{3 3}$ & 0.281 & $\mathbf{3 5}$ & 0.340 \\
\hline $\mathbf{3 4}$ & 0.313 & $\mathbf{3 6}$ & 0.340 \\
\hline $\mathbf{3 5}$ & 0.344 & $\mathbf{4 5}$ & 0.583 \\
\hline $\mathbf{3 5}$ & 0.375 & $\mathbf{4 6}$ & 0.583 \\
\hline $\mathbf{3 6}$ & 0.406 & $\mathbf{5 0}$ & 0.777 \\
\hline $\mathbf{3 7}$ & 0.438 & & \\
\hline $\mathbf{3 8}$ & 0.469 & & \\
\hline $\mathbf{3 8}$ & 0.500 & & \\
\hline $\mathbf{4 7}$ & 0.563 & & \\
\hline $\mathbf{4 8}$ & 0.625 & & \\
\hline $\mathbf{4 8}$ & 0.688 & & \\
\hline $\mathbf{4 9}$ & 0.750 & & \\
\hline $\mathbf{5 0}$ & 0.813 & & \\
\hline $\mathbf{5 1}$ & 0.875 & & \\
\hline $\mathbf{5 2}$ & 0.938 & & \\
\hline $\mathbf{5 2}$ & 1.000 & & \\
\hline & & & \\
\hline
\end{tabular}

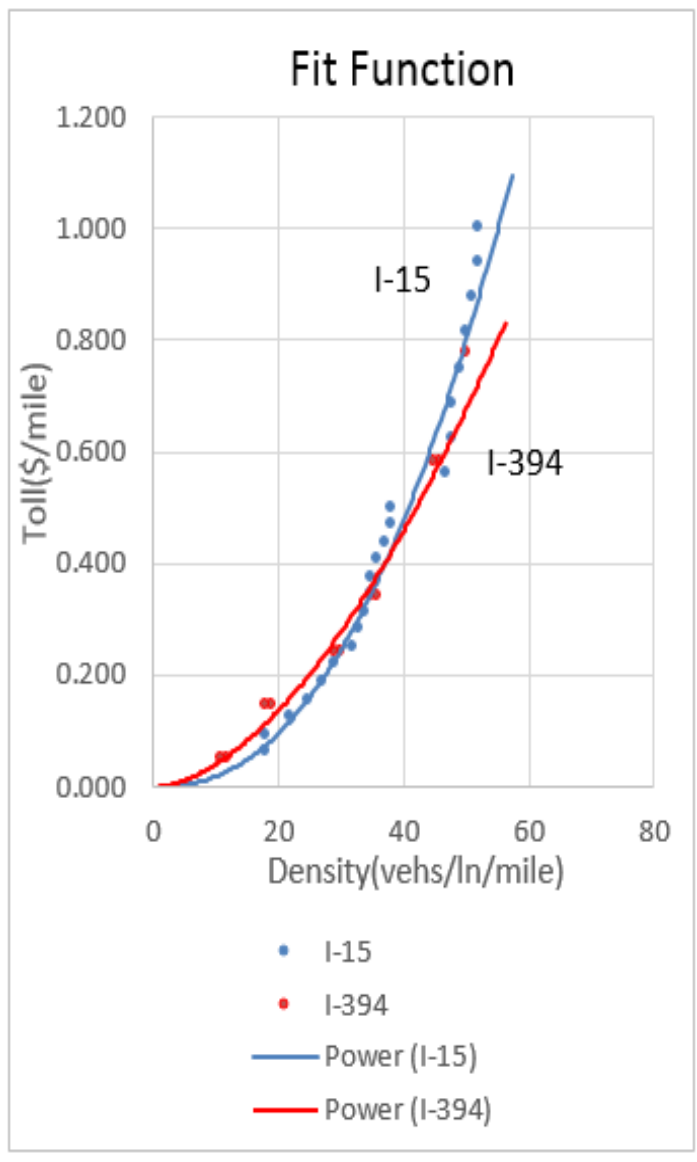

(a)

(b)

Figure 4 Toll Rates and Continuous Toll Functions for I-15 and I-394

Table 6 Willingness to pay for different HOT facilities in the US

\begin{tabular}{|c|c|c|}
\hline Reference & Willingness to Pay & Notes \\
\hline Brownstone et al. (2003) & $\$ 30 / \mathrm{hr}$ & I-15 average \\
\hline Burris et al. (2012) & $\$ 73 / \mathrm{hr} \& \$ 116 / \mathrm{hr}$ & I-394 AM \& PM peak \\
\cline { 2 - 3 } & $\$ 49 / \mathrm{hr} \& \& 54 / \mathrm{hr}$ & I-15 AM \& PM peak \\
\hline Devarasetty et al. (2012) & $\$ 51 / \mathrm{hr}$ & I-10 average \\
\hline Devarasetty et al. (2012) & $\$ 22 / \mathrm{hr}$ & I-10 average \\
\hline Sheikh et al. (2014) & $\$ 36 / \mathrm{hr} \& 26 / \mathrm{hr}$ & I-85 AM\&PM peak \\
\hline Wood et al. (2014) & $\$ 19.45 / \mathrm{hr} \& \$ 33.17 / \mathrm{hr}$ & I-85 off-peak periods \& AM peak \\
\hline Burris et al. (2016) & $\$ 1.96 / \mathrm{hr}$ to $\$ 8.06 / \mathrm{hr}$ & I-10 range \\
\hline
\end{tabular}

\subsubsection{Combination Toll for a Single Zone}

The final toll for each zone in this proposed toll framework is a combination of both dynamic and TOD toll components, with each component weighed accordingly based on the relative difference between dynamic and historical traffic densities. If the near real-time dynamic densities are the same (or similar) to the historical densities at a specific time of day, 
the weight of the TOD toll component will be equal or near 1). However, if the dynamic traffic densities vary significantly from the historical densities at a specific time of the day, the combination toll will mostly depend on the dynamic toll component by assigning a higher weight for the dynamic component. In other words, if the dynamic densities are reflective of a typical travel day, the toll rate will be primarily determined by the TOD toll component. Else, if the dynamic densities are atypical (significantly higher or lower) than a typical travel day, the toll rate will be primarily determined by the dynamic toll component. Once the dynamic and TOD weights are determined based on densities, the two components can then be aggregated into a single zone toll by Equation 3 below:

$$
\operatorname{Toll}_{Z}=W_{T O D} \times \operatorname{Toll}_{T O D}+W_{\text {Dynamic }} \times \text { Toll }_{\text {Dynamic }}
$$

Where,

- $\operatorname{Toll}_{Z}$ : Toll in $\$$ for zone z

- $W_{T O D} \& W_{\text {Dynamic }}$ : Respective weights for TOD \& dynamic toll components, which sum to 1 .

- Toll $_{T O D} \&$ Toll $_{\text {Dynamic }}$ : Respective tolls for TOD and dynamic toll components

\subsubsection{Weight Assignment}

In this study, a generic equation (Equations 4) is proposed for assigning weights to dynamic and TOD toll components. The basic principle behind both weight assignment methods is that as the dynamic density varies more from the historical density at a specific time of the day, more weight will be attributed to the dynamic toll component. In both approaches shown below, the assumption is that if the dynamic density change from historical density anticipated is greater than $100 \%$, then the weight of the dynamic toll component will be 1 . In other words, in such extreme conditions, the combination toll rate will depend only on the dynamic toll component. In the equation, $\mathrm{n}$ can be changed based on reality.

$$
W_{T O D}=\left(1-\frac{\left|D_{t, \text { dynamic }}-D_{t, \text { historic }}\right|}{D_{t, \text { historic }}}\right)^{n}
$$

When $\mathrm{n}$ equals 1 , the weight function takes on a linear form. As weight for TOD toll component proportionally decreases as the percentage of change of density (between dynamic density readings and historical density readings) increases. When $\mathrm{n}$ equals 2 , the weight function is a square function. As densities increase, lane performance is expected to deteriorate 
in a non-linear fashion (similar to LOS curves). The use of this function implies that as the change in dynamic and historical densities increases, the weight should reflect more heavily upon the dynamic density readings.

Figure 5(a) offers an illustration of how the TOD and dynamic component weights as dynamic traffic densities changes, assuming that historical density at this specific time period is 25 vehicles per lane per mile (equivalent to LOS C). When traffic density is the same as historic density, the price is the same as TOD price (the weight of TOD component is 1 , and the dynamic component is 0 ). When the change from dynamic density to historical density is greater than $100 \%$, then the weight of the dynamic toll component will be 1 .

Figure 5(b) illustrates how the toll rate (per mile) changes under the combination tolling framework for dynamic densities in all ranges of LOS, assuming historical density is 25 vehicles per lane per mile (equivalent to LOS C). It is evident that when dynamic densities are close to historical densities (also at LOS C), the combined tolling rate is more stable in the face of small changes in dynamic densities, and thus offering drivers more user certainty.
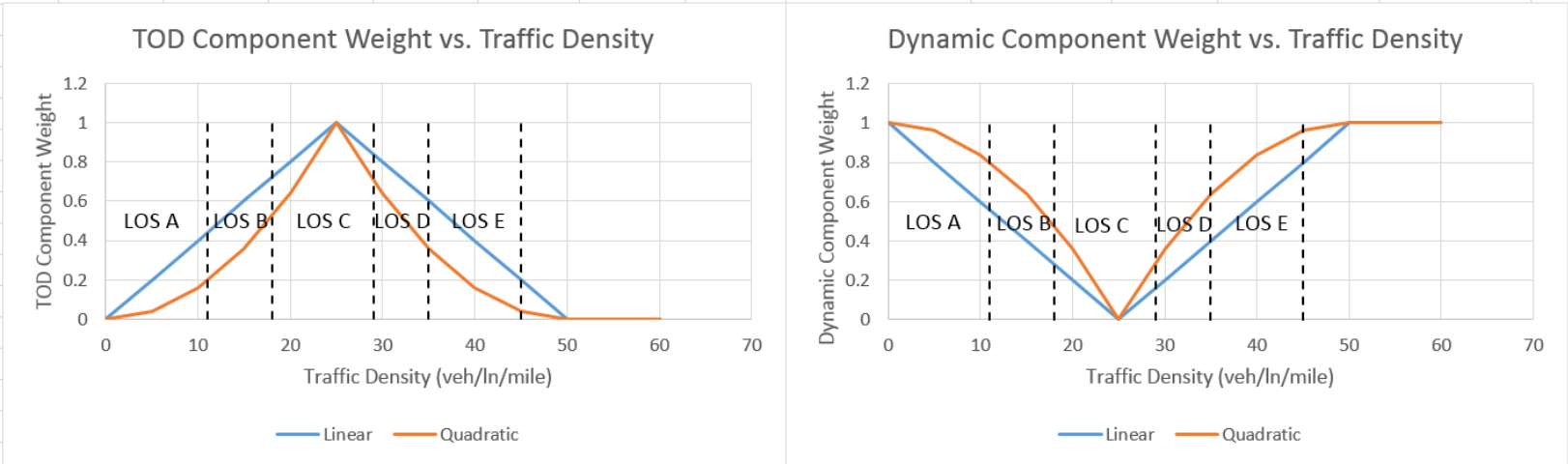

(a)
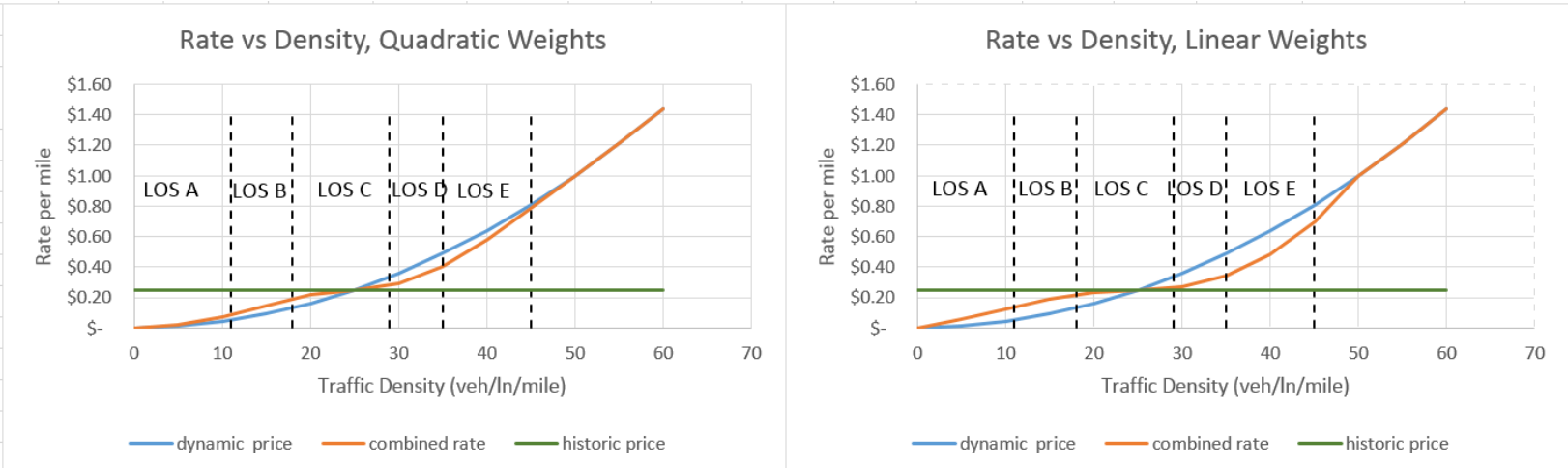

(b)

Figure 5 Weight and Rate vs. Traffic Density 


\subsubsection{Aggregate Trip (Multi-zone) Toll}

Once the tolls for each of the zones are determined, the pricing for a trip that traverses more than one zone can be aggregated by one of two approaches proposed here. One is a simple unweighted multi-zone pricing scheme, which simply adds up the pricing for each of the zones for a total toll. The other is a weighted multi-zone pricing scheme, which attempts to "reserve capacity" for a downstream bottleneck by pricing the upstream zones of the bottleneck more heavily. These two approaches are explained below.

\subsubsection{Unweighted Multi-zone Pricing}

The unweighted multi-zone pricing scheme follows the simple approach that the most congested detectors within each zone are used to determine the toll rate for each zone. Then, the total toll for a single trip is simply the sum of the individual zone toll rates.

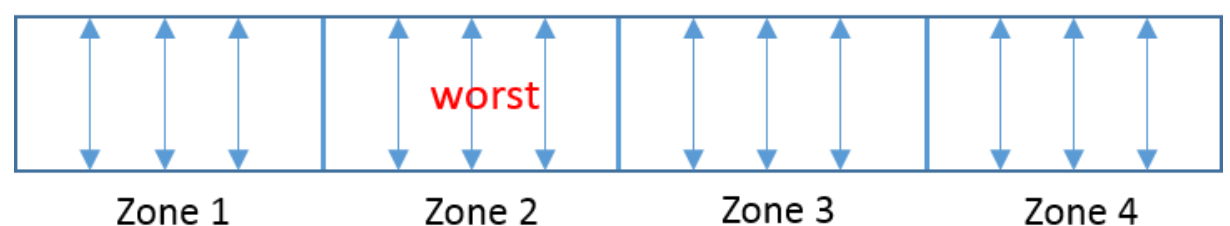

Figure 6 Example Trip Pricing Scenario

For example (Figure 6), if an eastbound AM peak trip traverses all 4 zones and the most congested zone is Zone 2, then the total toll price for the trip at time $t$ is simply:

$$
\begin{aligned}
\text { Toll }_{t, \text { trip }}=\text { TollRate }_{t, 1}\left(\text { Distance }_{1}\right)+\text { TollRate }_{t, 2}\left(\text { Distance }_{2}\right) \\
+ \text { TollRate }_{t, 3}\left(\text { Distance }_{3}\right)+\text { TollRate }_{t, 4}\left(\text { Distance }_{4}\right)
\end{aligned}
$$

\subsubsection{Weighted Multi-zone Pricing}

Another approach to aggregate pricing for a trip across multiple zones attempts to reserve capacity for a downstream bottleneck by penalizing the toll in upstream zones. In other words, upstream zones of the most congested zone are tolled at the same rate as the most congested zone. In the example shown in Figure 6, the total toll rate for the trip at time t would be:

$$
\begin{array}{r}
\text { Toll }_{t, \text { trip }}=\text { TollRate }_{t, 2}\left(\text { Distance }_{1}\right)+\text { TollRate }_{t, 2}\left(\text { Distance }_{2}\right) \\
+ \text { TollRate }_{t, 3}\left(\text { Distance }_{3}\right)+\text { TollRate }_{t, 4}\left(\text { Distance }_{4}\right)
\end{array}
$$




\subsubsection{I-66 Sample Toll Rates}

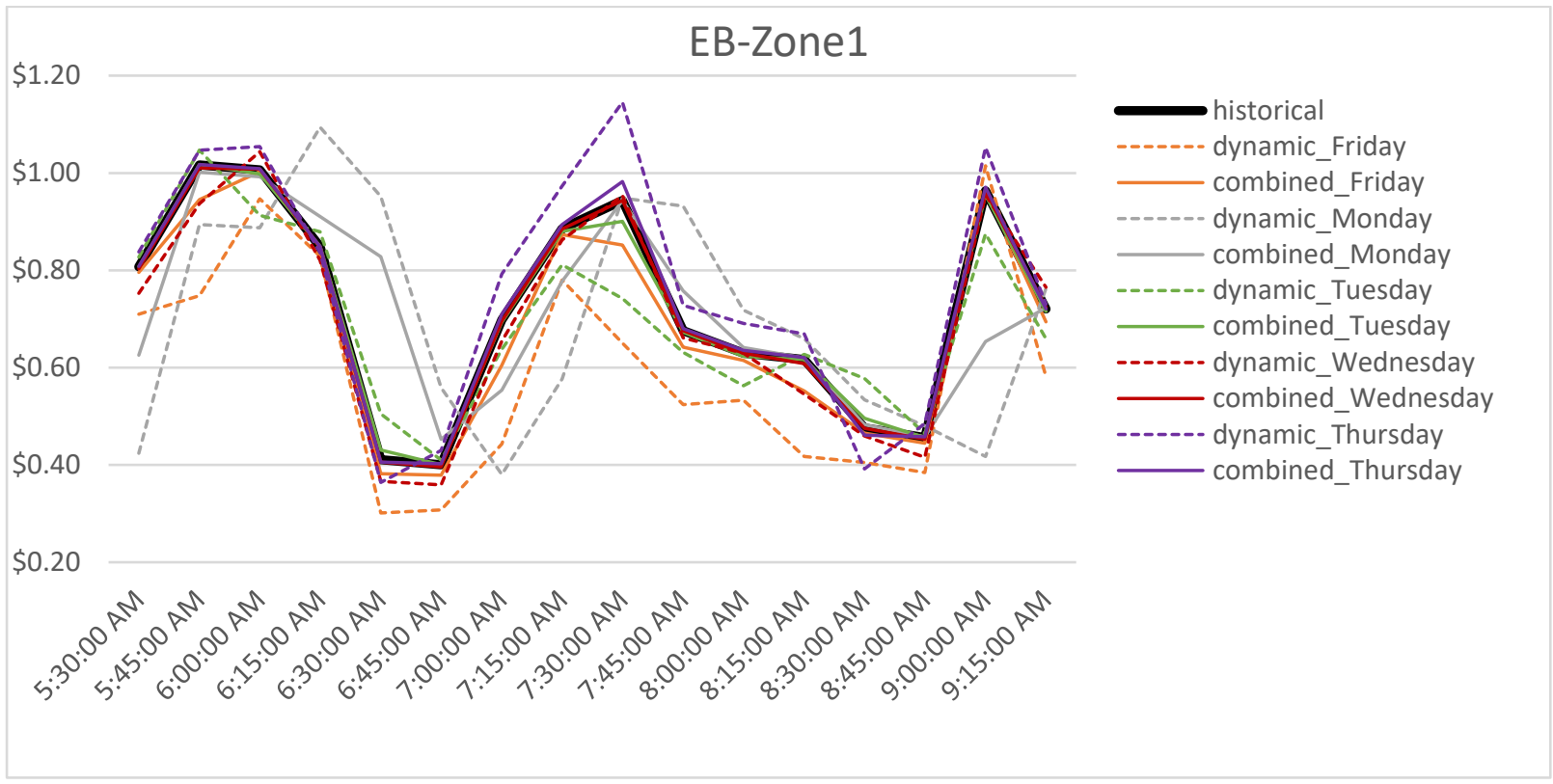

Figure 7 I-66 Sample Toll Rates

Figure 7 shows a sample toll rates of zone 1 in Eastbound based on November 2014 traffic volumes. The traffic volume data come from VDOT. Using speed limit of $45 \mathrm{mph}$ to calculate traffic density. Assume $\theta=0.02, \beta=2$. Then use quadratic weight assignment function to assign different weights to TOD toll and dynamic toll and finally calculate the combined toll.

The figure shows that dynamic tolls are more reactive and combined tolls are more stable compared with static pricing. At the beginning of toll operations each day (at 5:30 am), combined tolls help keep tolls stable and predictable.

\section{3. Conclusion and limitations}

There exists a gap in designing an appropriate variable tolling algorithm for a priced facility without a true substitute route, as existing dynamic priced facilities in the US are all HOT lanes with non-priced parallel GP lanes. In this paper, a proposed combination tolling framework is proposed for I-66 Inside the Beltway, an HOV facility going under conversion to a HOT facility with no GP lanes. This combination tolling framework considers both dynamic and TOD tolling components, to best accommodate predictability for the users and provides flexibility for real-time demand management. The two components are weighed by the relative difference between dynamic volume and historical volumes on the facility. Lastly, 
two forms of aggregation across multiple toll zones are also proposed here, to accommodate different ways to manage bottleneck situations.

However, the proposed combination tolling framework has limitations. It assumes tolling equipment is always well calibrated and can be sufficiently sensitive to accommodate all the changes in the TOD and dynamic component weights and change calculate dynamic price without any delay. The performance of combined framework is heavily dependent on the weight assignment on TOD and dynamic components. Different weights assignments can lead to very different pricing results. The two methods of weights assignments proposed here both relate to the magnitude of change from dynamic density to historical density and therefore is not consistent with absolute changes in LOS. In other words, if traffic conditions are not close to critical traffic boundaries (either similar to historical densities or extremely different from historic densities), a weighted average of TOD and dynamic pricing could lead to a very different toll rate than with dynamic pricing component alone, even if the quantifiable difference in LOS is not significant. 


\section{Tolling Framework on CAV environment}

Chapter 3 proposed a dynamic tolling framework with adding a predictive component to existing dynamic tolling schemes on the non-CAV environment. This method can increase the predictability, however, is still reactive to the real-time traffic flow. With the introduction of CAV technology, it is possible for the operator to gather traffic flow information ahead of time. Chapter 4 proposed a reservation-based tolling algorithm on CAV environment in a combination of simulation.

\section{1. Introduction and Previous Research}

A highway reservation system can be conceptualized as a system slicing the highway resource into different slots by space and time, shown in Figure 8. Vehicles can book in advance which time and space they want to use. Operators will keep track of all the reservations and adjust toll according to the potential traffic on both HOT and GP lane. Compared with traditional dynamic pricing algorithm, the proposed reservation tolling system is more predictive of the traffic demand on the route since this mechanism help operator gets potential lane use information ahead of time. The price setting can handle potential traffic congestion in advance.

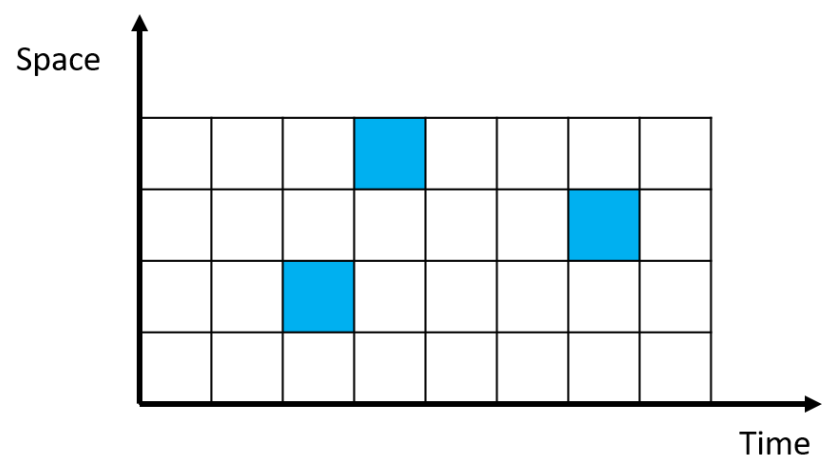

Figure 8 Highway resource slicing through space and time

Like in other reservation based systems (such as airline and hotel booking systems), users who want to use the resource can book in advance. In this case, both the user and the company can benefit from the reservation system. The user who booked earlier can hold the seat or room in advance; most of the time they can get a better price when they book earlier. The system operator can get the booking information and better manage their resources and inventory. It's a win-win system. 
The booking system is also widely used by other long-distance transportation sectors, such as railway and shipping industry. However, the basic concept of roadway reservation system was first created by Wong in 1990s (Wong, 1997) but still unimplemented in the real world due to technology limitations. Several papers have already studied some different aspects of Highway Reservation System, such as the policy, conceptual framework. Besides traditional reservation system, some new system such as token-based and auction-based reservation system has also been proposed.

\subsubsection{Policy of Highway Reservation System}

From the policy perspective, several studies have analyzed the benefit and public acceptance of highway reservation system and explored the possibility of adopting it. Koolstra (1999) analyzed the potential benefits of a freeway slot-reservation system. A single bottleneck was evaluated. The results show that the system can eliminate all queuing costs without increasing the cost of adjusting new departure time. The freeway reservation system has been proved effective and monetary beneficial. De Feijter (2004) also showed the benefit of using trip booking; it can improve travel time reliability and make the trip more predictable. $\mathrm{Su}$ (2013) used VISSIM simulation to test the feasibility of a roadway reservation system and also investigated the potential benefits. The study made a comparison of a baseline scenario and reservation scenario. In the baseline scenario, the departure time was randomly distributed within an hour, however, in the reservation scenario, all users had the same departure time, and they made reservations for the departure time. The results show that the reservation scenario is outperformed the baseline scenario in total delay time and emissions.

Since the highway reservation system has so many potential benefits, some studies have studied public acceptance of such systems. For example, Chun et al. (2012) surveyed drivers in South Korea, and most of the respondents (66\%) agreed with the proposed "freeway booking" strategy. With increase in age, household income and the number of family members, public acceptance of "freeway booking" strategy was found to be higher. Traditional Frameworks of Highway Reservation System

In other previous studies, conceptual frameworks of the highway reservation system have been developed. Some papers specified the key components in the reservation system. Wong (1997) explored four key components of the system including the booking process, inventory control, vehicle detection and operation control. Ravi et al. (2007) presented a lane reservation for highways to allow users make a reservation of a slot on a high-priority lane by 
paying a premium price. The price is differentiated by frequent users and urgent (but less regular) users. The proposed framework is focused on the physical aspects of the system, including three main components: reservation system, lane entrance assistance, and enforcement system. Edara and Teodorovic (2008) conceptualized a Highway Space Inventory Control System (HSICS), which consists of two modules---Highway Allocation System (HAS) and the Highway Reservation System (HRS). The HAS attempts to maximize the total passenger miles over a defined time period for a certain length of the highway. The HRS decides whether to accept or reject a trip reservation request. This paper provides a detailed framework of the proposed highway reservation system. However, the study uses passengermiles-traveled as an objective which is questionable based on operators' goal, and the framework does not consider adjustments in departure time.

\subsubsection{Token- and Auction-based Reservation Systems}

Liu (2011, 2013) developed a token-based reservation system (TBRS), which focuses on the issue of admission control and request scheduling. There are a set of tokens on each road, vehicle who want to travel that road need a token. The total number of tokens on a segment was calculated by Greenshield's model. The policy ensures that a token is always held by at most one vehicle at a time. However, it is hard to know the exact number of vehicles who booked the system until all the requested has been issued. Then may cause the road to become oversaturated. Additionally, this system may raise equity issues because tokens are not granted on the first come first serve principle.

Other scholars also proposed auction-based congestion pricing frameworks. Teodorovic (2008) proposed an auction-based congestion pricing scheme for people to bid on entry to a downtown area. The time within a week will be divided into small time intervals for people to bid. The researchers produced a mixed-integer program and solved it by using heuristics.

Su and Park (2015) proposed an auction-based implementation, in which the users can bid for the right to use a route during a certain period. In the system, user agents notify the Reservation Management Center (RMC) their preferred route and on-ramp interval with a bid, then all the conflicting requests are sorted by the bid from high to low. RMC maintains a spatial-temporal table to manage the reserved highway resource when a new request is accepted, the corresponding cells in the table are updated. 
Cetin et al. (2015) proposed a tolling scheme in connected vehicle environment where users can participate in a Vickrey auction for access to the toll road. The bid price is based on users' VOT. In this mechanism, the operator will accept about one-fifth of the drivers who request the toll road.

Basar and Cetin (2017) proposed a descending price auction mechanism implemented on a hypothetical two-route network (one toll route and one toll-free route) assuming an autonomous vehicle environment. This paper is focused on the public's acceptance of new price mechanisms and conducted a stated-preference survey to examine the public perception of futuristic auction-based tolling system. The results show that for those people who are familiar with the current tolling methods, there is no outright rejection of the proposed auctionbased tolling mechanism. Based on the survey results, the proposed new tolling mechanism yields higher average toll rates and more revenue and also improves capacity utilization compared to fixed time-of-day tolls.

\subsubsection{Literature Review Summary}

In this section, we have overviewed various previous studies that have designed, evaluated, and simulated highway reservation systems. The majority of these previous papers propose theoretical framework and do not relate the tolls to traffic flow conditions. Furthermore, many of these papers assume a static tolling scheme, which is not flexible enough to handle varying traffic conditions.

Unlike commercial airplanes and rail cars, personal vehicles are flexible and convenient for the user, without scheduled departure time limitations. In this sense, advanced booking of routes with precision to the minute seems unrealistic.

The proposed auction-based system provides more schedule flexibility by allowing users to bid, which then generates a personalized toll. However, this requires all vehicles who use the highway to be connected to the system, and would be infeasible in mixed fleet environments with non-connected vehicles

This chapter of the thesis proposes a reservation based tolling scheme which innovatively combines highway reservation system with existing best practices of dynamic tolling using theories of second-best pricing. Such a highway reservation system can collect incoming traffic demand information in advance. Simultaneously, a dynamic pricing schemes can manage traffic density on the managed lane. The system rewards connected vehicles to 
book the managed lane early by adding a toll discount component. The proposed system is more realistic since it does notexclude the opportunity for managed lane use for non-connected vehicles. They can choose to use HOT lane at the lane entrance point (or gantry) exactly like in current dynamic priced HOT lane systems.

\section{2. Methodology}

\subsubsection{HOT Lane Reservation System}

The HOT lane reservation system assumes that there is one managed HOT lane and one GP lane. In this study, we focus on one tolled segment (which can be interpreted as the distance from one entrance to one exit). Vehicles who want to use HOT lane can book the space and time slot in advance. In other words, if the vehicle chooses to use GP lane, there is no need to make a reservation in advance. Ideally, all vehicles can choose different time and space slots, however, since traffic flow is generally sequential, vehicles who use the previous space and time slot would continue to use the space and time in the next time interval. When the managed lane is a single lane (with no possibility of passing vehicles), then the reservation process becomes simplified. The vehicles only need to indicate at what time they will enter the managed lane. Figure 9 demonstrates the space and time slicing under this setup. There are different time slots for the vehicle to choose: For example, the first time interval is the blue one, then the green one, and lastly, is the yellow one. Then, if one vehicle reserves the blue spot in the first time interval, it will keep driving, then at next time interval, it will move to next blue space interval, so on and so forth. The vehicle will always occupy all the blue slots along the tolled link. Once the vehicle passes the last blue spot (physically representing an exit and the beginning of the next tolled link), the entrance space is cleared for next platoon of vehicles.

As vehicles approach the entrance to the managed lane, the operator provides them several opportunities to choose whether to use HOT lane. The decision points can represent either time or distance. As shown in Figure 10, at time $t_{0}$, the all the vehicles are asked whether to use the HOT lane or not. After the first decision point, the operator will update the toll and discount information and provide the second decision point at time $t_{1}$. This time, the vehicles who have booked the HOT lane at time $t_{0}$ are excluded from the deciding pool. Vehicles who have made the reservation in previous time intervals cannot cancel reservations in future time intervals. Only those who have not yet reserved the HOT lane will be provided the subsequent chance to "buy in" to the HOT lane. In other words, the operator assumes that vehicles who 
have not yet booked the HOT lane always have the potential to book HOT lane (until the entry point).

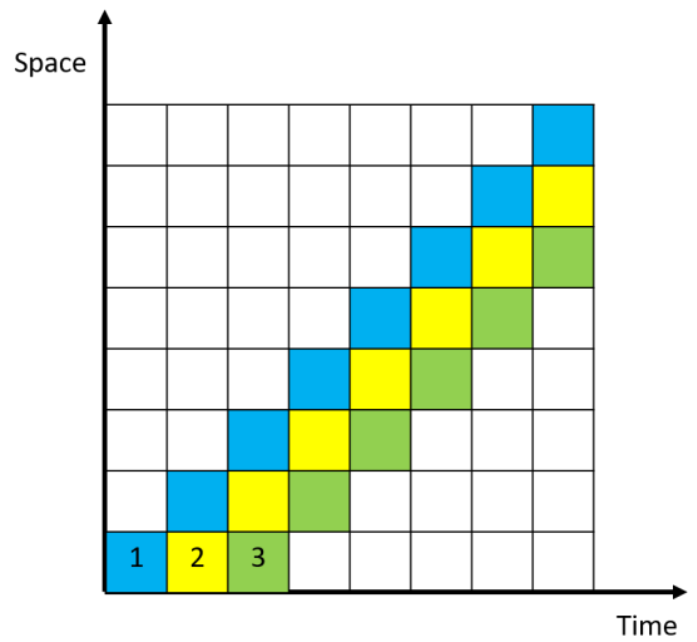

Figure 9 HOT lane resource sliced by space and time

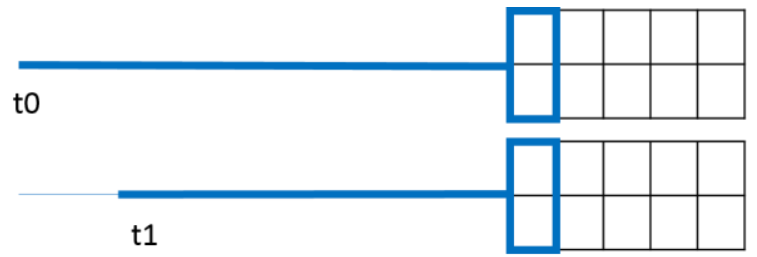

Figure 10 Different time to choose the same slot

\subsubsection{Framework of Highway Reservation System}

There are two main participants in this highway reservation system. One is the operator; the other is the individual approaching vehicles. There are seven steps (within each time interval) for vehicles to make reservations on the HOT lane. The reservation procedure is illustrated in Figure 11. 


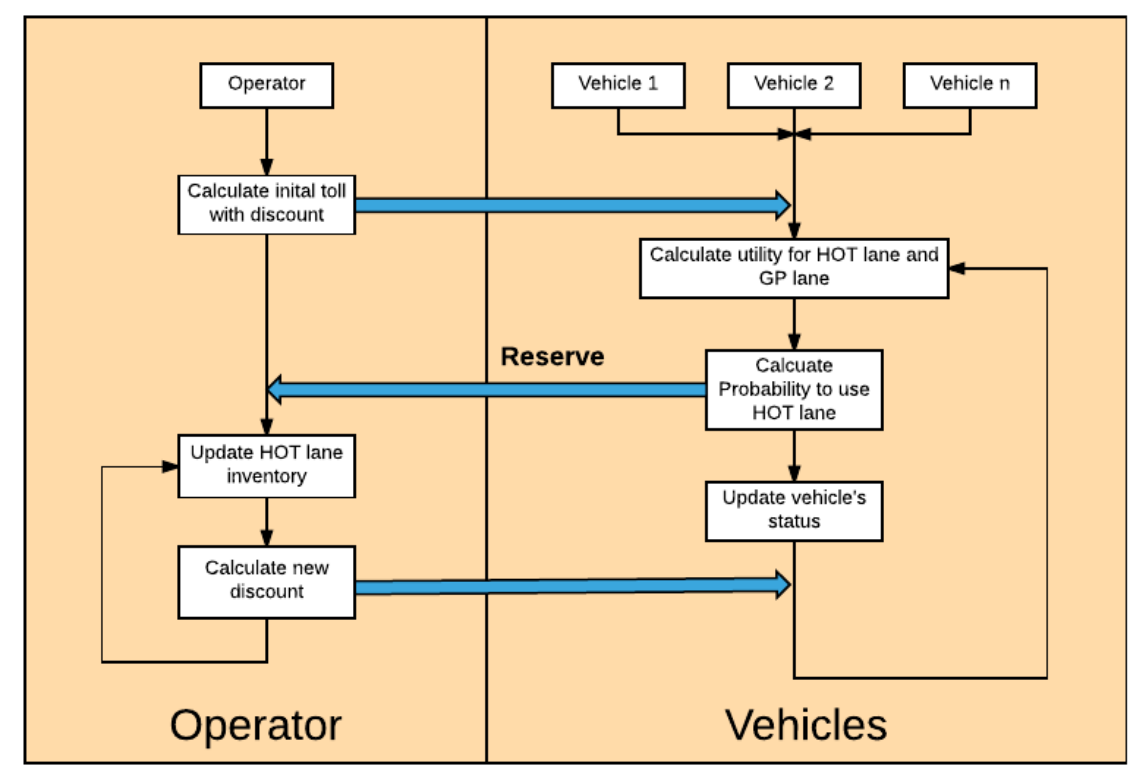

Figure 11 Highway reservation procedure

\section{Step 1. The operator calculates the initial toll with discount}

At the initialization of the system, since no vehicles have reserved the HOT lane, the initial toll is set to 0 . Once vehicles start to make reservations for the HOT lane, the operator calculates a new toll based on the number of reservations they receive. For illustration, the discount is set as a percentage of the total toll (and decreases as vehicles approach the managed lane entrance). After having the initial toll and discount, the operator uses V2I communication technology to convey the toll and discount information to all approaching vehicles.

\section{Step 2. The vehicles calculate their utility function on HOT lane and GP lane}

After receiving the initial toll and discount, each approaching vehicle can calculate their own utility for both HOT lane and GP lane. In the HOT lane, the vehicle will consider the travel time, travel reliability, travel cost, plus some other consideration, such as safety, comfort and so on. In the, GP lane, the vehicle will also consider travel time and some other elements. The utility function for HOT and GP lane shows as below, where values of travel time and schedule delay, toll and toll discount are explicitly modeled. The error term $\varepsilon$ captures the other considerations not explicitly modeled (differential in safety, comfort, etc. between HOT and GP lanes).

$$
\begin{aligned}
\text { Utility }(H O T)= & \text { VOT } \times \text { Traveltime }+ \text { VOR } \times \text { ScheduleDelay }- \text { Toll } \\
& + \text { TollDiscount }+ \text { Other }+\varepsilon
\end{aligned}
$$




$$
\operatorname{Utility}(G P)=\text { VOT } \times \text { Traveltime }+ \text { VOR } \times \text { ScheduleDelay }+ \text { Other }+\varepsilon
$$

Where:

- VOT: Value of travel time

- VOR: Value of reliability

Each user in the vehicle has a different value of travel time. Their tolerance to travel time reliability is also different. So individual vehicles will have different utilities for HOT lane and GP lane.

Cooncas and Kolpakov (2009) shown that VOT can be measured as 50\% of wage rate. In this paper, we base the wage rates on the northern Virginia Area (inspired by the I-66 project), which are shown in Table 7.

Table 7 Income and VOT on Northern Virginia Area

\begin{tabular}{|c|c|c|c|c|c|c|c|c|}
\hline \multirow[b]{2}{*}{ Total households } & \multirow{2}{*}{$\begin{array}{l}\text { average } \\
\text { income }\end{array}$} & \multicolumn{5}{|c|}{ Number of Households } & \multirow{2}{*}{$\begin{array}{c}\text { Hourly } \\
\text { wage }(\$ / \mathrm{hr})\end{array}$} & \multirow[b]{2}{*}{$\operatorname{VOT}(\$ / h r)$} \\
\hline & & $\begin{array}{c}\text { Loudoun } \\
\text { County }\end{array}$ & $\begin{array}{l}\text { Fairfax } \\
\text { County } \\
\end{array}$ & $\begin{array}{c}\text { Arlington } \\
\text { County }\end{array}$ & $\begin{array}{c}\text { Prince William } \\
\text { County }\end{array}$ & Total & & \\
\hline Less than $\$ 10,000$ & $\$ 5000$ & 1,798 & 10,202 & 3,656 & 2,895 & 18,551 & 2.40 & 1.20 \\
\hline$\$ 10,000$ to $\$ 14,999$ & $\$ 12500$ & 1,056 & 5,477 & 1,832 & 1,853 & 10,218 & 6.01 & 3.00 \\
\hline$\$ 15,000$ to $\$ 24,999$ & $\$ 20000$ & 3,153 & 12,676 & 4,511 & 5,363 & 25,703 & 9.62 & 4.81 \\
\hline$\$ 25,000$ to $\$ 34,999$ & $\$ 30000$ & 3,265 & 16,598 & 4,115 & 6,496 & 30,474 & 14.42 & 7.21 \\
\hline$\$ 35,000$ to $\$ 49,999$ & $\$ 42500$ & 7,682 & 24,744 & 6,180 & 12,118 & 50,724 & 20.43 & 10.22 \\
\hline$\$ 50,000$ to $\$ 74,999$ & $\$ 62500$ & 12,443 & 50,517 & 12,465 & 21,274 & 96,699 & 30.05 & 15.02 \\
\hline$\$ 75,000$ to $\$ 99,999$ & $\$ 87500$ & 13,069 & 49,692 & 12,948 & 19,419 & 95,128 & 42.07 & 21.03 \\
\hline $\begin{array}{c}\$ 100,000 \text { to } \\
\$ 149,999\end{array}$ & $\$ 125000$ & 27,430 & 85,346 & 20,300 & 30,824 & 163,900 & 60.10 & 30.05 \\
\hline $\begin{array}{c}\$ 150,000 \text { to } \\
\$ 199,999\end{array}$ & $\$ 175000$ & 18,903 & 54,927 & 12,968 & 18,602 & 105,400 & 84.13 & 42.07 \\
\hline$\$ 200,000$ or more & $\$ 300000$ & 24,633 & 82,176 & 19,466 & 17,950 & 144,225 & 144.23 & 72.12 \\
\hline
\end{tabular}

This VOT data has a mean of $\$ 32.663 /$ hour and a standard deviation of $\$ 22.36 /$ hour. Normally income data can be modeled as lognormal distribution since high-income household has a long tail in the distribution graph (Van Praag, 1968). Here, we transform this wage distribution to a lognormal distribution with $\mu=3.3521$ and standard deviation $\sigma=0.5179$. 


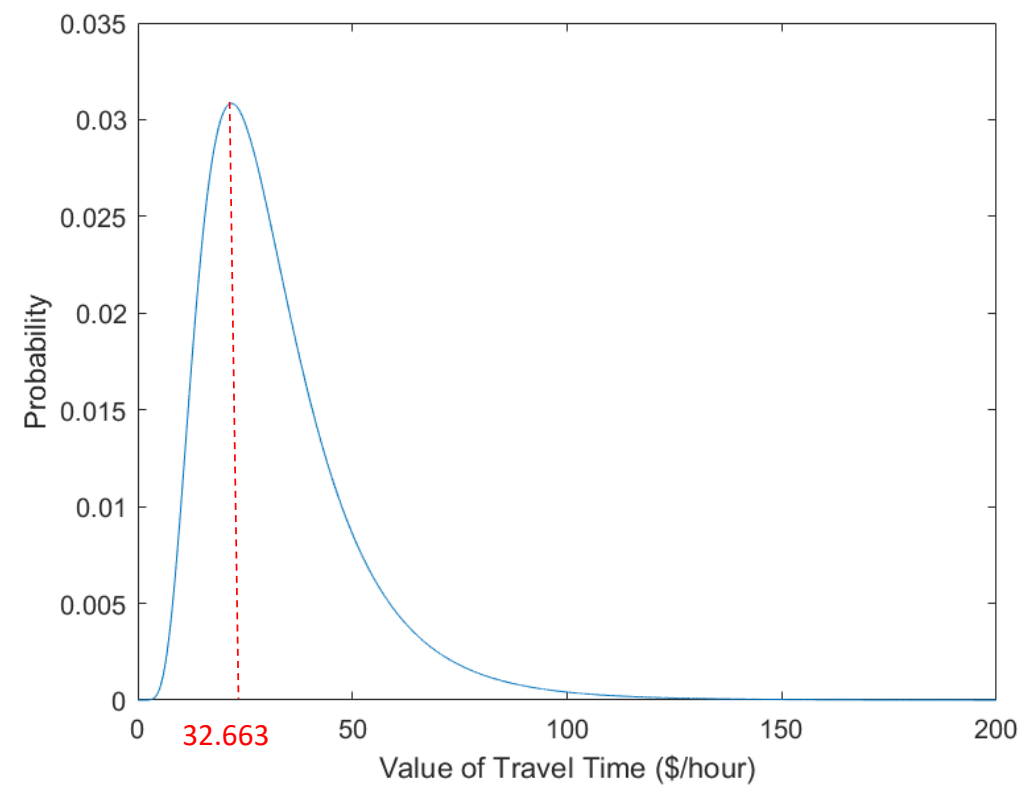

Figure 12 Value of Travel Time Distribution

Step 3. The vehicles use logit model to calculate probability of using HOT and GP lane

After getting each vehicles' utility for both HOT and GP lane, we use a logit model to model vehicles' lane choice.

The probability of selecting HOT lane:

$$
P_{H O T}=\frac{e^{U_{H O T}}}{e^{U_{H O T}}+e^{U_{G P}}}
$$

The probability of selecting GP lane:

$$
P_{G P}=1-P_{H O T}
$$

\section{Step 4. The operator update HOT lane inventory}

All approaching vehicles use a logit model to calculate the probability and decide whether to use HOT lane or not. Then all vehicles provide the choice information to the operator. The operator will update the HOT lane inventory information.

\section{Step 5. The vehicle update their status}

Simultaneously, all vehicles will update their own status. For those vehicles who choose to use the HOT lane, their toll is held at the price (with discount) agreed upon with the operator. While it is possible that the total toll for using HOT lane (toll plus discount) in the 
next time interval will be lower than the previous decision chance. However, cancellations of reservations in the subsequent time intervals are not permitted in this scheme.

\section{Step 6. The operator calculates new toll and discount}

Based on the booking information and the HOT lane inventory, the operator will calculate new toll and discount. Then the operator will deliver the new toll with discount information to those vehicles who haven't booked the HOT lane in the next time interval.

\section{Step 7. The vehicle recalculate the utility for HOT and GP lane}

The system proceeds to next round of decisions. The vehicles receive the new toll and discount and recalculate the individual utility for HOT and GP lane and make route choice between HOT and GP lanes.

\subsubsection{Goal of the Reservation System}

\section{Encourage vehicles to make decisions as early as possible}

The main goal of this reservation-based tolling system is to provide better predictability of incoming vehicles' lane choice. In other words, the proposed reservation system is encourages vehicles to make the lane choice decision as early as possible so that the operator can collect the reservation information and calculate more informed dynamic tolls.

\section{Keep the traffic density on HOT lane at desired density}

In the meantime, the system should be able to guarantee reasonable and reliable speeds in the HOT lane. The travel time on HOT lane should be ensured, that is the density of HOT lane should always around the desired density (which is often set as LOS C).

\section{The system should be adaptable to approaching traffic volume}

The proposed system should be adaptive based on approaching traffic conditions. The tolling scheme should be flexible enough to attract vehicles when HOT lane usage is low, and keep vehicles away when the HOT lane is nearing oversaturation.

\section{The system is functional with a mixed fleet}

While the majority of highway reservation tolling systems are designed to work with all connected vehicles, the reality is that mixed fleets will exist long before $100 \%$ market penetration of CAVs. This proposed framework allows non-CAVs to choose the HOT lane 
immediately prior to the entrance, much like how managed lanes work in today's nonconnected setting.

In the proposed reservation framework, the primary goal for the operator is to manage traffic flow on HOT lane. The operator tries to attract vehicles to make their decision as early as possible. In the meantime, the operator adjusts the toll to keep the density on HOT lane at a goal density.

\subsection{1. $\quad$ Second-Best Pricing-Based Dynamic Pricing Policy}

In this study, a second-best pricing-based dynamic tolling system is proposed. In a perfectly competitive market with all tolled routes, first-best pricing can be achieved if users know perfect information on travel time, tolls and all links are tolled. However, this situation is not realistic as users may not know all possible routes and toll information while making their route choice. In this case, a second-best pricing attempts to maximize the user's welfare based on marginal cost pricing principles while reflecting technological, political, and financial constraints (Kockelman et al., 2016). There are many different forms of second-best pricing. Here, our tolling framework is based on a second-best pricing scheme generated by Verhoef (2000), representing the pricing for the case that not all links in the network are tolled. Verhoef's study (2000) shows that there are two comparable parallel routes, one tolled (T), one untolled (U). In a perfect market, both routes are tolled and the number of trips on each route will be roughly the same $\left(Q_{U}=Q_{T}=Q_{\text {equilibrium }}\right)$. However, since one is untolled, users tend to use untolled route, which result in the final number of trips on untolled route is larger than tolled road $\left(Q_{U}>Q_{\text {equilibrium }}>Q_{T}\right)$. The second-best toll for HOT/GP lane system shows as below. This second best pricing's total consumer welfare is shown to be lower than the first-best pricing case (where both routes are tolled) but higher than if only the tolled route was considered in the pricing scheme. Here, $Q_{\text {goal }}$ represents the equilibrium, in this case, we set the goal volume as the mid-point of LOS C (24 veh/lane/mile) times the speed (60mph).

$$
T o l l=T M S C_{H O T}-A C_{H O T}-\left(T M S C_{G P}-A C_{G P}\right) \frac{Q_{G P}-Q_{\text {goal_GP }}}{Q_{H O T}-Q_{\text {goal_HOT }}}
$$

Where,

- $T M S C_{\text {HOT }} / T M S C_{G P}$ : total marginal social cost of HOT and GP lane

- $A C_{\text {НОT }} / A C_{G P}$ : average cost of HOT and GP lane

- $Q_{\text {Hот }} / Q_{G P}$ : volume on HOT and GP lane 
- $Q_{\text {goal_HOT }} / Q_{\text {goal_GP }}$ : equilibrium volume on HOT and GP lane

- $\left(T M S C_{H O T}-A C_{H O T}\right)$ : the marginal social cost of the HOT lane

- $\left(T M S C_{G P}-A C_{G P}\right)$ : the marginal social cost of the GP lane

- $\frac{Q_{G P}-Q_{\text {goal_GP }}}{Q_{\text {HoT }}-Q_{\text {goal_HOT }}}:$ the number of trips added to GP lane per trip removed from HOT lane

Thus, in our system where the operator has a service goal for the HOT lane, the equation can be translated as:

$$
\begin{gathered}
\text { Toll }=\text { Toll }_{H O T}-\operatorname{Toll}_{G P} \frac{Q_{G P}-Q_{\text {goal_GP }}}{Q_{H O T}-Q_{\text {goal_HOT }}} \\
\operatorname{Toll}_{H O T}=(Q-1)_{H O T}\left(\operatorname{VOTT}_{\text {aveHOT }(Q-1)}\right)\left(T T_{Q}-T T_{Q-1}\right)_{H O T} \\
\operatorname{Toll}_{G P}=(Q-1)_{G P}\left(\operatorname{VOTT}_{\text {aveGP }(Q-1)}\right)\left(T T_{Q}-T T_{Q-1}\right)_{G P}
\end{gathered}
$$

Where

- $T T_{Q-1}$ : the average travel time of all the vehicles before the arrival of the $Q$ th vehicle.

- $T T_{Q}$ : the travel time of all vehicles once the marginal Qth vehicle has arrived

- $(Q-1)_{\text {нот }}$ the total volume of all the vehicles on the HOT lane before the $Q$ th vehicle

- $(Q-1)_{G P}$ : the total volume of all the vehicles on the GP lane before the Qth vehicle

The proposed dynamic pricing algorithm considers the added total system delay with the addition of the marginal vehicle. When the marginal additional vehicle makes a reservation for the HOT lane, the vehicle causes some travel time delay for all vehicles who have already reserved the HOT lane. The monetary cost is the added travel time to all vehicles which made the reservation earlier, translated to a dollar amount via their average value of travel time.

\subsubsection{Discount}

The discount is an adjustment component to the total toll. It adjusts the total toll by time/distance to the entrance.

$$
\text { Toll Discount }=f(\text { distance to entrance })
$$

In this tolling framework, the operator wishes to receive reservation information as early as possible. To incentivize this behavior, the earlier the vehicle reserves the space in HOT lane, the better the discount. The discount is a monotonic decreasing function of the distance 
(or time) to the entrance. The function can be linear or a concave function. In this framework, the discount is illustrated as a linear adjustment factor.

\section{3. Performance Evaluation}

In this section, a simulation is designed to test the performance of the proposed reservation tolling system. In this simulation, we assumed a hypothetical two-lane route, with one HOT lane and one GP lane. Here, we are modeling one segment of the tolled route (from the entrance to the exit). The length of the segment is assumed to be 1 mile long for illustration (the number of vehicles on this link is equal to the density). The free flow speed for both HOT and GP lane is $60 \mathrm{mph}$. This simulation is coded in Python, the results shows the average of 10000 times run.

\subsubsection{Simulation Setup}

\section{Travel Time}

\section{Free-flow travel time}

Since the segment is assumed to be 1 mile in distance and the free flow speed is 60 mph, the free-flow travel time in both HOT and GP lane is

$$
\frac{1 \mathrm{mile}}{60 \mathrm{mph}} \times \frac{60 \mathrm{~min}}{h r}=1 \mathrm{~min}
$$

\section{Travel time on the HOT lane and GP lane --- Bureau of Public Roads (BPR) Function}

The BPR function was developed in the late 1960s by BPR (now the Federal Highway Administration, FHWA). Data was collected on uncongested freeways with no signals, which was fitted to a polynomial equation to the freeway speed-flow curves in the $1965 \mathrm{HCM}$. Various metropolitan planning organizations (MPOs) modified the original equation by fitting local data or hypothetical data from simulation models. There are some other forms of BPR function, such as Conical, Modified Davidson, Akcelik function and so on to calculate travel time (or speed). Because of the simple mathematical form and minimal input requirements, the BPR function has been widely used in the world. However, the predictive accuracy of BPR function mostly depends on the parameters of the function and the capacity of the land and free flow travel time. Equation 3 shows the standard form of BPR function. 


$$
\mathrm{t}=\mathrm{t}_{0}\left(1+\alpha\left(\frac{v}{c}\right)^{\beta}\right)
$$

where

- $t$ : predicted mean travel time,

- $t_{0}$ : free-flow travel time,

- v: volume,

- c: capacity,

$\alpha, \beta$ : parameters, $\alpha$ is the ratio of the free-flow speed to the speed at capacity; $\beta$ determines how abruptly speeds drop from free-flow speed.

Generally speaking, the high exponent in the dominator ( $\beta$ parameter) makes the function sensitive to oversaturated conditions (v/c ratio larger than 1.0), which leads to steeper slopes. The travel time will increase quickly.(BPR, 1964; Moses et al., 2013; Mtoi and Moses, 2015)

BPR functions parameters are specific to individual roadway facilities. In this simulation, the parameters generated for Virginia interstates of both under-saturated and oversaturated were used (Miller et al., 2002). Here, we assume the lane capacity for Virginia interstate is 2200 vehicles per lane per mile (HCM, 2010).

For under-saturated condition, the $\mathrm{v} / \mathrm{c}$ ratio is less than 1.0 ; the $\alpha$ is 0.15 ; the $\beta$ is 13.29 . The BPR function for GP lane is

$$
\begin{gathered}
\operatorname{TravelTime}(G P)=\text { Uncongested Travel Time }\left(1+\alpha\left(\frac{v}{c}\right)^{\beta}\right) \\
=1.0\left(1+0.15 *\left(\frac{v}{2200}\right)^{13.29}\right)
\end{gathered}
$$

Similarly, the BPR function for HOT lane is

$$
\begin{gathered}
\operatorname{TravelTime}(\text { HOT })=\text { Uncongested Travel Time }\left(1+\alpha\left(\frac{v}{c}\right)^{\beta}\right) \\
=1.0\left(1+0.15 *\left(\frac{v}{2200}\right)^{13.29}\right)
\end{gathered}
$$

For the over-saturated condition, the v/c ratio is greater than 1.0; the travel time is computed as: 


$$
\begin{gathered}
\text { TravelTime }(\text { HOT })=\text { Uncongested Travel Time }\left(1+\alpha\left(\frac{v}{c}\right)^{\beta}\right)+\frac{0.4(v-c)}{2 c} \\
=1.0\left(1+0.15 *\left(\frac{v}{2200}\right)^{13.29}\right)+\frac{0.4(v-2200)}{2 * 2200}
\end{gathered}
$$

$$
\begin{gathered}
\operatorname{TravelTime}(G P)=\text { Uncongested Travel Time }\left(1+\alpha\left(\frac{v}{c}\right)^{\beta}\right)+\frac{0.4(v-c)}{2 c} \\
=1.0\left(1+0.15 *\left(\frac{v}{2200}\right)^{13.29}\right)+\frac{0.4(v-2200)}{2 * 2200}
\end{gathered}
$$

\section{Utility function for Vehicles}

The general form of utility function has proposed in the previous section. For sake of simplicity, VOR was not accounted for in this simulation. Thus, the utility function for simulation is set as below.

$$
\begin{gathered}
\text { Utility }(\text { HOT })=\text { VOT } \times \text { Traveltime }- \text { Toll }+ \text { TollDiscount } \\
+ \text { Other }+\varepsilon \\
\text { Utility }(G P)=\text { VOT } \times \text { Traveltime }+ \text { Other }+\varepsilon
\end{gathered}
$$

\subsection{2. $\quad$ Simulation Scenarios}

To test the effectiveness of this tolling scheme, four scenarios with varying approaching volumes (representing various levels of congestion from LOS B to LOS E) are considered. The density specifications for these scenarios are shown in Table 8.

Within each time interval, the decision process of approaching vehicles is modeled after a Poisson arrival process with mean arrival rate of 1. Vehicles which "arrive" simultaneously are, in essence, reserving the HOT lane at the same time (and thereby paying the same toll). The decision of the previous group of vehicles will have direct impacts on the following group of vehicles, as the toll updates after vehicle reservations are accounted for after each group of vehicles.

We model 4 sequential time intervals. In other words, all CAVs are given 4 distinct opportunities (with 4 distinct toll offers) to make the route choice decision between HOT and GP lane. Non-connected vehicles are assumed to only have one opportunity (in time interval 4) to make the route choice decision, which is similar to current HOT lane operations. 


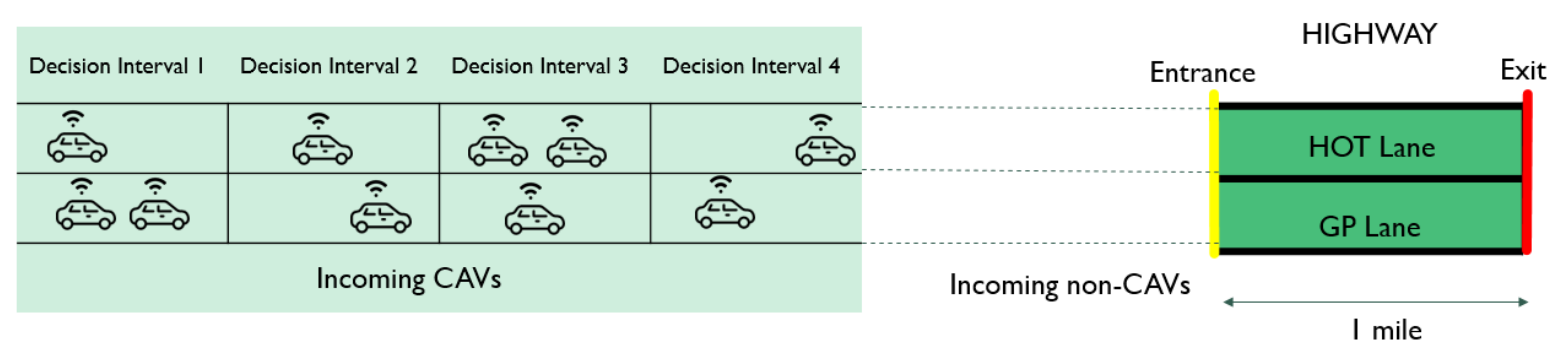

Figure 13 CAV Decision Graphical Demonstration

Table 8 Scenario Setup

\begin{tabular}{|c|c|c|c|}
\hline Scenario & LOS & Density & Approaching number of vehicles (2 lanes) \\
\hline 1 & B & 15 & 30 \\
\hline 2 & C & 24 & 48 \\
\hline 3 & D & 32 & 64 \\
\hline 4 & E & 40 & 80 \\
\hline
\end{tabular}

\subsubsection{Simulation Results}

The simulation results change each time because of the change in VOT distribution and vehicle decision distribution. We choose the average results of 10000 samples to see the trend of simulation. The table below shows the final number of vehicles choosing a HOT lane and GP lane after each decision time.

\section{Final Number of Vehicles on Each Lane}

Table 9 Simulation Result

\begin{tabular}{|c|c|c|c|c|c|c|c|c|c|}
\hline \multicolumn{8}{|c|}{$100 \%$ CAV Penetration } \\
\hline iteration & $\begin{array}{c}\text { Decision } \\
\text { time }\end{array}$ & \multicolumn{2}{|c|}{1} & \multicolumn{2}{|c|}{2} & \multicolumn{2}{|c|}{3} & \multicolumn{2}{c|}{4} \\
\hline \multicolumn{2}{|c|}{$\begin{array}{c}\text { Incoming } \\
\text { Vehicles }\end{array}$} & HOT & GP & HOT & GP & HOT & GP & HOT & GP \\
\hline B & 30 & 14.96 & 15.04 & 22.31 & 7.69 & 25.49 & 4.51 & 26.80 & 3.20 \\
\hline C & 48 & 22.77 & 25.23 & 26.16 & 21.84 & 27.08 & 20.92 & 27.50 & 20.50 \\
\hline D & 64 & 23.77 & 40.23 & 23.77 & 40.23 & 23.77 & 40.23 & 23.77 & 40.23 \\
\hline E & 80 & 23.54 & 56.46 & 23.54 & 56.46 & 23.54 & 56.46 & 23.54 & 56.46 \\
\hline
\end{tabular}




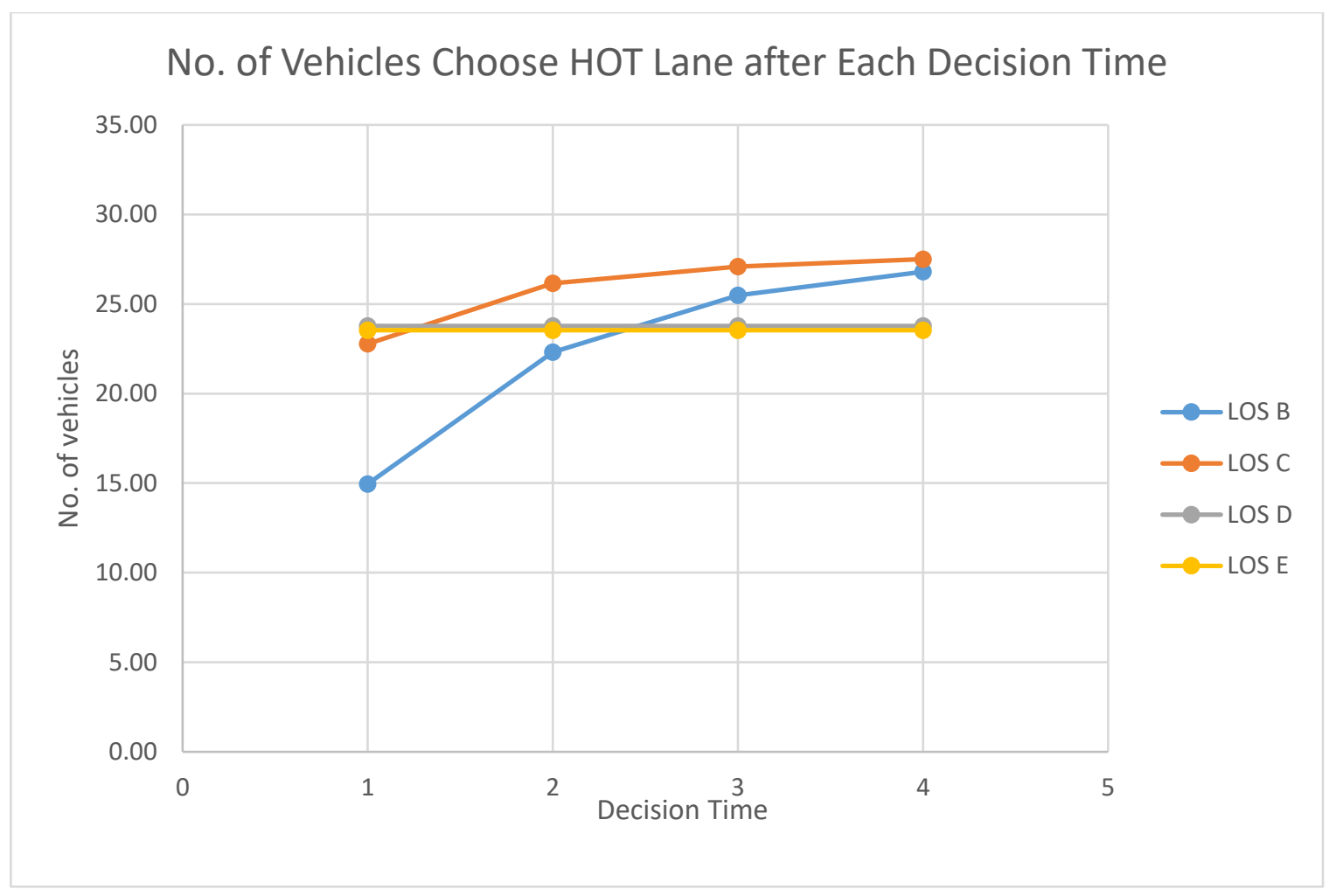

Figure 14 No. of Vehicles Choose HOT Lane after Each Decision Time

\section{Vehicles made their decision as early as possible}

Figure 14 is the graphical illustration of a number of vehicles choose HOT lane after each decision time. From the figure, we can see that for incoming vehicles within LOS B and $\mathrm{C}$; the proposed dynamic tolling algorithm works well for attracting vehicles make the decision as early as possible. Figure 15 shows the percentage of total vehicles choose the HOT lane. At the first decision time, the majority of vehicles choose the HOT lane; then some vehicles still choose HOT lane at the second decision time. There are few vehicles made their decision at the third and fourth decision time.

However, for incoming vehicles within LOS D and E, almost all the vehicles made their decision whether to choose HOT lane or not at the first decision time. That is due to the high volume of incoming vehicles; the GP lane will always get congested. All the vehicles made their decision at the first decision point and then the HOT lane is fully booked. There is no more room for more vehicles to reserve.

\section{Final density on HOT lane converge to goal density}

Since the goal density was set as the mid-point of LOS C. The final number of vehicles which choose HOT finally when incoming vehicles are in LOS D and E converge to the goal density, which is 24 veh/lane/hour. However, when incoming vehicles are in LOS B and C, 
the final number of the vehicle which chooses HOT lane is slightly larger than the goal density. That is because most of the vehicles have multiple chances to make their decision (during different decision intervals). So the final number of vehicles which choose HOT lane is slightly larger than the goal density.

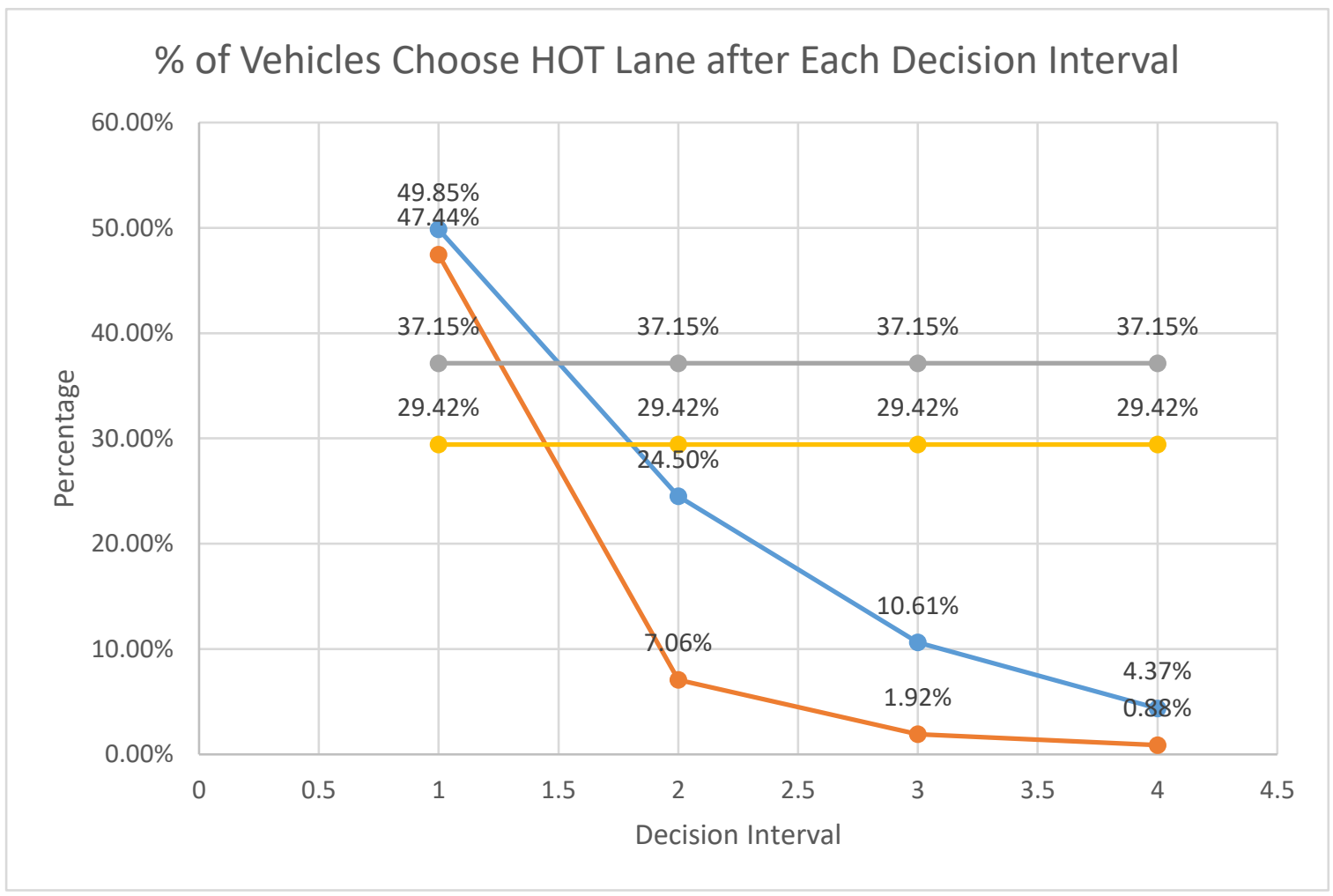

Figure 15 Percentage of Vehicles Choose HOT Lane after Each Decision Time

\section{Discount}

Adding a discount component to the total is trying to use the discount to adjust the total number of vehicles which choose the HOT lane. With the discount, more vehicles will make the reservation to use HOT lane at an earlier time, which give the operator more certainty about potential lane use of incoming vehicles.

The discount in this simulation was set as 30\%, 20\%, 10\%, 0\% percentage of toll during decision intervals $1,2,3,4$. The earlier the vehicles make their decision, the better discount they will get. Finally, comparison results show that the discount did work to increase reservations at earlier decision intervals. However, the increase is small. The discount has little effective on adjusting a final number of vehicles on HOT lane. But it can be an adjusting factor to attract more vehicles on HOT lane compared with the situation w/o discount. 
Table 10 Comparison of Final No. of Vehicles Choose HOT lane of Discount and No Discount

\begin{tabular}{|c|c|c|c|c|c|}
\hline Incoming Vehicle & Decision Time & 1 & 2 & 3 & 4 \\
\hline \multirow{2}{*}{$\mathrm{B}$} & w/o discount & 14.99 & 22.32 & 25.57 & 26.89 \\
\cline { 2 - 6 } & w/ discount & 14.97 & 22.39 & 25.71 & 27.03 \\
\hline \multirow{2}{*}{$\mathrm{C}$} & w/o discount & 22.90 & 26.62 & 27.58 & 28.01 \\
\cline { 2 - 6 } & w/ discount & 23.37 & 28.06 & 28.75 & 28.92 \\
\hline \multirow{2}{*}{$\mathrm{D}$} & w/o discount & 23.69 & 23.69 & 23.69 & 23.69 \\
\cline { 2 - 6 } & w/ discount & 25.43 & 25.43 & 25.43 & 25.43 \\
\hline \multirow{2}{*}{$\mathrm{E}$} & w/o discount & 23.60 & 23.60 & 23.60 & 23.60 \\
\cline { 2 - 6 } & w/ discount & 25.79 & 25.79 & 25.79 & 25.79 \\
\hline
\end{tabular}

\section{Revenue}

This part explores the revenue change within different situations. Table 11 below shows the results of total revenue. The discount makes more vehicles book earlier, especially work well for LOS C. Since the introduction of discount to the total toll equation. How will the discount influence the final revenue?

For LOS B, since the road will never get congested. The toll is set to be really low. The possibility for vehicles to choose HOT and GP is roughly the same as 50\%. However, it has little impact on the final density, since the price is low, the revenue even lower compared with no discount.

For LOS C, more vehicles book earlier with a lower price, which results in the lower revenue. However, this is a tradeoff between revenue and certainty. With more vehicles book earlier, the operator gets more certainty about incoming vehicles. This algorithm works well for incoming vehicles of LOS C.

For LOS D, E, more vehicles book earlier, result in slightly higher density on HOT lane, which increases the revenue slightly.

Table 11 Comparison of Revenue W/ Discount and W/O Discount

\begin{tabular}{|c|c|c|c|c|}
\hline & B & C & D & E \\
\hline w/o discount & 2.4738 & 8.7871 & 2.5478 & 2.4660 \\
\hline w/ discount & 2.0101 & 8.2500 & 2.6380 & 2.5883 \\
\hline
\end{tabular}

Figure 16 shows the total toll change for different incoming vehicles. The total toll has an increasing trend, however, may drop a little bit during decision time change. The final toll 
is consist of HOT lane toll component and GP lane toll component. During the decision time change, the density on HOT may increase, the density in GP may decrease. Since the VOT and Volume on each lane may different, this may result in slightly decrease on the total toll. However, the trend for total toll is still increasing. Especially when the density of HOT approaching to the desired density, the toll increase rapidly. Finally, the toll will be very high to keep more vehicles away from the HOT lane.

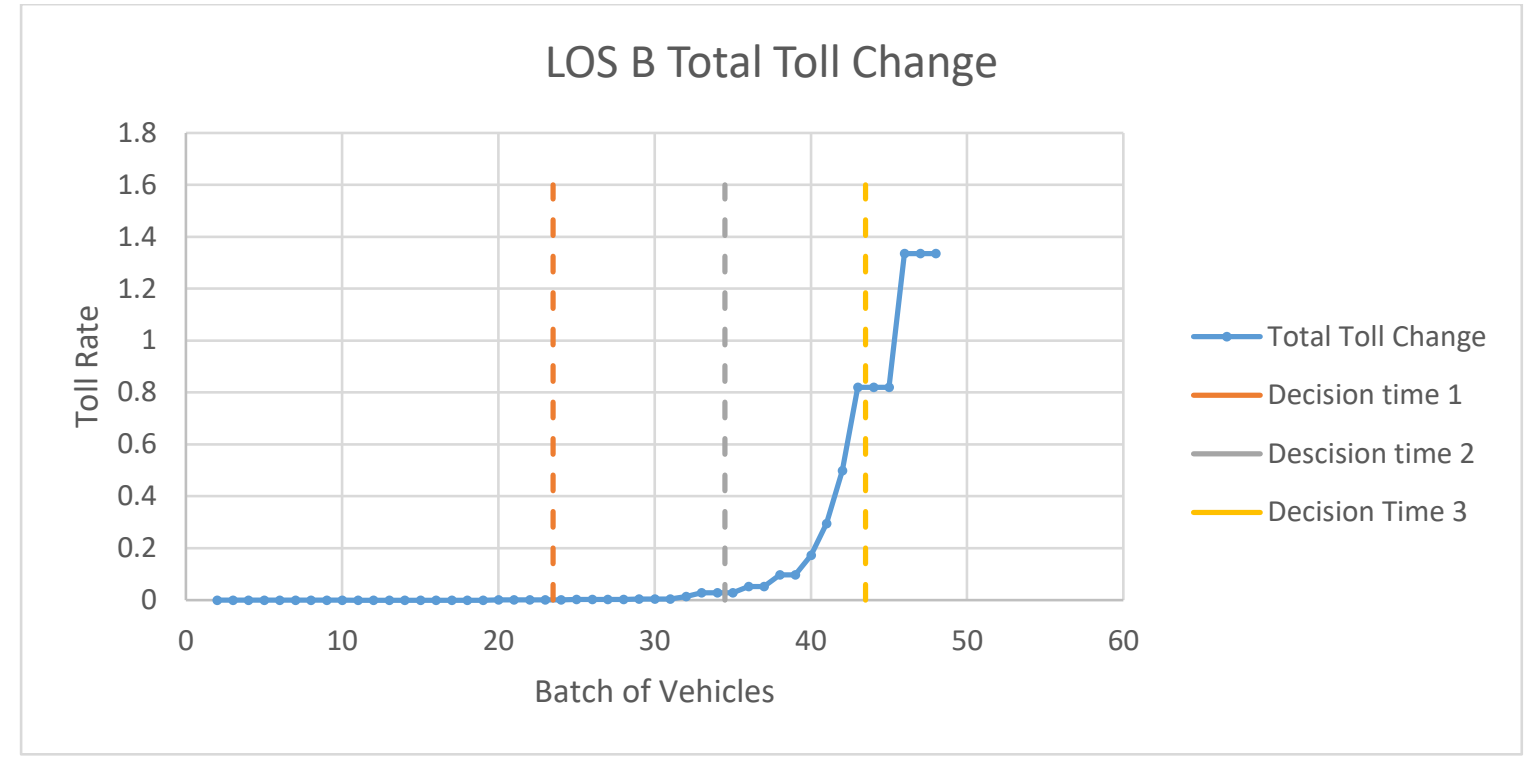

(a)

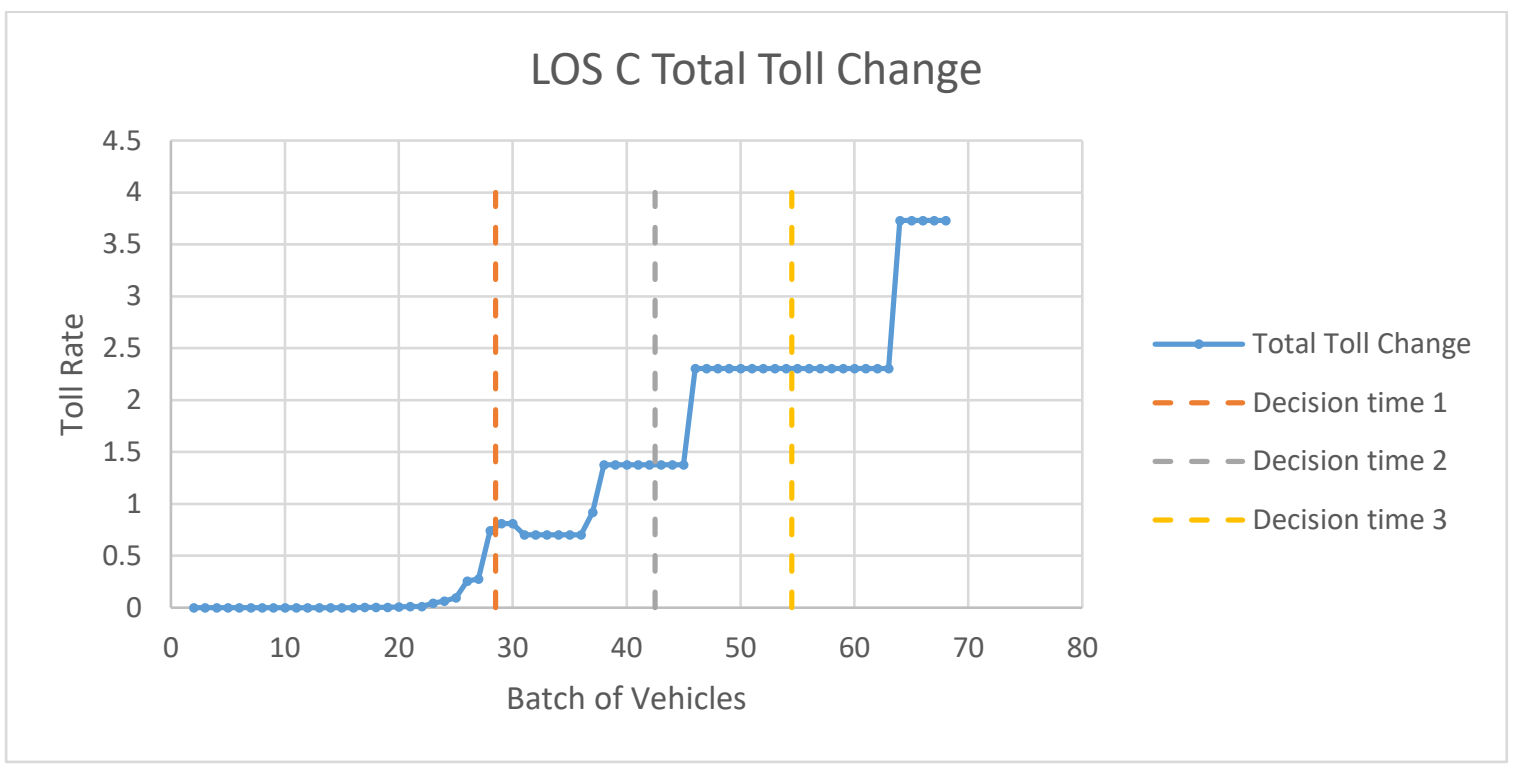

(b) 


\section{LOS D Total Toll Change}

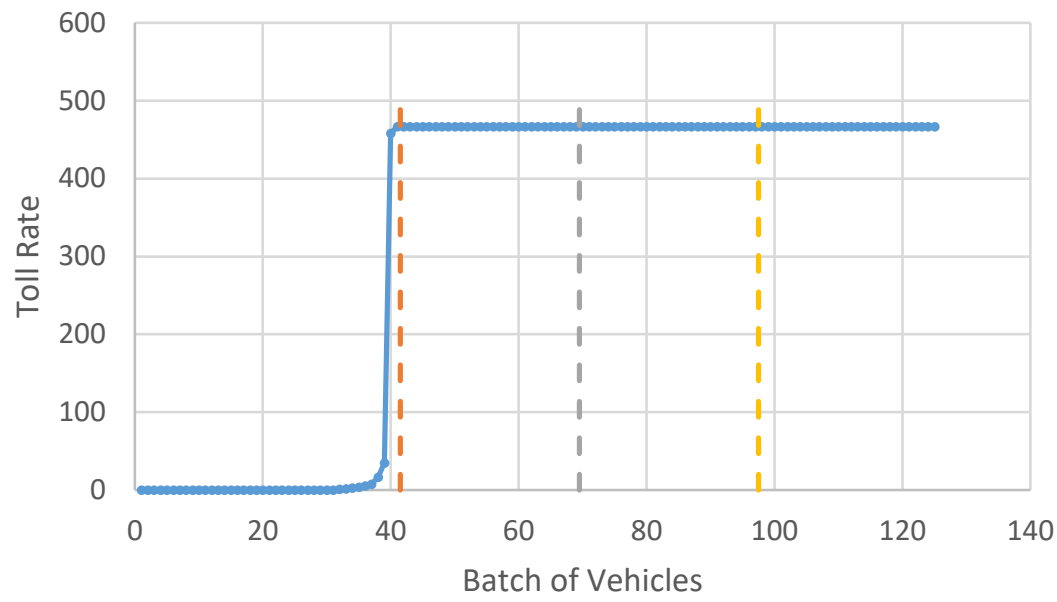

$\longrightarrow$ Total Toll Change

Decision time 1

- - Decision time 2

- - Decision time 3

(c)

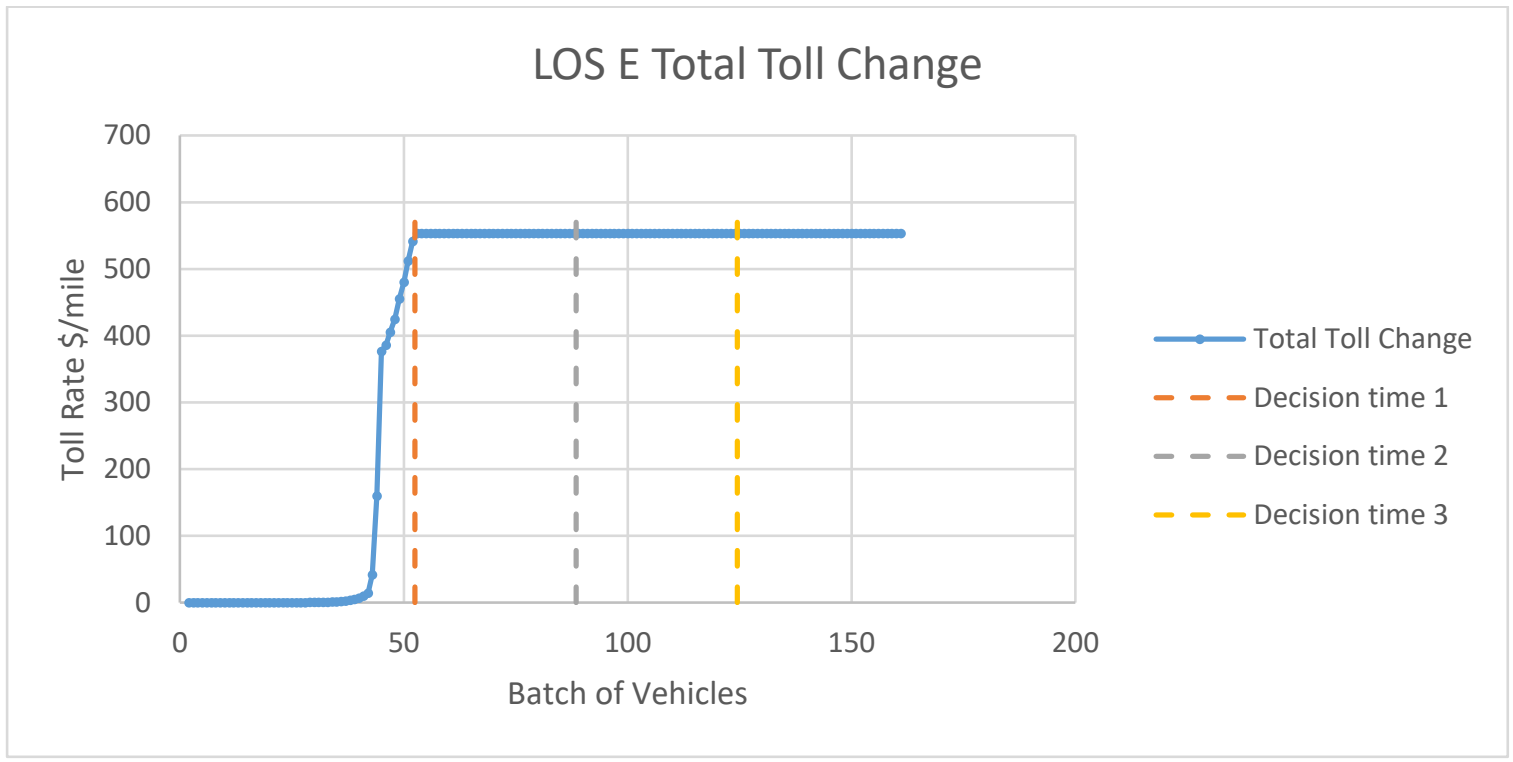

(d)

Figure 16 Total Toll Change for Different LOS

\section{Equity}

The proposed reservation-based dynamic tolling framework is relatively equitable to everyone with a different value of travel time during the initial decision time intervals. The toll is low, and everyone can buy into the HOT lane at the beginning. The toll increase rapidly as the distance to the entrance and gradually favor those people with higher VOT.

The figure below shows the average value of travel time on HOT and GP lane when incoming vehicles are in LOS E in one case. In the beginning, the average VOT on HOT is 
larger than average VOT on GP, then, the average VOT on GP is slightly larger than VOT on HOT. At last, the final average VOT on HOT is larger than final average VOT on GP lane.

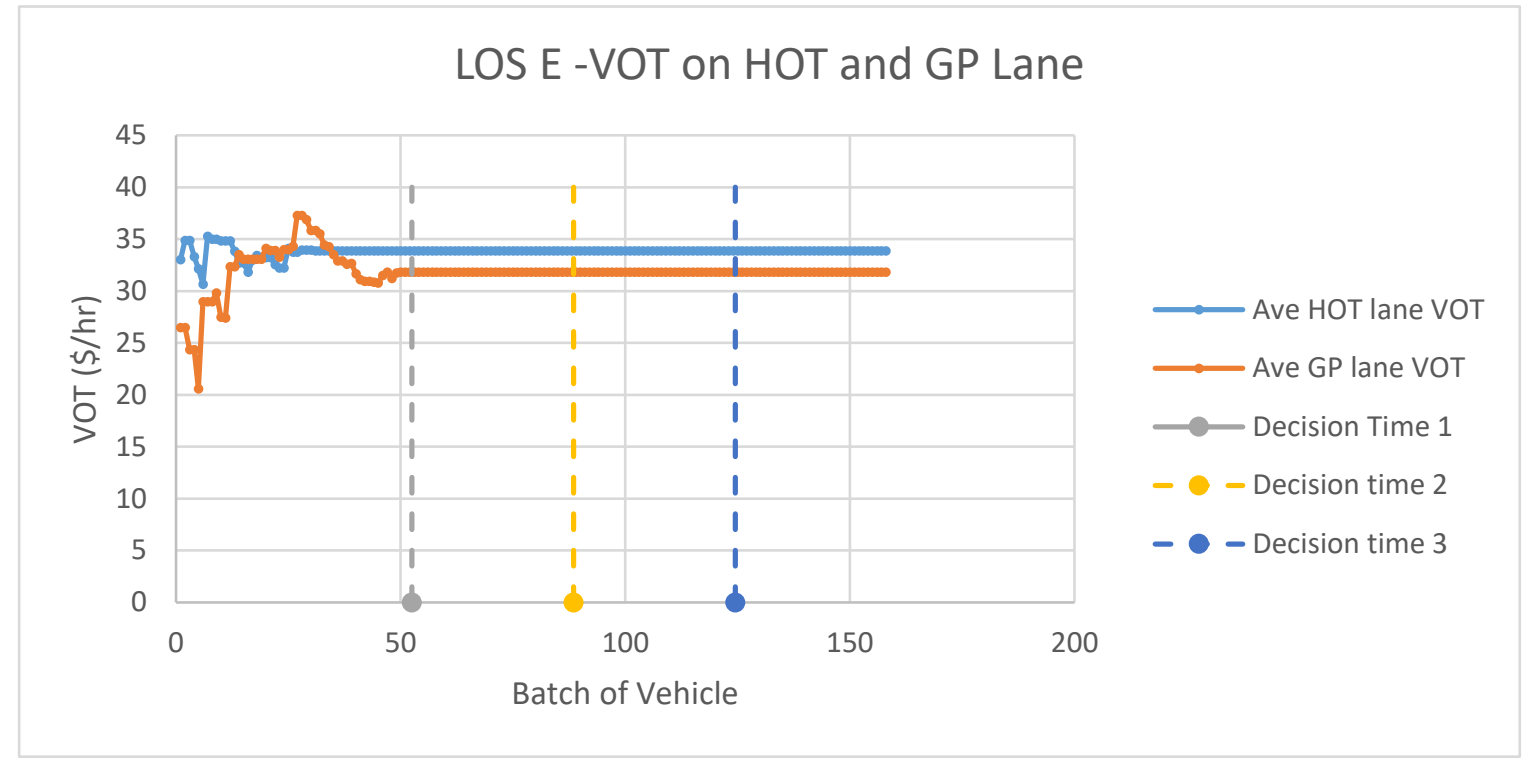

Figure 17 VOT change on HOT and GP lane

\section{Mixed Fleet}

The proposed tolling framework should be operational under mixed fleet conditions. In the mixed fleet scenarios, the CAVs continue to be able to reserve the HOT lane in four decision intervals as in the all CAV scenario. Their toll is calculated by second-best pricing scheme, identical to the all CAV scenario. However, for non-CAVs, since they cannot communicate with the operator in advance to the entrance (gantry) of the HOT lane, they can only choose to use HOT lane or not at the entrance point. There is only one flat toll for all nonCAVs during the decision interval. In this thesis, three approaches were tested to examine the best approach to the tolling of non-CAVs in a mixed fleet environment. The primary difference between the tested approaches is how the operator anticipates non-CAV route choice decision. Based on the percentage of anticipation, three approaches can be classified as $0 \%$-anticipatory rate (where the operator only uses CAV reservation information to inform the toll), $100 \%$ anticipatory rate (where the operator anticipates non-CAVs will choose the HOT lane at the same rate as CAVs and tolls all non-CAVs based on the total anticipated CAV plus non-CAV volumes) and 50\%-anticipatory rate (where the operator anticipates non-CAVs will choose the HOT lane at the same rate as CAVs and tolls all non-CAVs based on the total anticipated CAV volume and $50 \%$ of the anticipated non-CAV volume). 
To measure whether the tolling algorithm is effective, the operator's perspective and the users' perspective can be considered separately. The operator has two goals: one is to keep HOT lane density around goal density and second goal is to maximize the revenue. From the user's perspective, both CAV and non-CAV users would like to have the ability to buy into HOT lane when necessary. The system should not heavily favor CAV users (who can make advanced reservations). The analysis of three different approaches was based on these two different perspectives.

\section{$0 \%$-anticipatory Rate for non-CAVs}

This no-anticipatory flat rate worked when the CAV toll didn't consider the incoming non-CAV information. We assumed that the operator don't know anything about the nonCAVs. However, CAVs make their reservation as normal. Then after all CAVs made their decision whether to use HOT or GP lane, the operator gets the information of CAVs final density on HOT and GP lane.

The toll for non-CAVs is set to use the final density of CAVs reservation on HOT and GP. Basically, every non-CAVs is tolled like the first non-CAV that is making the route choice decision, which result in a low toll for non-CAVs.

The simulation results show that this $0 \%$-anticipatory rate not working well on the total number of HOT lane reservation, especially when the incoming vehicles are in LOS C, D, E (see figure 16 (b) (c) (d)). The reason is the toll for CAVs is underestimated since the system didn't consider the total amount of incoming non-CAVs. The final vehicles choose HOT lane (including both CAVs and non-CAVs) often exceed the goal density on HOT lane.

\section{$100 \%$-anticipatory Rate for non-CAVs}

This $100 \%$-anticipatory rate assumes that $100 \%$ of non-CAVs choose just like the CAVs. The toll set for CAVs consider the potential non-CAV reservation, which is the same proportional as CAV reservation. Basically, every non-CAV is tolled like the last non-CAV that is making the route choice decision, which result in a high toll for non-CAVs.

The simulation results show that this $100 \%$-anticipatory rate not working well on the total number of HOT lane reservation. The operator tries to keep HOT lane density at a desired density, at the meantime attracting more users choose HOT lane (maximize the HOT lane usage). Figure 16 (b) (c) (d) shows that the toll for CAVs is overestimated since the system 
consider all incoming non-CAVs. The final vehicles choose HOT lane (including both CAVs and non-CAVs) often under the goal density on HOT lane.

\section{$50 \%$-anticipatory Rate for non-CAVs}

Based on the analysis of $0 \%$-anticipatory rate and 100\%-anticipatory rate, a 50\%anticipatory rate was proposed. The toll for non-CAVs corresponds to the middle number of non-CAV reservation. In other words, the toll that corresponds to $50 \%$ of the non-CAVs choosing HOT/GP in the same proportion as CAVs.

The simulation results shows that, this method works well on control total HOT lane reservations. At meantime, didn't decrease revenue dramatically. From user's perspective, the results show on figure 18, this approach didn't favor CAVs when incoming vehicles are not congested on the route. However, when the incoming vehicles already congested, the toll scheme become favor CAVs. 
Results

- HOT Lane Reservation

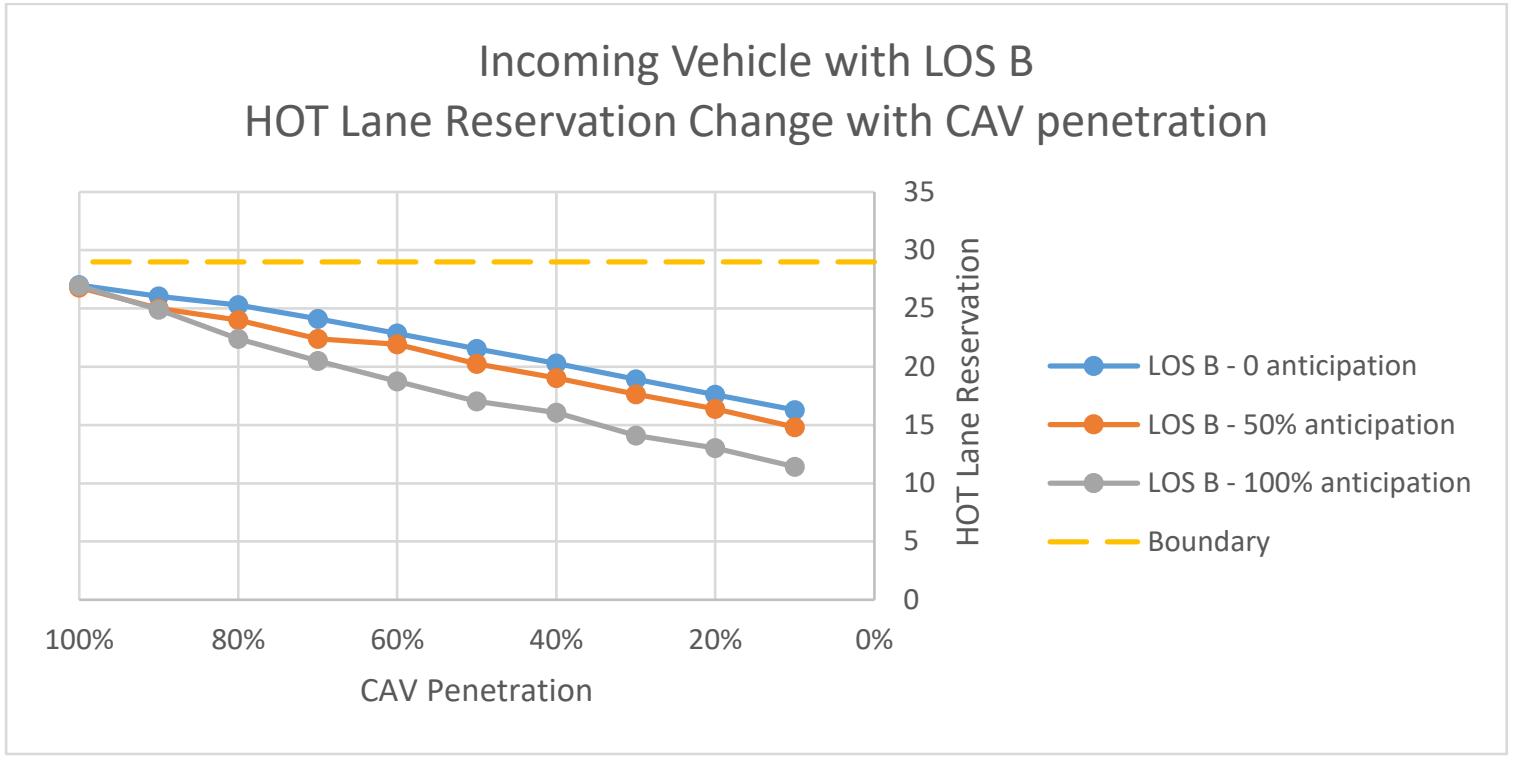

(a)

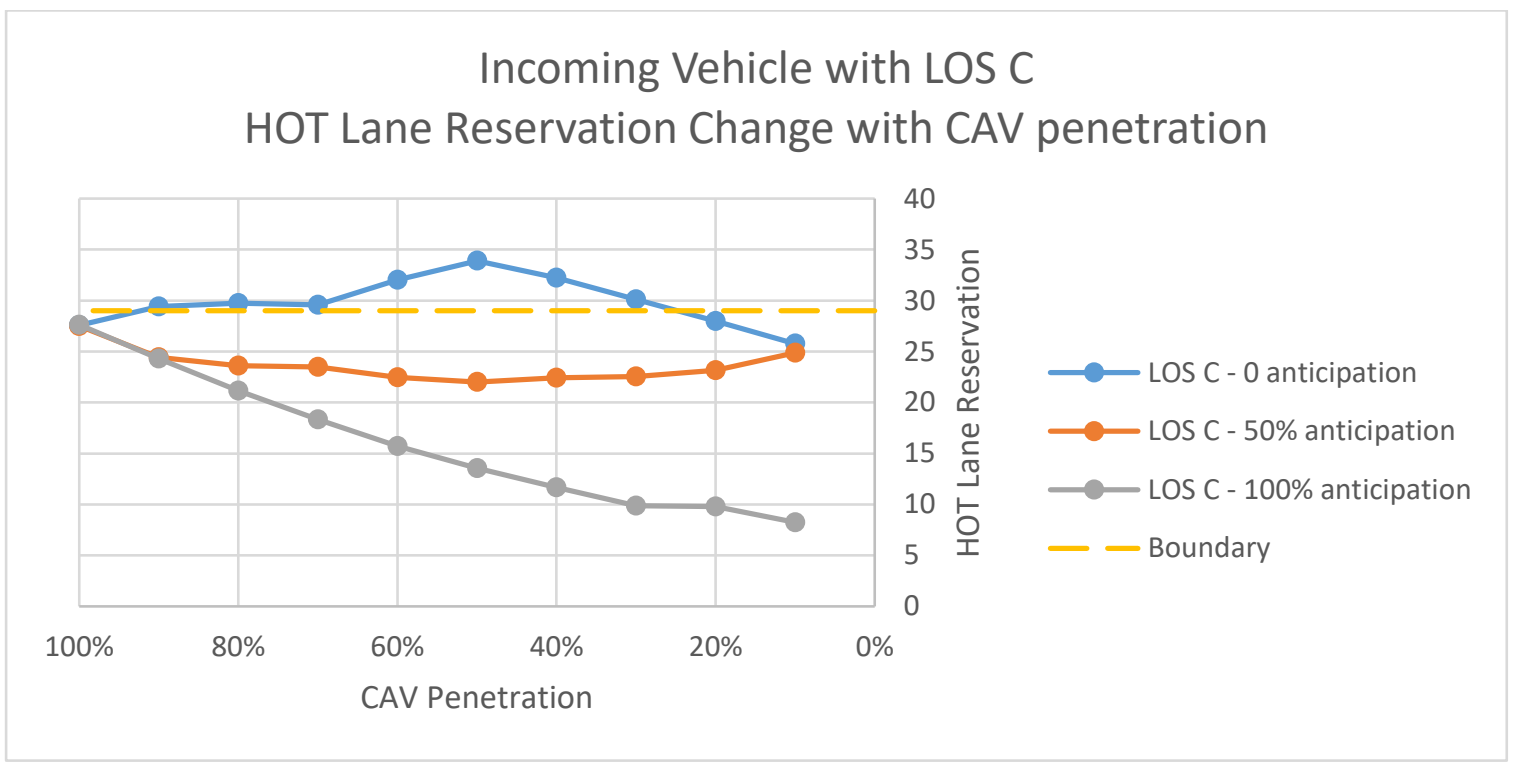

(b) 


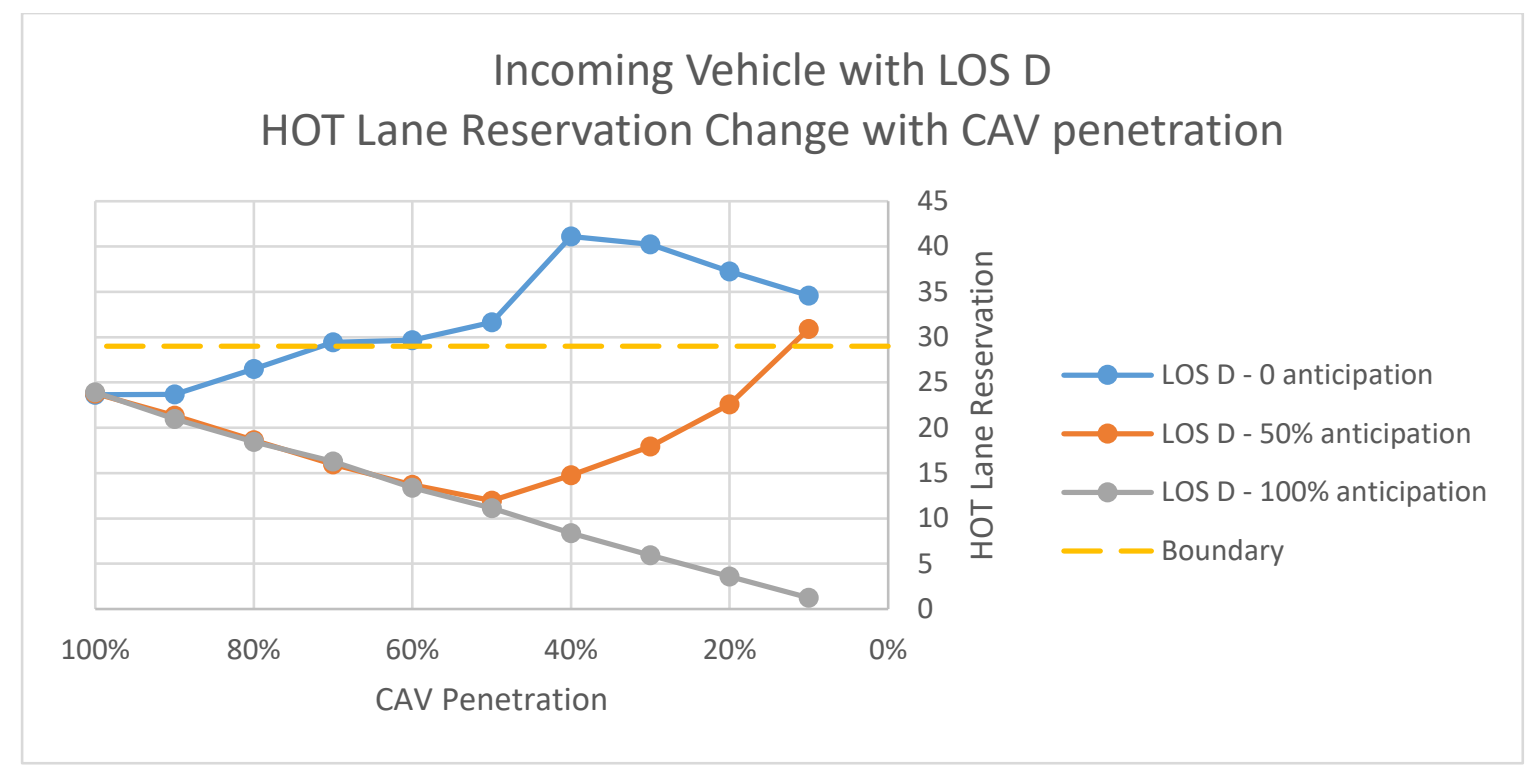

(c)

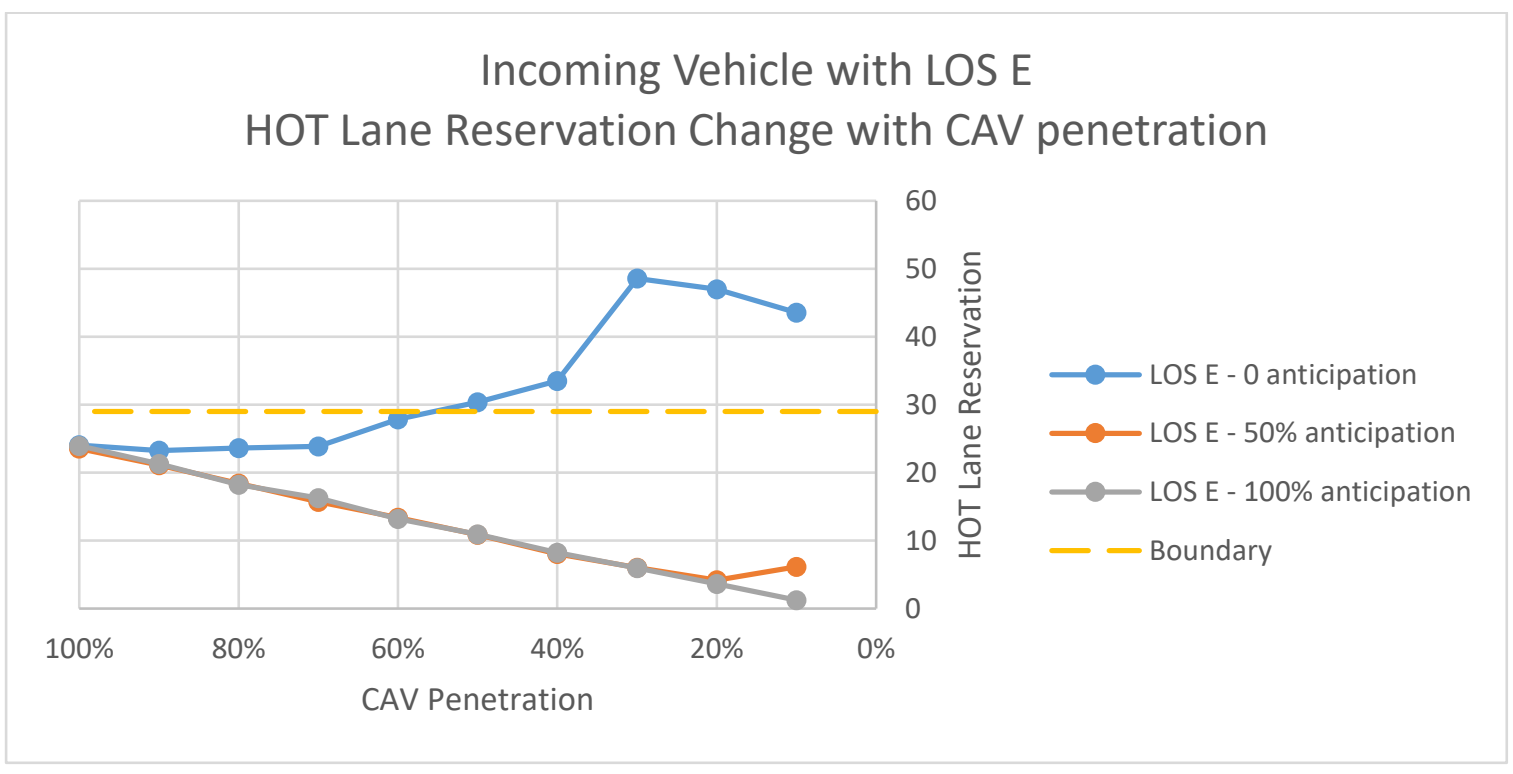

(d)

Figure 18 HOT Lane Reservation 
- Revenue

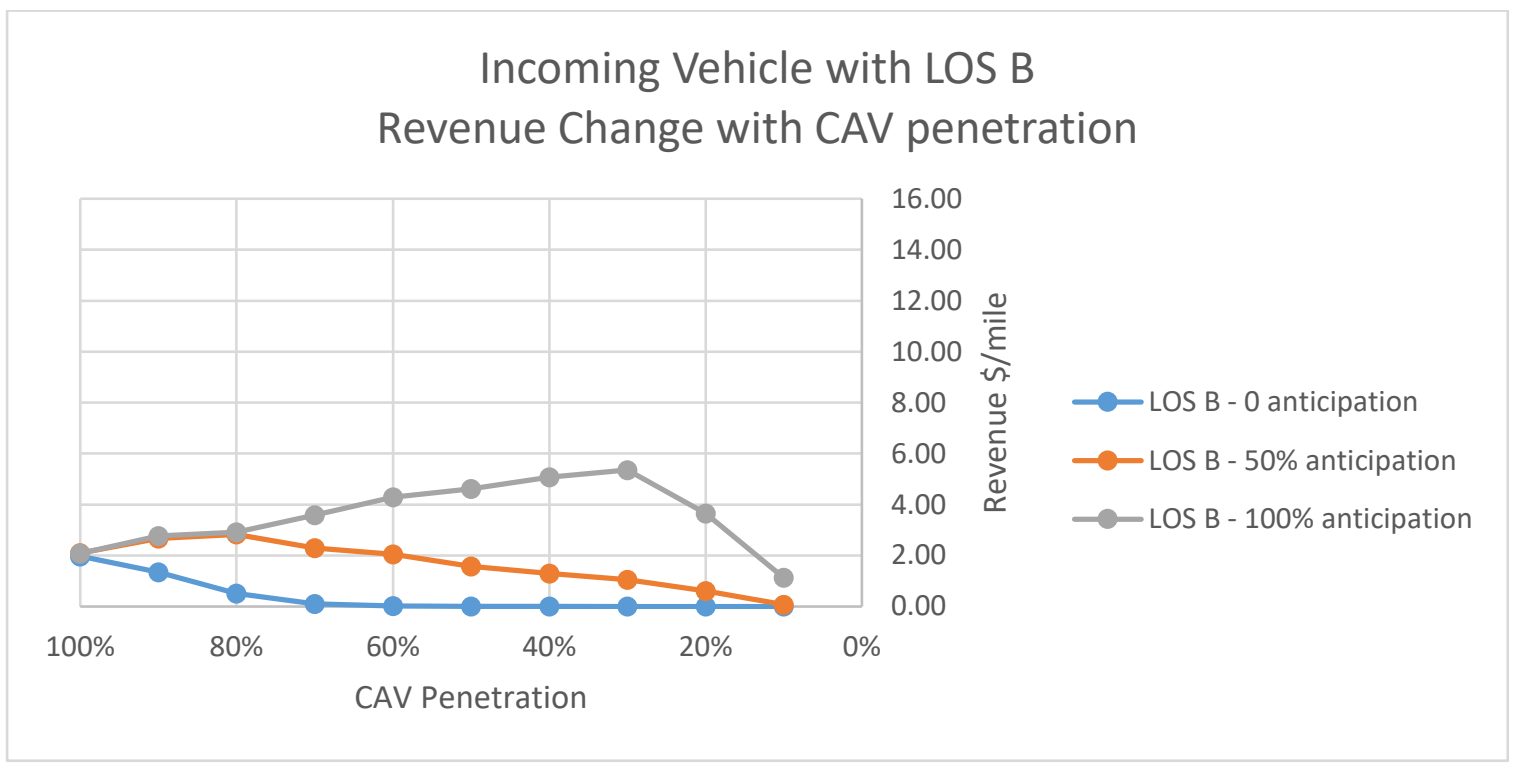

(a)

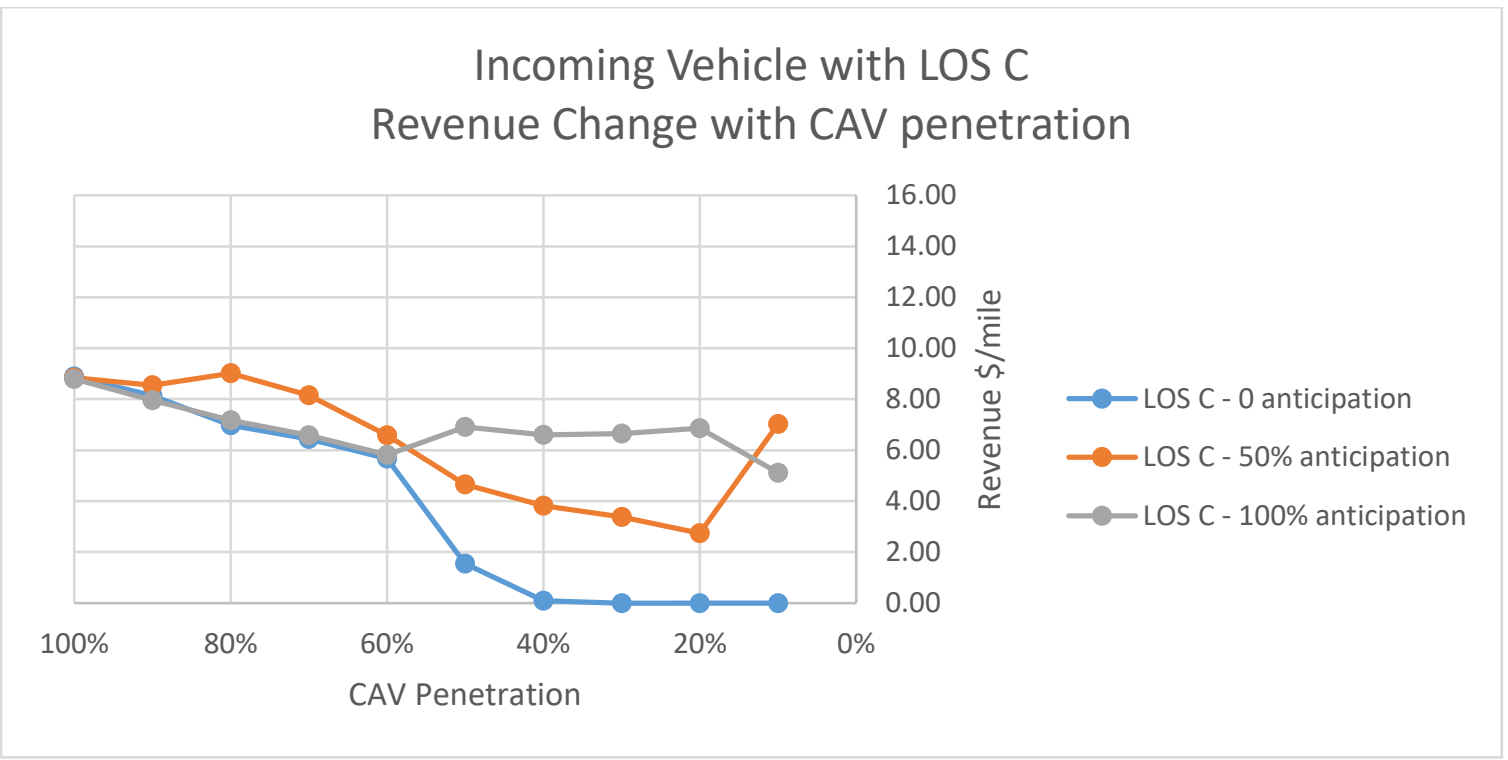

(b) 


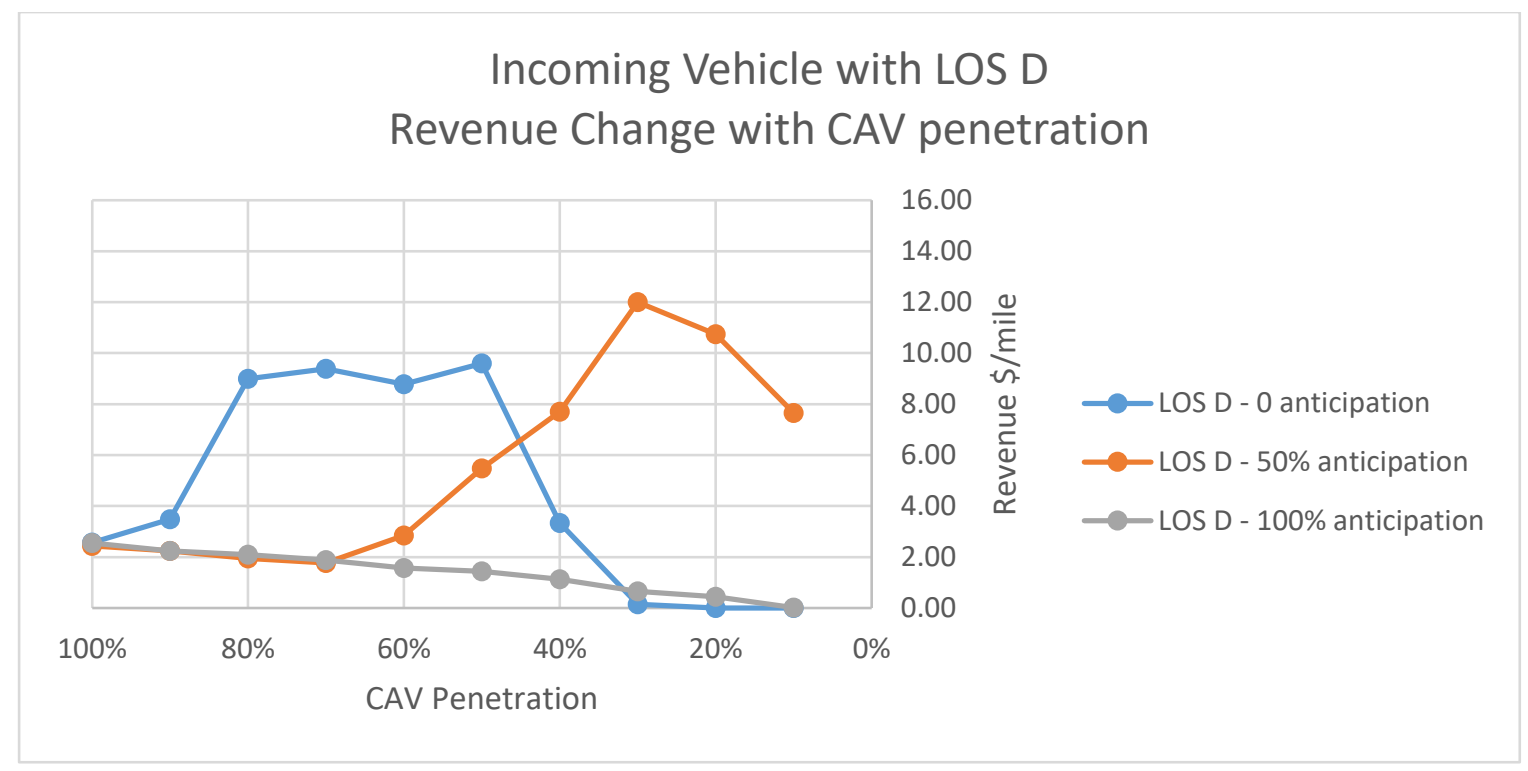

(c)

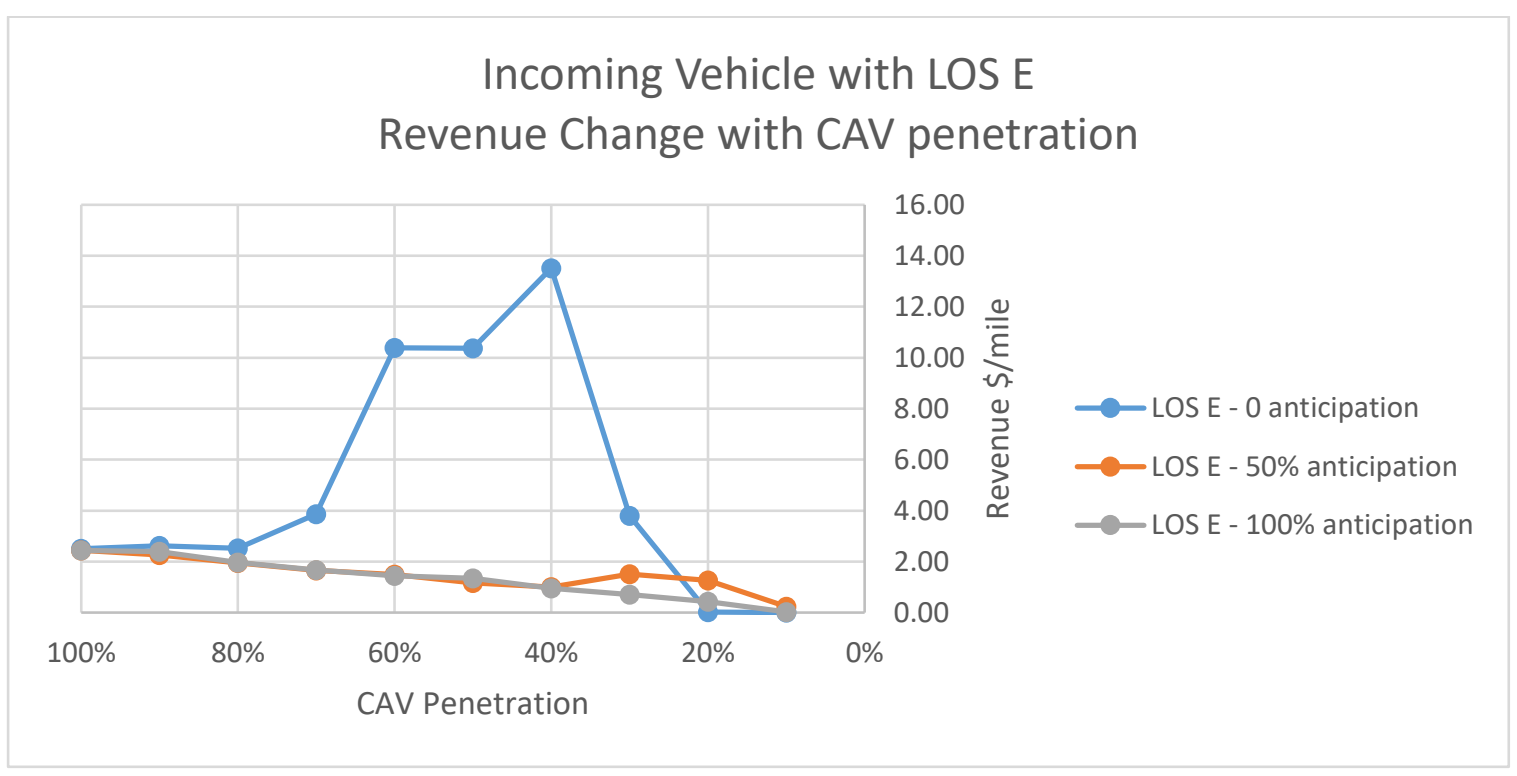

(d)

Figure 19 Revenue 
- Percentage of HOT Lane Reservation

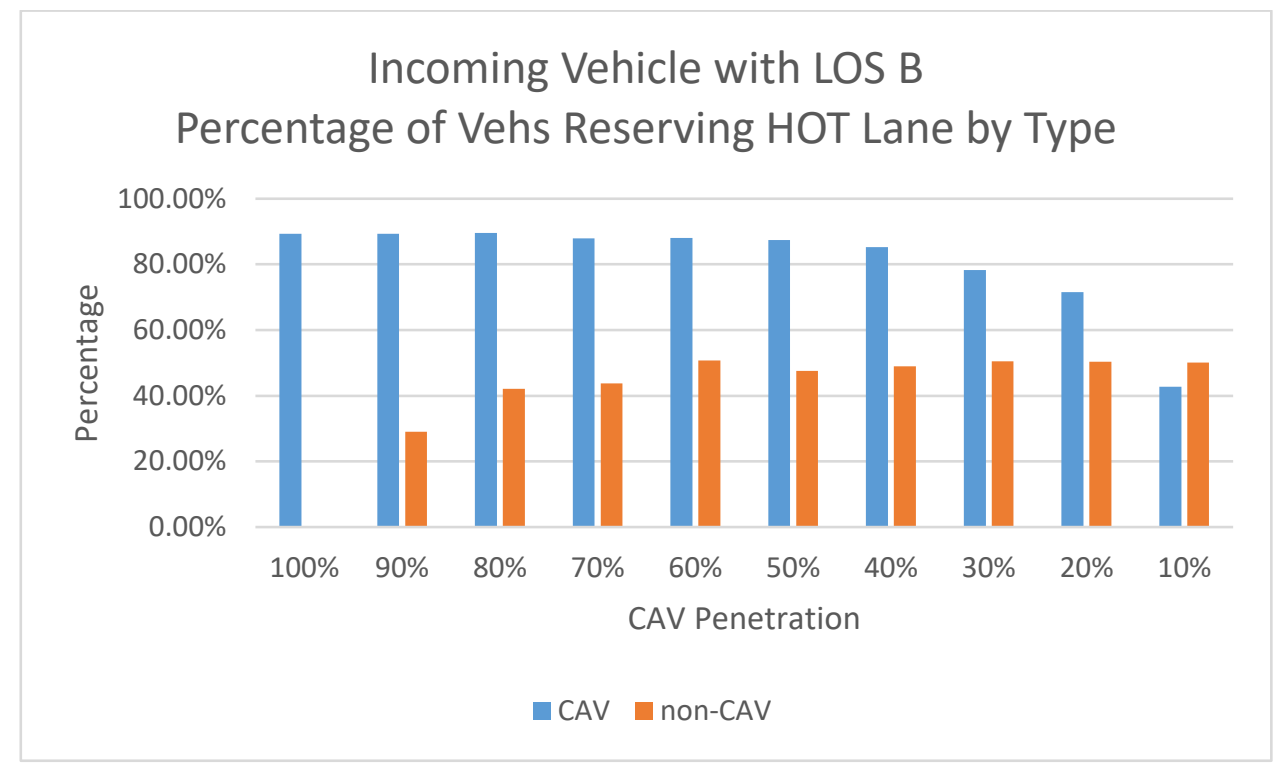

(a)

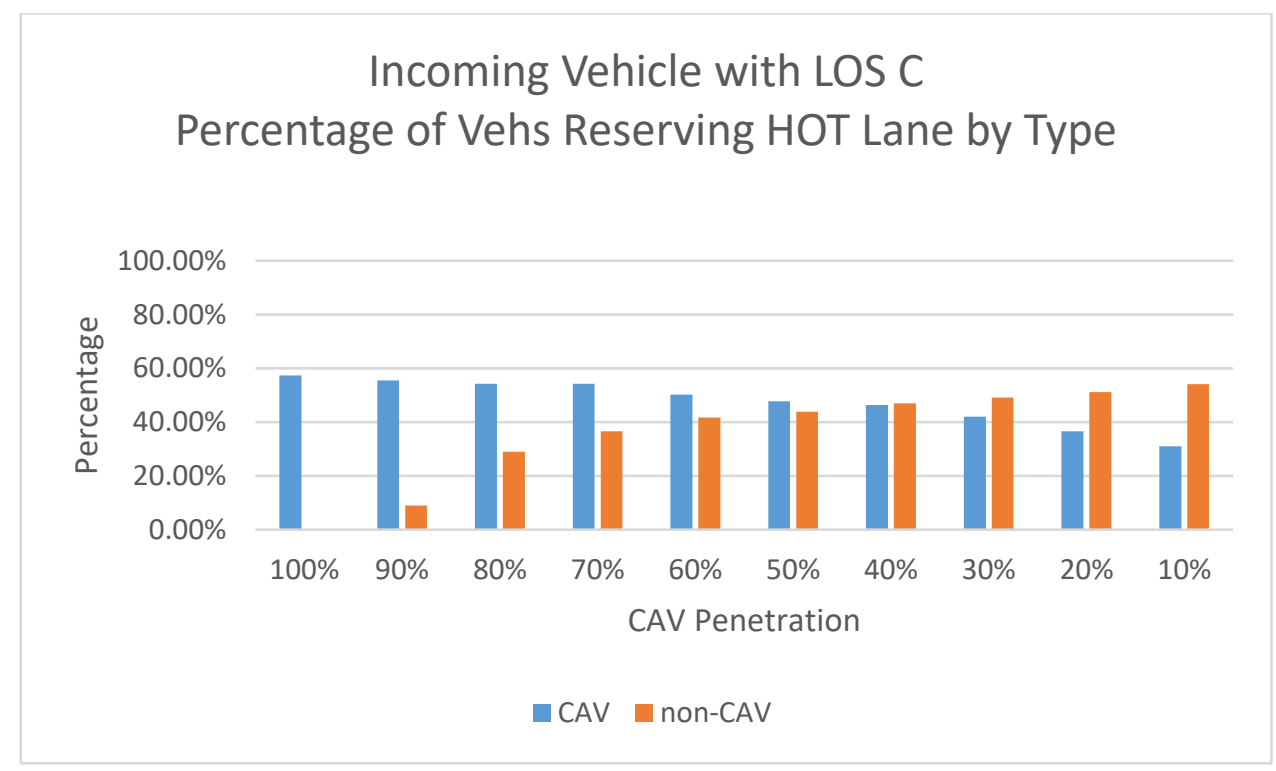

(b) 


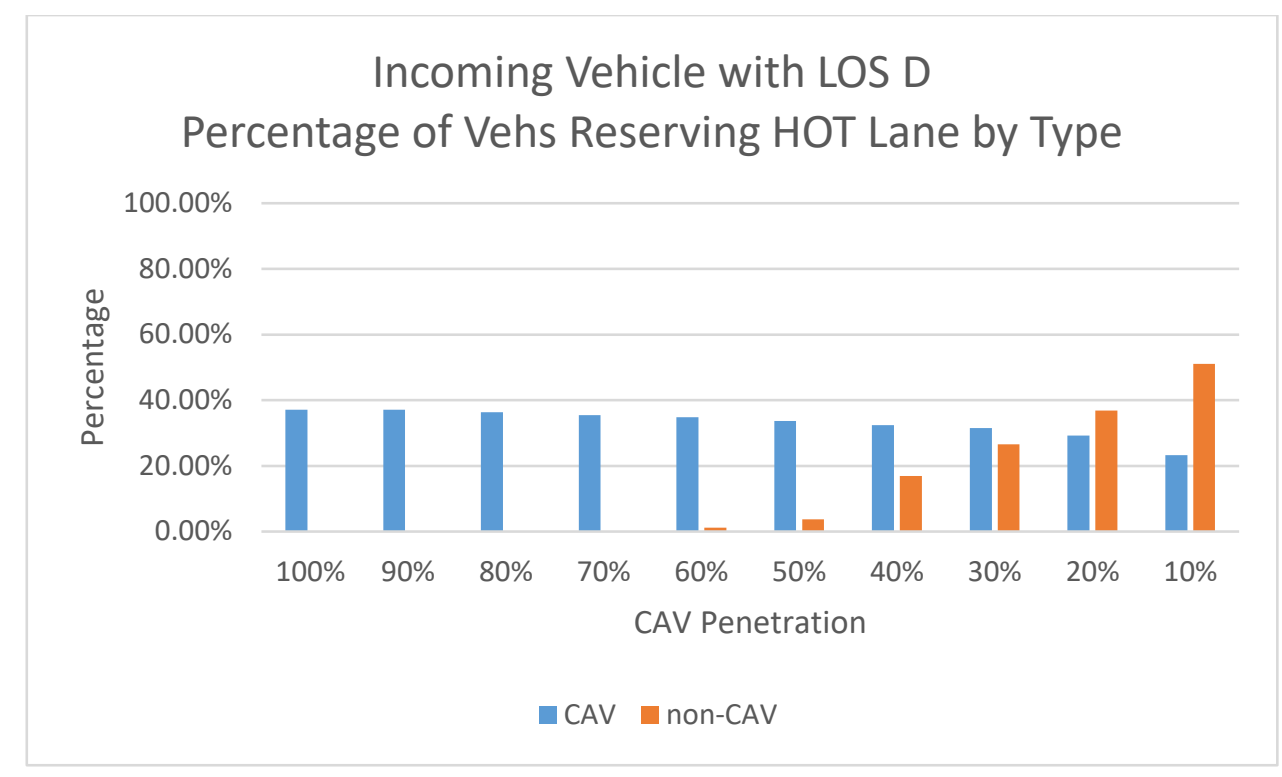

(c)

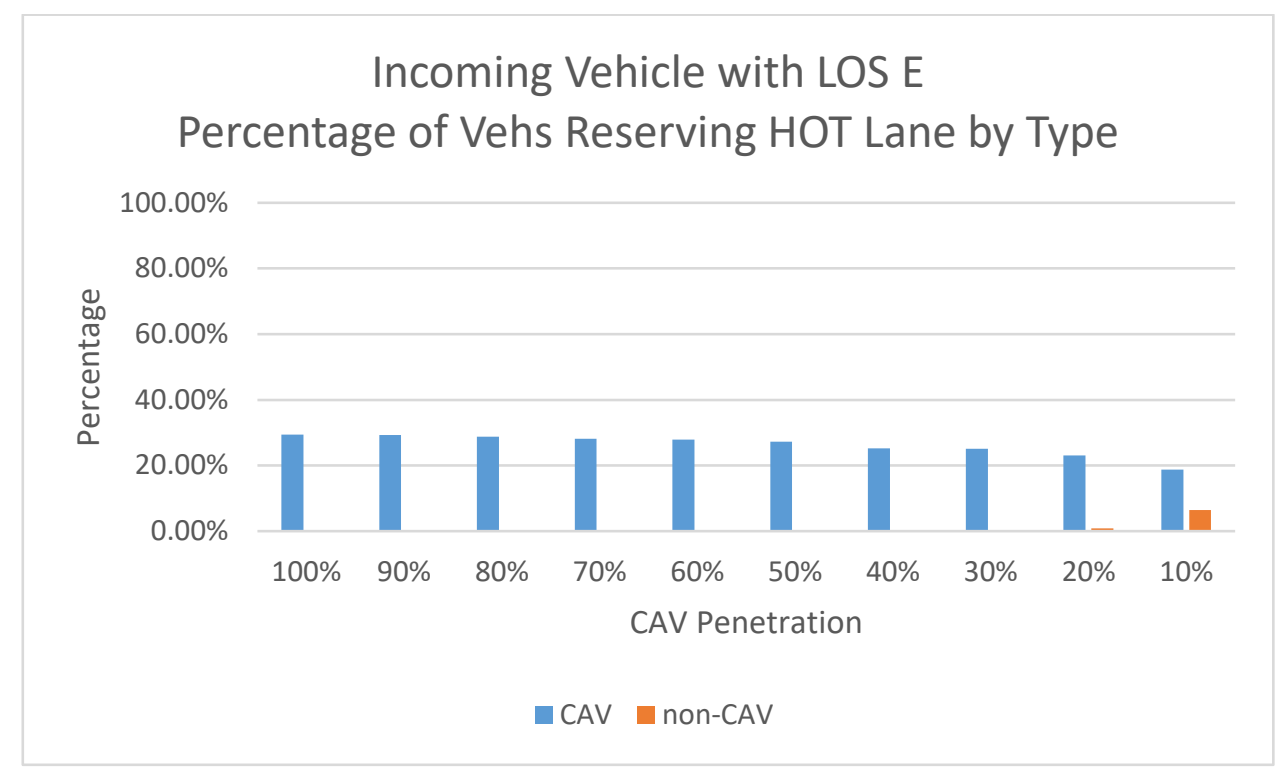

(d)

Figure 20 Percentage of HOT Lane Reservation

\section{4. Conclusion and Limitations}

The proposed reservation-based dynamic pricing algorithm works well for encouraging vehicles to make reservations as early as possible. In this way, give more predictability to the operator, so that the operator can better manage traffic demand on the facility. In the meantime, the proposed framework can keep the traffic density on HOT lane at a desired density. In our simulation, the mid-point of LOS C was set to the desired density. However, this value can be 
set to other values if needed. Although the desired density was set at mid-point at LOS C. The simulation results shows that final density on HOT lane may slightly larger than the desired density. The basic goal of the system is to keep the traffic flow on HOT lane smoothie. Since users pay to use the HOT lane, their travel time should be ensured. The system is also sensitive to approaching traffic volume. The tolling mechanism works well to attract as many vehicles as possible on HOT lane when the incoming vehicles are not too many. And the tolling mechanism all works well to dismiss more vehicles choose HOT lane when the HOT lane is oversaturated. The proposed system also considers the equity issue. People with lower VOT can also have the opportunity to buy into HOT lane at early decision time. At last, the system is friendly to the mixed fleet. The proposed 50\%-anticipatory tolling scheme for non-CAVs works well on manage traffic demand on the HOT lane, at the meantime didn't decrease revenue dramatically. In addition, the proposed scheme didn't favor CAV users when incoming vehicles are not congested, which ensure the equity to non-CAVs. 


\section{Conclusions, Limitations and Future Work}

\section{1. Conclusions}

This thesis examines managed lane practices in existing and future environments by developing a dynamic pricing scheme for managed lanes in the non-CAV environment, the CAV environment, and the mixed fleet environment.

The thesis first reviewed existing dynamic priced facilities in the United States and best practices for their pricing schemes. 11 facilities in the United States were reviewed and 11 experts' interviews were carried out with academic and agency experts to enhance the understanding of existing HOT tolling practices. Generally speaking, most existing HOT facilities allow HOV2+ vehicles to travel toll-free. However, some are only free for HOV3+ vehicles. The dynamic toll rate update frequency ranges from every 3 to 15 minutes. Most facilities toll 24/7, with select facilities only toll during morning and afternoon peak hours.

Motivated by the I-66 Inside the Beltway managed lane conversion project, this thesis then set out to develop a new pricing algorithm in the non-CAV environment for HOT facilities which do not have parallel GP lanes. This framework considers both user preference for the price-certainty of a time-of-day pricing scheme as well as the flexibility of a dynamic pricing scheme to accommodate real-time fluctuations in traffic demand. Without GP lane metrics, the framework utilizes historical traffic on the managed lanes as a predictive tolling component. Using existing traffic volumes on I-66, the calculated sample toll rates demonstrate that the proposed pricing scheme help keep tolls stable and predictable.

Extending beyond current practices, the second part of the thesis proposes a new reservation-based dynamic pricing algorithm in the CAV environment. As demonstrated in the first part of the thesis, current dynamic pricing schemes on managed lanes rely on reactive pricing. That is to say, dynamic tolls for upstream traffic (making the decision to enter the facility) is set based on volumes of downstream traffic (already on the priced facility). In the CAV environment, managed lane operators have the opportunity to allow for advanced reservations, which would introduce a predictive component to the dynamic tolling scheme. The proposed system rewards CAVs to book the managed lane early by adding a toll discount component. A simulation based in Python tested the proposed reservation system. The results show that, in the $100 \% \mathrm{CAV}$ environment, the second-best pricing scheme is able to keep HOT lane density near the goal density and the discount marginally improves predictability. The 
system is also adaptable to varying upstream traffic volumes and effective at keeping the HOT lane from becoming over-saturated, even in high-demand scenarios. This thesis also set out to demonstrate a second-best pricing scheme that could be functional with mixed fleets, as $100 \%$ CAV environment will not be feasible for some time. From the operator perspective, the proposed 50\%-anticipatory second-best tolling scheme for non-CAVs works well (in all but the LOS E scenario) in managing traffic demand on the HOT lane, while keeping revenue consistent. From the user perspective, under most scenarios, non-CAV users are able to buy-in to the HOT lane at nearly the same rates as CAVs (despite the CAVs' ability to reserve the HOT lane in advance), demonstrating equity towards both vehicle types in a mixed fleet environment.

\section{2. Limitations and Future Work}

There are clear limitations to both the combination tolling framework proposed here in the non-CAV environment and the second-best pricing scheme proposed here for the CAV and mixed fleet environment.

For the combination tolling framework, historical TOD data is a need. TOD toll rates based on day of the week, the season of the year. There is all significant toll difference between weekday and weekend. A good TOD toll requires sufficient data to calibrate, which is impossible for newly implemented facilities. In addition, adding both TOD and dynamic components may make it harder to derive facility-specific alpha and theta parameters.

For the second-best pricing scheme for CAV and mixed fleet environments, limitations also exist. The proposed system assumed all vehicles would use HOT lane once they booked it and never change their decisions. However, it is more realistic for vehicles to move between HOT and GP if there is no physical barrier separation between HOT and GP lane. The proposed system assumes that vehicles which book one single space on the HOT lane will continue using the rest of the space on HOT lane. In reality, it is possible for vehicles to book several discontinuous spaces on HOT lane. Future work could consider more sophisticated scenarios and take booking multiple spaces into account.

In terms of comparing lane choice between vehicle and traveler types, there are several limitations. In the simulation, the utility of the lane is based only on travel time and VOT and did not consider other factors. We derive VOT from the regional household income distribution. However, VOT may vary by time of day, trip purpose, vehicles type, etc. In 
addition, we assumed occupancy of the vehicles to be 1 , so that the vehicle VOT is represented by one person's VOT. In future work, high occupancy vehicles should be considered, and the VOT may need to be better calibrated. Further, here we assume the CAVs have the same VOT distribution as non-CAVs. In reality, in the CAV environment, it is likely the VOT will decrease compared with the non-CAV counterparts, since people can better utilize their time inside the vehicle (to work or rest, for example).

Furthermore, there are limitations to the physical movement of vehicles in the simulation. Here, only a two-lane system was considered. In this simplified case, there is no passing of vehicles. When it comes to multi-lane facilities, this assumption will not hold. The model also did not consider the actual arrival process and platooning through space. The simulation does not consider the vehicles' actual arrival process when vehicles are coming from various directions. Instead, the simulation simplifies the upstream traffic to two lanes of traffic feeding directly into the HOT and GP lanes.

In summary, the main contribution of this thesis is devising frameworks for adding HOT lane operations predictability in both non-CAV environment and CAV environment with dynamic pricing. Though only simplified scenarios were considered in this thesis; future work building upon these frameworks can explore more realistic scenarios. Furthermore, it would also be interesting to see what are the best strategies for users to maximize their own utilities (whether to choose the HOT lane and when to choose). This can introduce an examination of the game theory-based tradeoff between operator and users. 


\section{REFERENCES}

(2010). HCM 2010 : highway capacity manual. Washington, D.C. :Transportation Research Board,

495/95 Express lane, DC. Retrieved from https://www.expresslanes.com/

91 Express lanes, Orange County, CA. Retrieved from https://www.91expresslanes.com/

95 Express Lanes, Miami, FL. Retrieved from http://www.95express.com/

Brownstone, D., Ghosh, A., Golob, T. F., Kazimi, C., \& Amelsfort, D. V. (2003). Drivers' Willingness-to-Pay to Reduce Travel Time: Evidence from the San Diego I-15 Congestion Pricing Project. Transportation Research Part A: Policy and Practice, 37(4), 373-387.

Bureau of Public Roads. (1964). Traffic Assignment Manual. Urban Planning Division, U.S. Department of Commerce, Washington, D.C.

Burris, M. (2016, March 2). Phone interview.

Burris, M., \& Stockton, B. (2004). HOT Lanes in Houston: Six Years of Experience. Journal of Public Transportation, 7(3), 1-21.

Burris, M., Nelson, S., Kelly, P., Gupta, P., and Cho, Y. (2012). Willingness to Pay for HighOccupancy Toll Lanes: Empirical Analysis from I-15 and I-394. Transportation Research Record: Journal of the Transportation Research Board, (2297), 47-55.

Carey, M., Srinivasan, A. (1993). Externalities, average and marginal costs, and tolls on congested networks with time-varying flows. Operations Research 41, 217-231.

Cetin, M., Collins, A., Basar, G., Frydenlund, E., \& Robinson, R. M. (2015). Open Toll Lanes in a Connected Vehicle Environment Development of New Pricing Strategies for a Highly Dynamic and Distributed System.

Cho, Y., Goel, R., Gupta, P., Bogonko, G., and Burris, M. (2011). What are I-394 HOT-lane Drivers Paying For? Proceedings of the Transportation Research Board $90^{\text {th }}$ Annual Meeting, Washington, DC. 
Chung, C. (2013). A Review and Advance of High-Occupancy Toll Lanes' Toll Schemes. Journal of Eastern Asia Society for Transportation Studies, Vol 10, 240-259.

Chung, C. (2013). A Review and Advance of High-Occupancy Toll Lanes' Toll Schemes. Journal of Eastern Asia Society for Transportation Studies, Vol 10, 240-259.

Chung, Y., Songa, T., \& Park, J. (2012). Freeway booking policy: Public discourse and acceptability analysis. Transport Policy, 24, 223-231. http://doi.org/10.1016/j.tranpol.2012.08.004

Concas, S., and A. Kolpakov. Synthesis of Research on Value of Time and Value of Reliability. Final Report, Contract No. BD549-46. Center for Urban Transportation Research, University of South Florida, Tampa, 2009. http://www.nctr.usf.edu/pdf/77806.pdf.

de Feijter, R., Evers, J.J.M., Lodewijks, G. (2004). Improving travel-time reliability by the use of trip booking. IEEE Trans. Intell. Transp. Syst. 5, 288-292.

De Palma, A., Lindsey, R., Quinet, E., and Vickerman R. A Handbook of Transport Economics. Edward Elgar Publishing, Northampton, 2011.

Devarasetty, P., Burris, M., and Shaw, W.D. (2012). Do Travelers Pay for Managed Lane Travel as They Claimed They Would? A Before-After Study of Travelers on Katy Freeway, Houston, Texas. Transportation Research Record: Journal of the Transportation Research Board, (2297), 56-65.

Devarasetty, P.C., Burris, M., \& Shaw, W.D. (2012). The Value of Travel Time and Reliability: Evidence from a Stated Preference Survey and Actual Usage. Transportation Research Part A: Policy and Practice 46(8), 1227-1240.

Edara, P., Teodorovic, D. (2008). Model of an advance-booking system for highway trips. Transp. Res. Part C 16, 36-53.

Emoto, C. (2016, March 4). Phone interview.

FHWA, Transit and Congestion Pricing: A PRIMER, 2014.

Florida State University (2013)

Gillespie, A. (2016, March 11). Phone interview. 
Gocman, C., Phillips, R. \& Ryzin, G. (2015). Revenue Maximizing Dynamic Tolls for Managed Lanes: A Simulation Study. Columbia University. Retrieved from http://www8.gsb.columbia.edu/cprm/sites/cprm/files/TollPricingWorkingPaper_2015_01.pdf

Hourdos, J., Janson, M., Levinson D., \& Parikh, G. (2015). MnPASS Modeling and Pricing Algorithm Enhancement. Minnesota Department of Transportation. Retrieved from http://www.dot.state.mn.us/research/TS/2015/201522.pdf

Hourdos, J., Janson, M., Levinson D., \& Parikh, G. (2015). MnPASS Modeling and Pricing Algorithm Enhancement. Minnesota Department of Transportation. Retrieved from http://www.dot.state.mn.us/research/TS/2015/201522.pdf

I-15 Express Lanes, Salt Lake City, UT. Retrieved from http://www.udot.utah.gov/expresslanes/

I-15 Express Lanes, San Diego, CA. Retrieved from http://511sd.com/fastrak511sd/I15ExpLanes

I-15 Express Lanes, San Diego, CA. Retrieved from http://511sd.com/fastrak511sd/I15ExpLanes

I-394 MnPass Express Lanes, Minneapolis, MN. Retrieved from http://www.mnpass.org/394/ I-394 MnPass Express Lanes, Minneapolis, MN. Retrieved from http://www.mnpass.org/394/ Joksimovic, D., Bliemer, M.C.J., Bovy, P.H.L. (2005). Optimal toll design problem in dynamic traffic networks with joint route and departure time choice. Transportation Research Record 1923, 61-72.

Janson, M. \& Levinson, D. (2014). HOT or Not: Driver Elasticity to Price and Alternative Pricing Strategies on the MnPASS HOT Lanes. Research in Transportation Economics 44, 21 32.

Katy Managed Lanes, Houston, TX. Retrieved from https://www.hctra.org/katymanagedlanes/

Koblentz, S. (2016, March 31). Phone interview.

Koolstra, K. (1999). Potential benefits of a freeway slot-reservation system : Queuing costs versus scheduling costs. 
LBJ Express Lane, Dallas, TX. Retrieved from http://www.lbjtexpress.com/

Lemp, J. \& Kockelman, K. (2009). Understanding and Accommodating Risk and Uncertainty in Toll Road Projects. Transportation Research Record 2132, 106-112.

Levinson, D. (2016, February 26). Phone interview.

Lindsey, R. (2016, February 24). Phone interview.

Liu, K., Chan, E., Lee, V., Kapitanova, K., \& Son, S. H. (2013). Design and evaluation of token-based reservation for a roadway system. Transportation Research Part C: Emerging Technologies, 26, 184-202. http://doi.org/10.1016/j.trc.2012.09.001

Liu, K., Chan, E., Lee, V., Kapitanova, K., Son, S. (2013). Design and evaluation of tokenbased reservation for a roadway system. Transp. Res. Part C 26, 184- 202.

Liu, K., Son, S. H., Lee, V. C. S., \& Kapitanova, K. (2011). A token-based admission control and request scheduling in lane reservation systems. IEEE Conference on Intelligent Transportation Systems, Proceedings, ITSC, 1489-1494. http://doi.org/10.1109/ITSC.2011.6082959

Liu, K., Son, S. H., Lee, V. C. S., \& Kapitanova, K. (2011). A token-based admission control and request scheduling in lane reservation systems. IEEE Conference on Intelligent Transportation Systems, Proceedings, ITSC, 1489-1494. http://doi.org/10.1109/ITSC.2011.6082959

May, A.D. and Milne, D.S. (2000). Effects of Alternative Road Pricing System on Network Performances. Transportation Research (34A), No. 6, 407-436.

Mtoi, E. and Moses, R. (2014) Calibration and Evaluation of Link Congestion Functions: Applying Intrinsic Sensitivity of Link Speed as a Practical Consideration to Heterogeneous Facility Types within Urban Network. Journal of Transportation Technologies, 4, 141-149. doi: $10.4236 /$ jtts.2014.42014.

Patterson, T. (2016, March 10 \& May 23). Phone interview.

R. Moses, E. Mtoi, H. McBean, S. Ruegg. (2013). Development of Speed Models for Improving Travel Forecasting and Highway Performance Evaluation. 
Ravi, N., Smaldone, S., Iftode, L., Gerla, M. (2007). Lane reservation for highways (position paper). In: 2007 IEEE Intelligent Transportation Systems Conference. http://dx.doi.org/10.1109/ITSC.2007.4357746.

Sheikh, A., Guin, A., and Guensler, R. (2014). Value of Travel Time Savings: Evidence from Atlanta's I-85 Express Lanes. Transportation Research Board 93rd Annual Meeting. No. 144852.

SR-167 HOT lanes, Seattle, WA. Retrieved from http://www.wsdot.wa.gov/Tolling/SR167HotLanes/

Su, P., Park, B. (2014). Analytical modeling of a highway reservation system: an integrated traffic management approach. In: Transportation Research Board 93th Annual Meeting, 2014, Washington DC.

Su, P., Park, B. (2015). Auction-based highway reservation system an agent-based simulation study. Transport. Res. Part C: Emerg. Technol. 60, 211-226.

Tomlinson, C. (2016, March 11). Phone interview.

Van Praag B. (1968).Individual Welfare Functions and Consumer Behavior, North-Holland, Amsterdam, The Netherlands.

VDOT (2016). I-66 Multimodal Improvements Inside the Beltway. Retrieved from http://inside.transform66.org/learn_more/default.asp

Verhoef, E. \& Small, K. (2004) Product Differentiation on Roads: Constrained Congestion Pricing with Heterogeneous Users. Journal of Transport Economics and Policy, 38, 127-156.

Verhoef, E. (2000) The Implementation of Marginal External Cost Pricing in Road Transport: Long Run vs. Short Run and First-Best vs. Second Best. Papers in Regional Science, 79, 307332.

Vickrey, W.S. (1969). Congestion theory and transport investment. Am. Econ. Rev. 59, 251260 http://www.jstor.org/stable/1823678.

Wilkins, M. (2016, March 11). Phone interview. 
Wong, J.-T. (1997). Basic concepts for a system for advance booking for highway use. Transport Policy, 4(2), 109-114. http://doi.org/http://dx.doi.org/10.1016/S0967070X(97)00006-1

Wood, N., Burris, M., \& Danda, S. (2014). Examination of Paid Travel on I-85 Express Lanes. Transportation Research Record 2450, 44-51.

Wu, D., Kulshrestha, A., Yin, Y., Tillander, T. \& Plass, M. (2010). Impacts of Dynamic Pricing on Managed Lane Operations. Paper \#11-1772, Transportation Research Board 90th Annual Meeting, Washington, DC.

Yin, Y. \& Lou, Y. (2009). Dynamic Tolling Strategies for Managed Lanes. ASCE Journal of Transportation Engineering 135 (2), 45-52. 


\section{APPENDICES}

\section{APPENDIX A: PUBLICATIONS \& PRESENTATIONS}

\section{Presentations}

"Best Practices for Existing HOT Lanes and Conceptual Framework for Variably Priced Fully Tolled Facilities”, TRB Annual Meeting, Washington D.C., 2017.

"Pricing Policy in HOT Lane Reservation System for Connected Automated Vehicles", Accepted for Poster Presentation. TRB Annual Meeting, Washington D.C., 2018. 


\section{APPENDIX B: SIMULATION RESULTS FOR MIXED FLEET}

Appendix B shows the simulation results of three different toll scheme for mixed fleet situation. The highlighted shows the situation when the HOT lane reservation exceed the density of upper bound of LOS C (29 veh/lane/mile).

\begin{tabular}{|c|c|c|c|c|c|c|c|c|c|c|c|c|c|}
\hline \multicolumn{14}{|c|}{ 0\%-Anticipatory Toll for non-CAVs } \\
\hline \multirow{3}{*}{$\begin{array}{c}\text { CAV } \\
\text { percentage }\end{array}$} & \multirow{3}{*}{$\begin{array}{c}\text { non-CAV } \\
\text { percentage }\end{array}$} & \multicolumn{6}{|c|}{ LOS B 30} & \multicolumn{6}{|c|}{ LOS C 48} \\
\hline & & \multirow{2}{*}{$\begin{array}{l}\text { no. of } \\
\text { CAV }\end{array}$} & \multirow{2}{*}{$\begin{array}{c}\text { no. of } \\
\text { nonCAV }\end{array}$} & \multicolumn{2}{|c|}{$\begin{array}{c}\text { Choose HOT } \\
\text { lane }\end{array}$} & \multirow[t]{2}{*}{ Total } & \multirow[t]{2}{*}{ Revenue } & \multirow{2}{*}{$\begin{array}{l}\text { no. of } \\
\text { CAV }\end{array}$} & \multirow{2}{*}{$\begin{array}{c}\text { no. of } \\
\text { nonCAV }\end{array}$} & \multicolumn{2}{|c|}{$\begin{array}{c}\text { Choose HOT } \\
\text { lane }\end{array}$} & \multirow[t]{2}{*}{ Total } & \multirow[t]{2}{*}{ Revenue } \\
\hline & & & & CAV & nonCAV & & & & & CAV & nonCAV & & \\
\hline $100 \%$ & $0 \%$ & 30 & 0 & 27.01 & 0 & 27.01 & 1.98 & 48 & 0 & 27.56 & 0 & 27.56 & 8.90 \\
\hline $90 \%$ & $10 \%$ & 27 & 3 & 24.93 & 1.1 & 26.04 & 1.35 & 43 & 5 & 29.31 & 0.11 & 29.42 & 8.14 \\
\hline $80 \%$ & $20 \%$ & 24 & 6 & 22.45 & 2.83 & 25.28 & 0.51 & 38 & 10 & 29.33 & 0.41 & 29.74 & 6.97 \\
\hline $70 \%$ & $30 \%$ & 21 & 9 & 19.67 & 4.45 & 24.11 & 0.10 & 34 & 14 & 28.07 & 1.52 & 29.59 & 6.43 \\
\hline $60 \%$ & $40 \%$ & 18 & 12 & 16.88 & 5.98 & 22.85 & 0.02 & 29 & 19 & 25.72 & 6.3 & 32.02 & 5.67 \\
\hline $50 \%$ & $50 \%$ & 15 & 15 & 14.07 & 7.49 & 21.55 & 0.00 & 24 & 24 & 22.47 & 11.42 & 33.89 & 1.54 \\
\hline $40 \%$ & $60 \%$ & 12 & 18 & 11.25 & 9.04 & 20.29 & 0.00 & 19 & 29 & 17.8 & 14.45 & 32.25 & 0.09 \\
\hline $30 \%$ & $70 \%$ & 9 & 21 & 8.44 & 10.5 & 18.94 & 0.00 & 14 & 34 & 13.12 & 16.99 & 30.11 & 0.00 \\
\hline $20 \%$ & $80 \%$ & 6 & 24 & 5.63 & 11.99 & 17.62 & 0.00 & 10 & 38 & 8.45 & 19.53 & 27.97 & 0.00 \\
\hline $10 \%$ & $90 \%$ & 3 & 27 & 2.82 & 13.48 & 16.29 & 0.00 & 5 & 43 & 3.75 & 22.01 & 25.76 & 0.00 \\
\hline \multirow{3}{*}{$\begin{array}{c}\text { CAV } \\
\text { percentage }\end{array}$} & \multirow{3}{*}{$\begin{array}{c}\text { non-CAV } \\
\text { percentage }\end{array}$} & \multicolumn{6}{|c|}{ LOS D 64} & \multicolumn{6}{|c|}{ LOS E 80} \\
\hline & & \multirow{2}{*}{$\begin{array}{l}\text { no. of } \\
\text { CAV }\end{array}$} & \multirow{2}{*}{$\begin{array}{c}\text { no. of } \\
\text { nonCAV }\end{array}$} & \multicolumn{2}{|c|}{$\begin{array}{c}\text { Choose HOT } \\
\text { lane }\end{array}$} & \multirow[t]{2}{*}{ Total } & \multirow[t]{2}{*}{ Revenue } & \multirow{2}{*}{$\begin{array}{l}\text { no. of } \\
\text { CAV }\end{array}$} & \multirow{2}{*}{$\begin{array}{c}\text { no. of } \\
\text { nonCAV }\end{array}$} & \multicolumn{2}{|c|}{$\begin{array}{c}\text { Choose HOT } \\
\text { lane }\end{array}$} & \multirow[t]{2}{*}{ Total } & \multirow[t]{2}{*}{ Revenue } \\
\hline & & & & CAV & nonCAV & & & & & CAV & nonCAV & & \\
\hline $100 \%$ & $0 \%$ & 64 & 0 & 23.65 & 0 & 23.65 & 2.57 & 80 & 0 & 24.05 & 0 & 24.05 & 2.51 \\
\hline $90 \%$ & $10 \%$ & 58 & 6 & 23.68 & 0.01 & 23.68 & 3.48 & 72 & 8 & 23.25 & 0 & 23.25 & 2.63 \\
\hline $80 \%$ & $20 \%$ & 51 & 13 & 26.35 & 0.15 & 26.51 & 8.99 & 64 & 16 & 23.62 & 0 & 23.62 & 2.53 \\
\hline $70 \%$ & $30 \%$ & 45 & 19 & 29.03 & 0.4 & 29.43 & 9.38 & 56 & 24 & 23.82 & 0.05 & 23.87 & 3.87 \\
\hline $60 \%$ & $40 \%$ & 38 & 26 & 28.69 & 0.96 & 29.65 & 8.77 & 48 & 32 & 27.4 & 0.49 & 27.88 & 10.39 \\
\hline $50 \%$ & $50 \%$ & 32 & 32 & 27.7 & 3.95 & 31.65 & 9.60 & 40 & 40 & 29.19 & 1.17 & 30.36 & 10.38 \\
\hline $40 \%$ & $60 \%$ & 26 & 38 & 23.34 & 17.77 & 41.11 & 3.34 & 32 & 48 & 27.85 & 5.66 & 33.5 & 13.51 \\
\hline $30 \%$ & $70 \%$ & 19 & 45 & 17.8 & 22.45 & 40.25 & 0.15 & 24 & 56 & 22.42 & 26.15 & 48.57 & 3.79 \\
\hline $20 \%$ & $80 \%$ & 13 & 51 & 11.25 & 25.99 & 37.24 & 0.00 & 16 & 64 & 15 & 32 & 47 & 0.02 \\
\hline $10 \%$ & $90 \%$ & 6 & 58 & 5.62 & 28.97 & 34.59 & 0.00 & 8 & 72 & 7.5 & 36.09 & 43.58 & 0.00 \\
\hline
\end{tabular}




\begin{tabular}{|c|c|c|c|c|c|c|c|c|c|c|c|c|c|}
\hline \multicolumn{14}{|c|}{ 50\%-Anticipatory Toll for non-CAVs } \\
\hline \multirow{3}{*}{$\begin{array}{c}\text { CAV } \\
\text { percentage }\end{array}$} & \multirow{3}{*}{$\begin{array}{c}\text { non-CAV } \\
\text { percentage }\end{array}$} & \multicolumn{6}{|c|}{ LOS B 30} & \multicolumn{6}{|c|}{$\operatorname{LOSC} 48$} \\
\hline & & \multirow{2}{*}{$\begin{array}{c}\text { no. of } \\
\text { CAV }\end{array}$} & \multirow{2}{*}{$\begin{array}{c}\text { no. of } \\
\text { nonCAV }\end{array}$} & \multicolumn{2}{|c|}{$\begin{array}{c}\text { Choose HOT } \\
\text { lane }\end{array}$} & \multirow[t]{2}{*}{ Total } & \multirow[t]{2}{*}{ Revenue } & \multirow{2}{*}{$\begin{array}{l}\text { no. of } \\
\text { CAV }\end{array}$} & \multirow{2}{*}{$\begin{array}{c}\text { no. of } \\
\text { nonCAV }\end{array}$} & \multicolumn{2}{|c|}{$\begin{array}{c}\text { Choose HOT } \\
\text { lane }\end{array}$} & \multirow[t]{2}{*}{ Total } & \multirow[t]{2}{*}{ Revenue } \\
\hline & & & & CAV & nonCAV & & & & & CAV & nonCAV & & \\
\hline $100 \%$ & $0 \%$ & 30 & 0 & 26.80 & 0.00 & 26.80 & 2.10 & 48 & 0 & 27.50 & 0.00 & 27.50 & 8.84 \\
\hline $90 \%$ & $10 \%$ & 27 & 3 & 24.13 & 0.87 & 25.00 & 2.67 & 43 & 5 & 24.00 & 0.43 & 24.43 & 8.55 \\
\hline $80 \%$ & $20 \%$ & 24 & 6 & 21.50 & 2.53 & 24.03 & 2.83 & 38 & 10 & 20.82 & 2.78 & 23.60 & 9.01 \\
\hline $70 \%$ & $30 \%$ & 21 & 9 & 18.47 & 3.94 & 22.42 & 2.29 & 34 & 14 & 18.23 & 5.27 & 23.50 & 8.15 \\
\hline $60 \%$ & $40 \%$ & 18 & 12 & 15.85 & 6.09 & 21.94 & 2.05 & 29 & 19 & 14.47 & 7.99 & 22.46 & 6.59 \\
\hline $50 \%$ & $50 \%$ & 15 & 15 & 13.11 & 7.13 & 20.24 & 1.57 & 24 & 24 & 11.47 & 10.53 & 22.00 & 4.66 \\
\hline $40 \%$ & $60 \%$ & 12 & 18 & 10.23 & 8.80 & 19.03 & 1.30 & 19 & 29 & 8.89 & 13.52 & 22.41 & 3.82 \\
\hline $30 \%$ & $70 \%$ & 9 & 21 & 7.05 & 10.59 & 17.64 & 1.05 & 14 & 34 & 6.05 & 16.50 & 22.55 & 3.38 \\
\hline $20 \%$ & $80 \%$ & 6 & 24 & 4.29 & 12.09 & 16.39 & 0.61 & 10 & 38 & 3.51 & 19.65 & 23.16 & 2.74 \\
\hline $10 \%$ & $90 \%$ & 3 & 27 & 1.28 & 13.54 & 14.82 & 0.08 & 5 & 43 & 1.49 & 23.39 & 24.88 & 7.03 \\
\hline \multirow{3}{*}{$\begin{array}{c}\text { CAV } \\
\text { percentage }\end{array}$} & \multirow{3}{*}{$\begin{array}{c}\text { non-CAV } \\
\text { percentage }\end{array}$} & \multicolumn{6}{|c|}{ LOS D 64} & \multicolumn{6}{|c|}{ LOSE 80} \\
\hline & & \multirow{2}{*}{$\begin{array}{l}\text { no. of } \\
\text { CAV }\end{array}$} & \multirow{2}{*}{$\begin{array}{c}\text { no. of } \\
\text { nonCAV }\end{array}$} & \multicolumn{2}{|c|}{$\begin{array}{c}\text { Choose HOT } \\
\text { lane }\end{array}$} & \multirow[t]{2}{*}{ Total } & \multirow{2}{*}{ Revenue } & \multirow{2}{*}{$\begin{array}{l}\text { no. of } \\
\text { CAV }\end{array}$} & \multirow{2}{*}{$\begin{array}{c}\text { no. of } \\
\text { nonCAV }\end{array}$} & \multicolumn{2}{|c|}{$\begin{array}{c}\text { Choose HOT } \\
\text { lane }\end{array}$} & \multirow[t]{2}{*}{ Total } & \multirow[t]{2}{*}{ Revenue } \\
\hline & & & & CAV & nonCAV & & & & & CAV & nonCAV & & \\
\hline $100 \%$ & $0 \%$ & 64 & 0 & 23.77 & 0.00 & 23.77 & 2.43 & 80 & 0 & 23.54 & 0.00 & 23.54 & 2.44 \\
\hline $90 \%$ & $10 \%$ & 58 & 6 & 21.36 & 0.00 & 21.36 & 2.25 & 72 & 8 & 21.11 & 0.00 & 21.11 & 2.26 \\
\hline $80 \%$ & $20 \%$ & 51 & 13 & 18.63 & 0.00 & 18.63 & 1.94 & 64 & 16 & 18.43 & 0.00 & 18.43 & 1.96 \\
\hline $70 \%$ & $30 \%$ & 45 & 19 & 15.91 & 0.03 & 15.94 & 1.77 & 56 & 24 & 15.74 & 0.00 & 15.74 & 1.65 \\
\hline $60 \%$ & $40 \%$ & 38 & 26 & 13.39 & 0.31 & 13.71 & 2.84 & 48 & 32 & 13.40 & 0.00 & 13.40 & 1.49 \\
\hline $50 \%$ & $50 \%$ & 32 & 32 & 10.78 & 1.18 & 11.96 & 5.48 & 40 & 40 & 10.88 & 0.00 & 10.88 & 1.16 \\
\hline $40 \%$ & $60 \%$ & 26 & 38 & 8.30 & 6.48 & 14.78 & 7.70 & 32 & 48 & 8.08 & 0.00 & 8.08 & 1.00 \\
\hline $30 \%$ & $70 \%$ & 19 & 45 & 6.04 & 11.91 & 17.95 & 12.00 & 24 & 56 & 6.03 & 0.00 & 6.03 & 1.52 \\
\hline $20 \%$ & $80 \%$ & 13 & 51 & 3.74 & 18.84 & 22.59 & 10.74 & 16 & 64 & 3.68 & 0.50 & 4.18 & 1.26 \\
\hline $10 \%$ & $90 \%$ & 6 & 58 & 1.49 & 29.43 & 30.92 & 7.66 & 8 & 72 & 1.50 & 4.63 & 6.13 & 0.24 \\
\hline
\end{tabular}

\begin{tabular}{|c|c|c|c|c|c|c|c|c|c|c|c|c|c|}
\hline \multicolumn{14}{|c|}{ 100\%-Anticipatory Toll for non-CAVs } \\
\hline \multirow{3}{*}{$\begin{array}{c}\text { CAV } \\
\text { percentage }\end{array}$} & \multirow{3}{*}{$\begin{array}{c}\text { non-CAV } \\
\text { percentage }\end{array}$} & \multicolumn{6}{|c|}{ LOS B 30} & \multicolumn{6}{|c|}{$\operatorname{LOSC} 48$} \\
\hline & & \multirow{2}{*}{$\begin{array}{l}\text { no. of } \\
\text { CAV }\end{array}$} & \multirow{2}{*}{$\begin{array}{c}\text { no. of } \\
\text { nonCAV }\end{array}$} & \multicolumn{2}{|c|}{$\begin{array}{c}\text { Choose HOT } \\
\text { lane }\end{array}$} & \multirow[t]{2}{*}{ Total } & \multirow[t]{2}{*}{ Revenue } & \multirow{2}{*}{$\begin{array}{l}\text { no. of } \\
\text { CAV }\end{array}$} & \multirow{2}{*}{$\begin{array}{l}\text { no. of } \\
\text { nonCAV }\end{array}$} & \multicolumn{2}{|c|}{ Choose HOT lane } & \multirow[t]{2}{*}{ Total } & \multirow[t]{2}{*}{ Revenue } \\
\hline & & & & CAV & nonCAV & & & & & CAV & nonCAV & & \\
\hline $100 \%$ & $0 \%$ & 30 & 0 & 26.94 & 0.00 & 26.94 & 2.08 & 48 & 0 & 27.6268 & 0 & 27.63 & 8.80 \\
\hline $90 \%$ & $10 \%$ & 27 & 3 & 24.14 & 0.76 & 24.91 & 2.77 & 43 & 5 & 24.216 & 0.0945 & 24.31 & 7.97 \\
\hline $80 \%$ & $20 \%$ & 24 & 6 & 21.35 & 1.05 & 22.40 & 2.92 & 38 & 10 & 20.958 & 0.2062 & 21.16 & 7.18 \\
\hline $70 \%$ & $30 \%$ & 21 & 9 & 18.58 & 1.92 & 20.50 & 3.58 & 34 & 14 & 17.9646 & 0.3885 & 18.35 & 6.58 \\
\hline $60 \%$ & $40 \%$ & 18 & 12 & 15.75 & 2.99 & 18.74 & 4.29 & 29 & 19 & 15.2 & 0.5346 & 15.73 & 5.82 \\
\hline $50 \%$ & $50 \%$ & 15 & 15 & 13.05 & 3.98 & 17.03 & 4.62 & 24 & 24 & 11.5859 & 1.957 & 13.54 & 6.92 \\
\hline $40 \%$ & $60 \%$ & 12 & 18 & 10.34 & 5.72 & 16.06 & 5.07 & 19 & 29 & 8.9135 & 2.7443 & 11.66 & 6.61 \\
\hline $30 \%$ & $70 \%$ & 9 & 21 & 7.02 & 7.07 & 14.09 & 5.36 & 14 & 34 & 6.121 & 3.7391 & 9.86 & 6.65 \\
\hline $20 \%$ & $80 \%$ & 6 & 24 & 4.53 & 8.51 & 13.04 & 3.66 & 10 & 38 & 3.7049 & 6.0815 & 9.79 & 6.86 \\
\hline $10 \%$ & $90 \%$ & 3 & 27 & 1.31 & 10.10 & 11.42 & 1.13 & 5 & 43 & 1.2325 & 7.0098 & 8.24 & 5.12 \\
\hline \multirow{3}{*}{$\begin{array}{c}\text { CAV } \\
\text { percentage }\end{array}$} & \multirow{3}{*}{$\begin{array}{c}\text { non-CAV } \\
\text { percentage }\end{array}$} & \multicolumn{6}{|c|}{ LOS D 64} & \multicolumn{6}{|c|}{ LOSE 80} \\
\hline & & \multirow{2}{*}{$\begin{array}{l}\text { no. of } \\
\text { CAV }\end{array}$} & \multirow{2}{*}{$\begin{array}{c}\text { no. of } \\
\text { nonCAV }\end{array}$} & \multicolumn{2}{|c|}{$\begin{array}{c}\text { Choose HOT } \\
\text { lane }\end{array}$} & \multirow{2}{*}{ Total } & \multirow{2}{*}{ Revenue } & \multirow{2}{*}{$\begin{array}{l}\text { no. of } \\
\text { CAV }\end{array}$} & \multirow{2}{*}{$\begin{array}{c}\text { no. of } \\
\text { nonCAV }\end{array}$} & \multicolumn{2}{|c|}{ Choose HOT lane } & \multirow[t]{2}{*}{ Total } & \multirow[t]{2}{*}{ Revenue } \\
\hline & & & & CAV & nonCAV & & & & & CAV & nonCAV & & \\
\hline $100 \%$ & $0 \%$ & 64 & 0 & 23.92 & 0 & 23.92 & 2.55 & 80 & 0 & 23.96 & 0 & 23.96 & 2.44 \\
\hline $90 \%$ & $10 \%$ & 58 & 6 & 20.98 & 0 & 20.98 & 2.24 & 72 & 8 & 21.28 & 0 & 21.28 & 2.39 \\
\hline $80 \%$ & $20 \%$ & 51 & 13 & 18.45 & 0 & 18.45 & 2.09 & 64 & 16 & 18.24 & 0 & 18.24 & 1.97 \\
\hline $70 \%$ & $30 \%$ & 45 & 19 & 16.27 & 0 & 16.27 & 1.89 & 56 & 24 & 16.25 & 0 & 16.25 & 1.67 \\
\hline $60 \%$ & $40 \%$ & 38 & 26 & 13.37 & 0 & 13.37 & 1.57 & 48 & 32 & 13.21 & 0 & 13.21 & 1.44 \\
\hline $50 \%$ & $50 \%$ & 32 & 32 & 11.11 & 0 & 11.11 & 1.43 & 40 & 40 & 10.92 & 0 & 10.92 & 1.35 \\
\hline $40 \%$ & $60 \%$ & 26 & 38 & 8.35 & 0 & 8.35 & 1.13 & 32 & 48 & 8.26 & 0 & 8.26 & 0.96 \\
\hline $30 \%$ & $70 \%$ & 19 & 45 & 5.94 & 0 & 5.94 & 0.65 & 24 & 56 & 5.95 & 0 & 5.95 & 0.71 \\
\hline $20 \%$ & $80 \%$ & 13 & 51 & 3.58 & 0 & 3.58 & 0.44 & 16 & 64 & 3.63 & 0 & 3.63 & 0.44 \\
\hline $10 \%$ & $90 \%$ & 6 & 58 & 1.23 & 0 & 1.23 & 0.01 & 8 & 72 & 1.25 & 0 & 1.25 & 0.03 \\
\hline
\end{tabular}

